
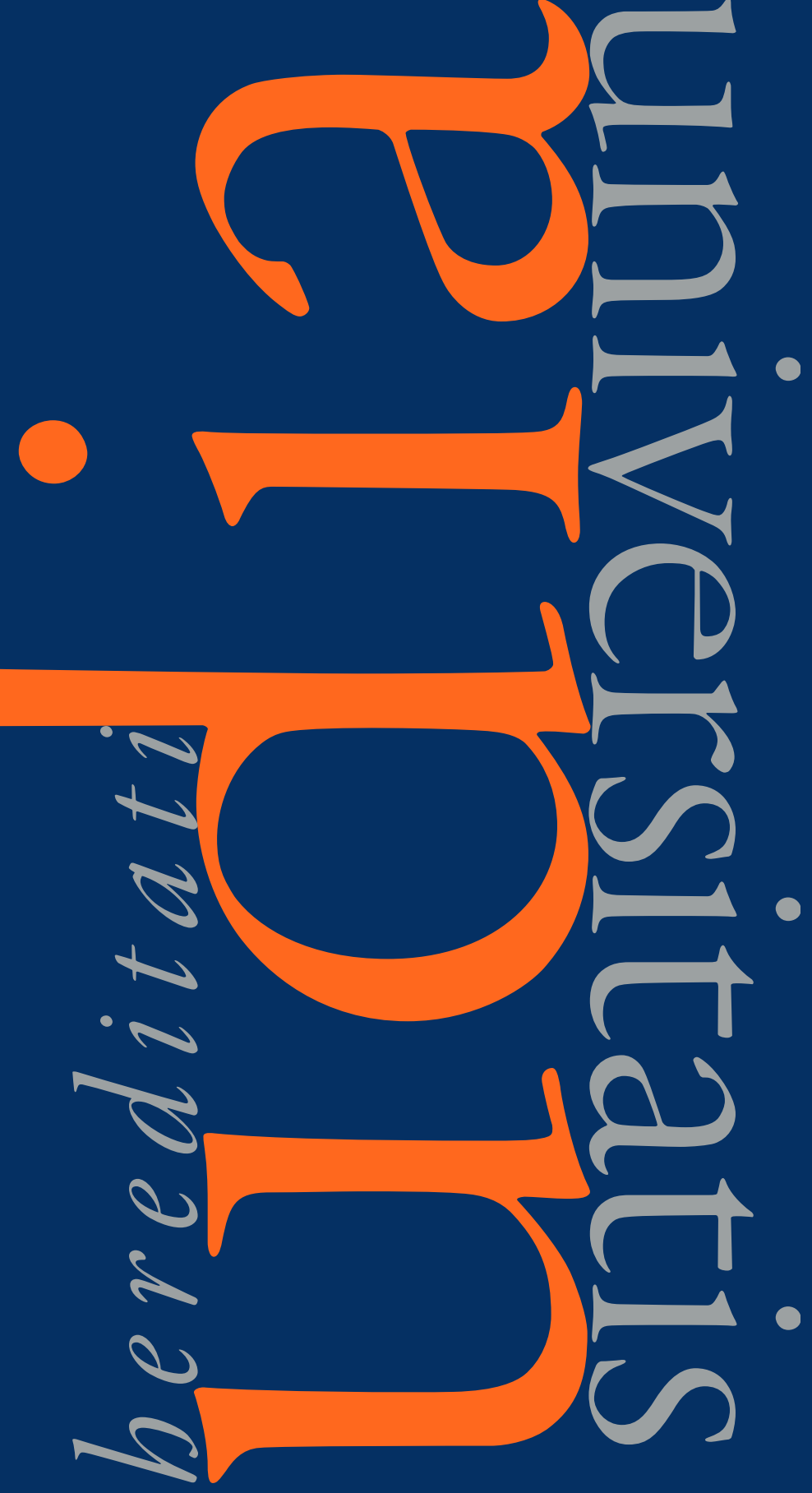

LETNIK 4

ŠTEVILKA 2

LETO 2016
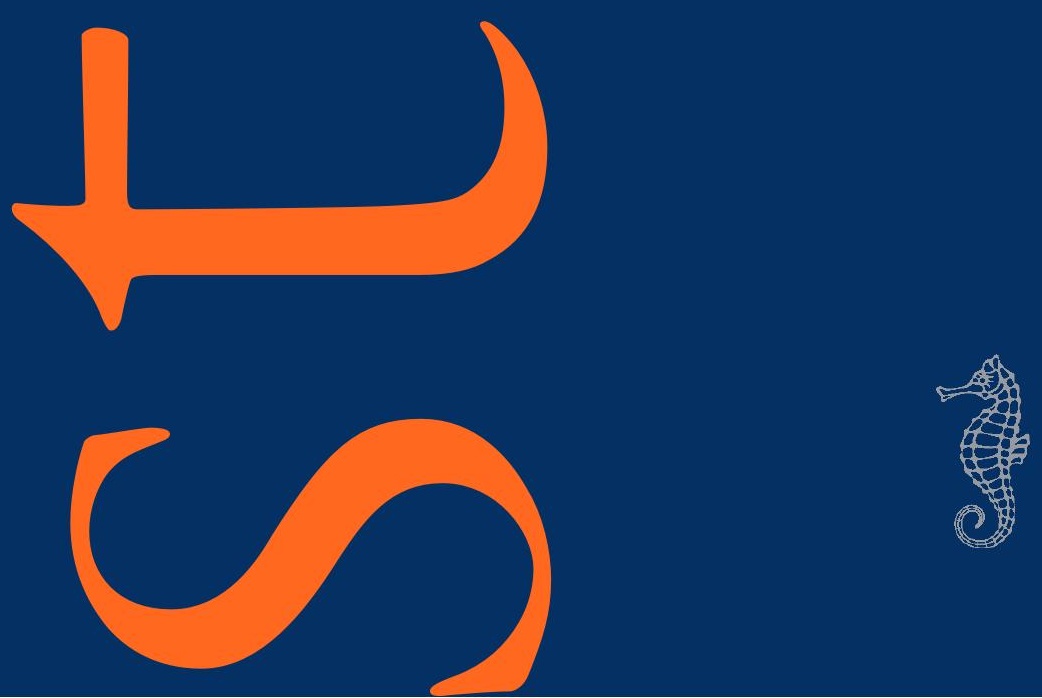


\section{STUDIA UNIVERSITATIS HEREDITATI}

Znanstvena revija za raziskave in teorijo kulturne dediščine

Letnik 4, stevilka 2, 2016

Studia universitatis hereditati je humanistična znanstvena revija za raziskave in teorijo kulturne dediščine z mednarodnim uredniškim odborom. Objavlja znanstvene in strokovne članke s širšega področja kulturne dediščine (arheologija, arhitektura, etnologija, jezikoslovje, literarna, kulturna, glasbena, intelektualna, religijska, vojaška zgodovina, zgodovina idej itn.) in pregledne članke ter recenzije tako domačih kot tujih monografij z omenjenih področij. Revija izhaja dvakrat letno. Izdajata jo Fakulteta za bumanistične študije (Oddelek za arheologijo in dediscino) in Založba Univerze na Primorskem.

Poglavitni namen revije je prispevati k razvoju raziskav kulturne dediščine v najširšem in k topoglednemu interdisciplinarnemu pristopu $k$ teoretičnim in praktičnim raziskovalnim vprašanjem. Tako revija posebno pozornost namenja razvoju slovenske znanstvene in strokovne terminologije, konceptov in paradigem na področju raziskovanja kulturne dediščine v okviru humanističnih ved.

\section{Glauni in odgovorni urednik}

dr. Gregor Pobežin (Fakulteta za humanistične študije Univerze na Primorskem, Koper)

Urednicas stevilke

dr. Helena Bažec (Fakulteta za humanistične študije Univerze na Primorskem, Koper)

Tehnična ureditev revije, oblikovanje

dr. Jonatan Vinkler (Fakulteta za humanistične študije, Univerza na Primorskem, Koper)

Prelom

Jana Habjanič in dr. Jonatan Vinkler (oba: Fakulteta za humanistične študije, Univerza na Primorskem, Koper) Lektor (slovenska besedila)

Davorin Dukič (Univerza na Primorskem, Koper)

\section{Uredniskiodbor}

dr. Zdravka Hincak (Filozofski fakultet, Sveučilište u Zagrebu), dr. Matej Hriberšek (Filozofska fakulteta, Univerza v Ljubljani), dr. Katja Hrobat Virloget (Znanstveno-raziskovalno središče Univerze na Primorskem, Koper), dr. Irena Lazar (Fakulteta za humanistične študije Univerze na Primorskem, Koper), dr. Maša Sakara Sučevič (Pokrajinski muzej, Koper), dr. Alenka Tomaž (Znanstveno-raziskovalno središčce Univerze na Primorskem, Koper), dr. Tomislav Vignjevič (Fakulteta za humanistične študije Univerze na Primorskem, Koper), dr. Jonatan Vinkler (Fakulteta za humanistične študije Univerze na Primorskem, Koper), dr. Paola Visentini (Museo Friulano di Storia Naturale, Udine)

Izdajatelj: Univerza na Primorskem - Založba Univerze na Primorskem (za Fakulteto za humanistične študije Univerze na Primorskem)

(C) 2016 Založba Univerze na Primorskem

Zanjo: prof. dr. Dragan Marušič, rektor

Titov $\operatorname{trg} 4$

SI-6000 Koper

ISSN $2350-5443$

DOI: https://doi.org/10.26493/2350-5443.4(2)

\section{(c) (1) $\odot \Theta$}


studia universitatis hereditati 



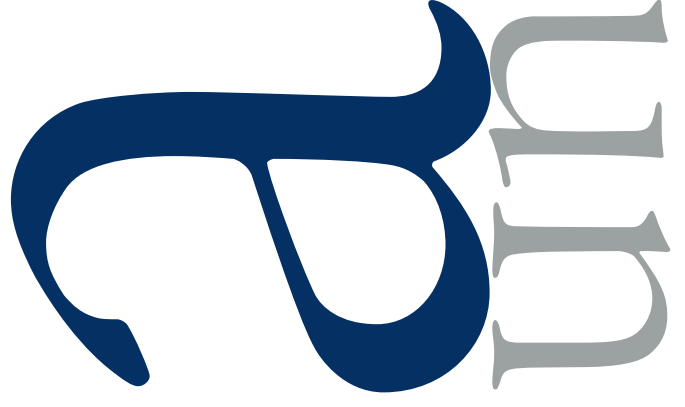

○
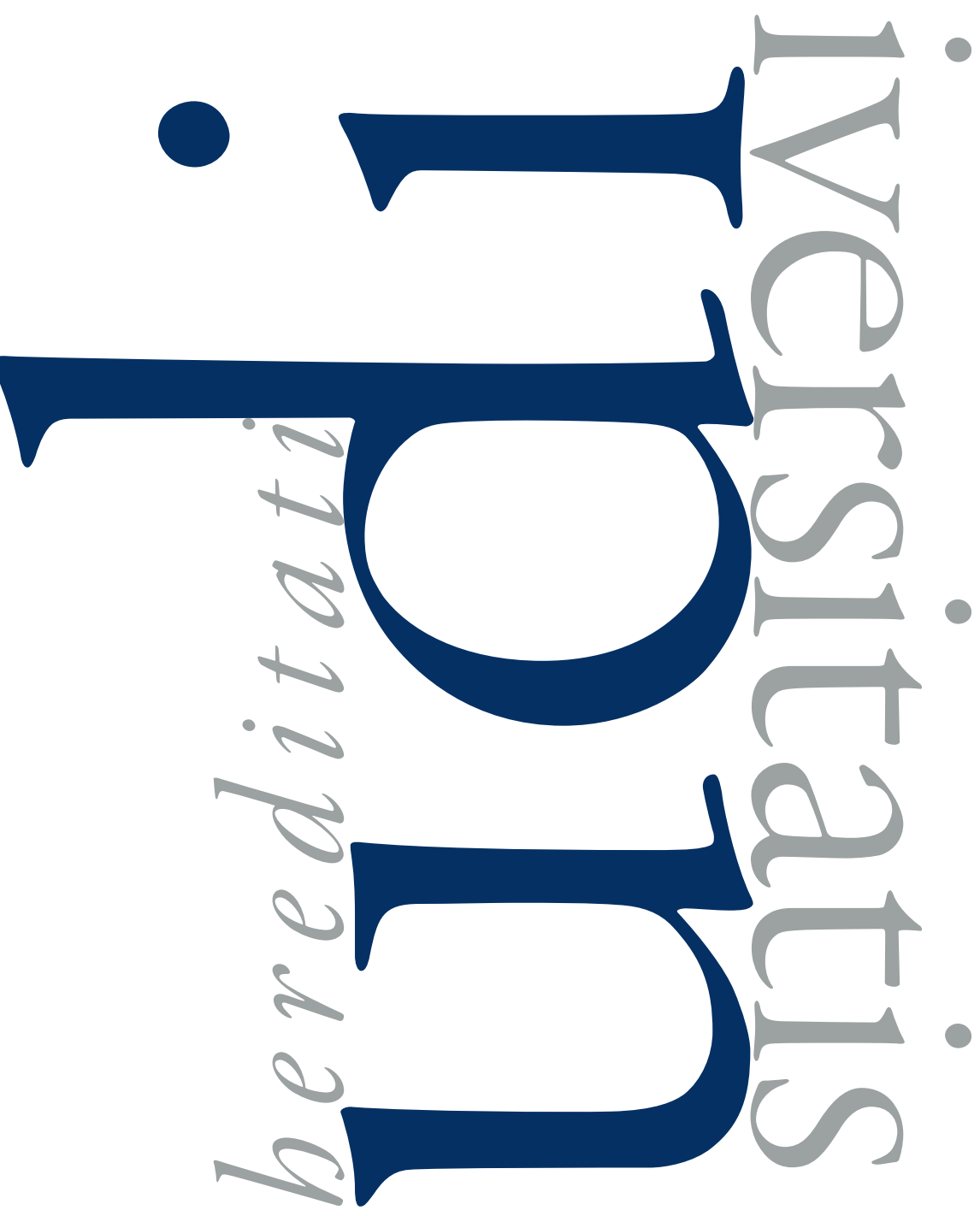

LETNIK 4

ŠTEVILKA 2

LETO 2016
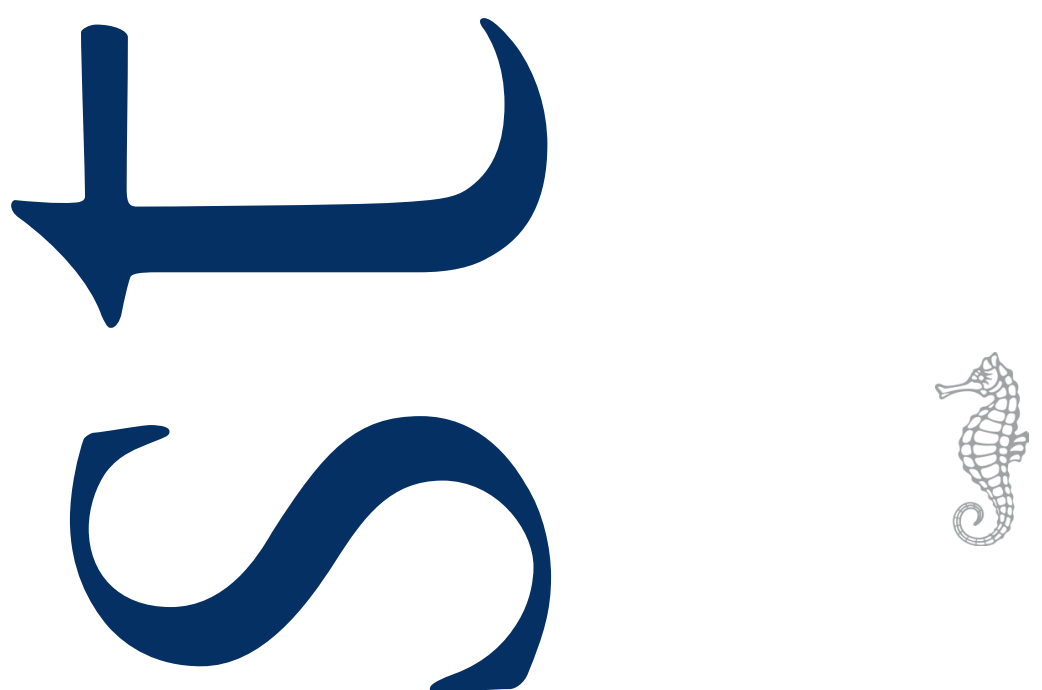
-

r

$\downarrow$

G

1

-

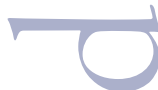

( )

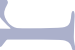

(U)

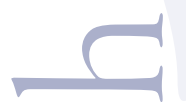




\section{Vsebina/Contents}

Elis Deghenghi Olujić

9 Dalla Trilogia istriana: appunti sul romanzo La ragazza di Petrovia di Fulvio Tomizza Nives Zudic Antonic, Anita Dessardo

2 I Girolamo Muzio, letterato Capodistriano

Nives Zudic Antonic

37 Diffusione del dramma pastorale in Istria Corinna Gerbaz Giuliano, Maja Durdulov

49 Lingua e identità nel carteggio degli intellettuali fiumani (1960-1987)

Srecko Jurisić, Paula Jurisić

6I Paolo Sorrentino, la cultura della serie TV e Young Pope

Jadranka Cergol

73 Letteratura dialettale come caratteristica della «letteratura minoritaria»

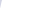


-

r

$\downarrow$

G

1

-

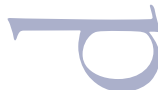

( )

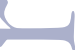

(U)

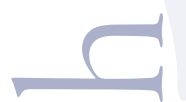




\title{
Dalla Trilogia istriana: appunti sul romanzo La ragazza di Petrovia di Fulvio Tomizza
}

\author{
Elis Deghenghi Olujić
}

L'uomo di confine per sua natura "sconfina”, non sta né

di qua né di là, va su e giù, eternamente inquieto e insod-

disfatto, doppio senza essere ambiguo.

Cesarr

Cesare De Michelis, Introduzione a Le mie estatiletterarie.

Lungo le tracce della memoria

Il saggio esamina il romanzo La ragazza di Petrovia, che con Materada (1960) e Il bosco di acacie (1967) costituisce la «trilogia istriana» di Fulvio Tomizza, nella quale lo scrittore sviscera la realtà dell'esodo istriano attraverso una rievocazione storico-documentaria oggettiva, che diventa una vera e propria autobiografia collettiva. Ne La ragazza di Petrovia si passa alla descrizione della condizione di alienazione vissuta dagli istriani dopo l'esodo, alla rappresentazione di una realtà sconosciuta e imprevedibile che la gente semplice della campagna non riesce a comprendere. Nel momento in cui si oltrepassa la frontiera è come se il «cerchio magico» si spezzasse irrimediabilmente, e di conseguenza mutasse anche il carattere dell' individuo: si diventa diversi e come stranieri gli uni agli altri.

Parole chiave: Fulvio Tomizza, La ragazza di Petrovia, "trilogia istriana”, esodo istriano.

V članku je razčlenjen roman La ragazza di Petrovia pisatelja Fulvia Tomizze, ki skupaj z Materado (1960) in Il bosco di acacie (1967) tvorijo »istrsko trilogijo $\ll, \mathrm{v}$ kateri avtor do podrobnosti secira realnost istrskega eksodusa z zgodovinsko dokumentirano objektivno uprizoritvijo, ki preraste v pravo kolektivno avtobiografijo. V La ragazza di Petrovia je opisano stanje odtujitve, ki so jo doživljali Istrani po eksodusu, predstavljeno pa je tudi tuje in nepredvidljivo okolje, nedoumljivo preprostemu kmečkemu človeku. V trenutku, ko prestopijo mejo, se »začarani krog« prekine brez možnosti vrnitve, ljudje pa spremenijo značaj in postanejo drug drugemu le še tujci.

Kljućne besede: Fulvio Tomizza, La ragazza di Petrovia, »istrska trilogija «, istrski eksodus.

\section{I}

a frase citata in esergo è tratta dall'Introduzione a Le mie estati letterarie. Lungo le tracce della memoria. L'opera, pubblicata da Marsilio nel 2009, a dieci anni dalla scomparsa di Fulvio Tomizza, è una raccolta di scritti autobiografici introdotta da Cesare De Michelis, che firma anche la postfazione del romanzo $\mathrm{La}$ ragazza di Petrovia edito dalla Marsilio nel 1986 , che di seguito è argomento d'analisi di questo intervento. Sono scritti d'occasione come quelli pubblicati nel 1995 in Alle spalle di Trieste, importanti perché riportano le riflessioni dell'auto- re materadese riguardo i grandi nodi che hanno segnato la sua esperienza di uomo e di scrittore "di confine" (o "di frontiera"), com'è stato coralmente definito dalla critica. Nell'articolo intitolato Frontiera reale, scritto nel maggio del $1987 \mathrm{e}$ inserito in Alle spalle di Trieste, (Bompiani, Milano 1995), a p. 195 Fulvio Tomizza scrive:

\footnotetext{
Molti mi hanno definito scrittore di frontiera per antonomasia. Mi preme subito precisare che tale titolo non costituisce per me motivo di orgoglio o di vanto, e forse nemmeno di conforto. Nutro piuttosto leale in-
} 
vidia verso tutti gli scrittori che elevano la frontiera a metafora di lacerazioni esclusivamente interiori e magari soltanto private. Dirò dunque che frontiera reale, frontiera "per antonomasia", è per me quel territorio sempre conteso, e in definitiva sempre estraneo ai contendenti, che alla sommità dell'Adriatico si insinua tra Italia, Austria e Jugoslavia, nel quale si radicano il mio destino di uomo e la mia ricerca di narratore.

La condizione dell'uomo e dello scrittore di frontiera, una condizione che arricchisce interiormente, pur se contrassegnata da storie di sradicamenti e di tragedie personali e collettive, è stata delineata esemplarmente da Fulvio Tomizza nel dialogo con Riccardo Ferrante, svoltosi tra l'ottobre del I991 e il gennaio del 1992, nel periodo in cui la Jugoslavia implodeva con una guerra sanguinosa. Tomizza ha sentito sempre in sé la frontiera, ha vissuto in essa cercando in ogni modo di abbatterla, inguaribilmente nomade, perennemente impegnato nella ricerca di una coerenza interiore che gli appariva spesso irragiungibile, instancabilmente immerso nel tentativo di sciogliere quel «contrasto irriducibile» e attuare l'«impossibile riconciliazione» tra culture diverse, giammai avverse, che egli sentiva presenti nella sua identità di uomo di frontiera. Una «riconciliazione» che ha cercato di concretare nel corso di tutta la vita sia come uomo sia come scrittore, con lo scopo di pervenire a quella condizione ideale per non dover più «scegliere tra le diverse e magari opposte componenti di sangue, di cultura, di mentalità, ma tentando piuttosto di accordarle, riconoscendole proprie di un uomo di frontiera, sentendole stimolanti anziché gravose». ${ }^{2}$ Nell'Introduzione alla raccolta di scritti pubblicata postuma, di cui si suggerisce la lettura perché lumeggiano molti aspetti della vita, della narrativa e delle abitudini scrittorie del Nostro, Cesare De Michelis eviden-

\footnotetext{
I L'intervista è stata pubblicata nel 1992 con il titolo Destino di frontiera: Fulvio Tomizza, Destino di frontiera (Genova: Marietti Editore, 1992).

2 Fulvio Tomizza, M'identifico con la frontiera (San Donà del Piave: Biblioteca civica, 1999), 23.
}

zia che, in queste «pagine divaganti e quotidiane», come in quelle «definitive e solenni» ${ }^{3}$ dei romanzi, «si manifesta un Tomizza al quadrato, che riflette su se stesso, ricostruisce il proprio itinerario biografico, fa i conti con la tradizione e la storia e coraggiosamente affronta le divisioni politiche, etniche e religiose con la certezza che nessuna frontiera ha scavato un solco incolmabile, anzi che i valori che accomunano tutti gli uomini sono più numerosi e più forti di quanti li dividano e li contrappongano». ${ }^{4}$

Dopo tensioni interiori, confusioni e malinconie alla fine del 1954, quando i confini tra la zona A e la zona B sono stabiliti definitivamente con il Memorandum di Londra, Tomizza imbocca la via della diaspora, lascia l'Istria e si trasferisce a Trieste. Nell'articolo intitolato $\mathrm{Nel}$ golfo di Trieste, inserito nella prima parte de Le mie estati letterarie. Lungo le tracce della memoria, una parte dedicata prettamente a Trieste e al suo retroterra, Tomizza scrive:

$$
\begin{aligned}
& \text { Trieste ci viene incontro con il faro della Vit- } \\
& \text { toria, a cui subito seguono le banchine e gli } \\
& \text { edifici identici tra loro e regolarmente alli- } \\
& \text { neati del porto vecchio, primo ricetto per i } \\
& \text { profughi istriani e poi tornati a costituire un } \\
& \text { borgo morto nella città. [...] Lembo estre- } \\
& \text { mo del suolo nazionale, Trieste inalbera la } \\
& \text { sua italianità, com’è naturale in questo seco- } \\
& \text { lo nel quale si sono combattute due guerre } \\
& \text { mondiali e si è vissuto un aspro dopoguerra } \\
& \text { per conquistarla e assicurarla all'Italia. Ma se } \\
& \text { estendiamo la riflessione ai secoli preceden- } \\
& \text { ti, mentre conserviamo nello sguardo la sua } \\
& \text { struttura urbanistica, non possiamo non ri- } \\
& \text { conoscere che la sua funzione primaria è } \\
& \text { quella di attrarre e amalgamare nuclei di et- } \\
& \text { nie, di culture e di civiltà diverse. Il suo futu- } \\
& \text { ro nel Duemila sarà reso possibile soltanto } \\
& \text { da un ripristino di tale ruolo e di tale spirito. }
\end{aligned}
$$

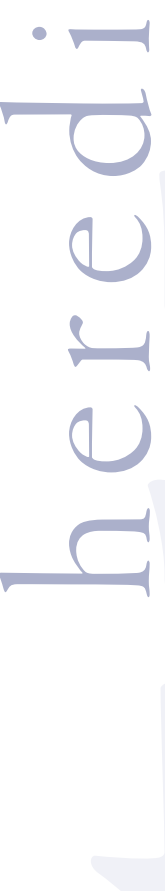

A Trieste comincia a scrivere nei primi anni Sessanta dello scorso secolo, quando l'Istria si

\footnotetext{
3 Cesare De Michelis, "Introduzione", in Le mie estati letterarie. Lungo

le tracce della memoria (Venezia: Marsilio, 2009), I4.

4 De Michelis "Introduzione", I I-I2.
} 
era ormai spopolata e la maggior parte dei suoi abitanti aveva intrapreso la via amara dell'esodo. Nell'intervista concessa poco prima di morire a Carmelo Aliberti, poeta e critico letterario siciliano, intitolata Incontro con lo scrittore, opportunamente riportata in apertura della monografia Fulvio Tomizza e la frontiera dell'anima, lo scrittore materadese ha confessato:

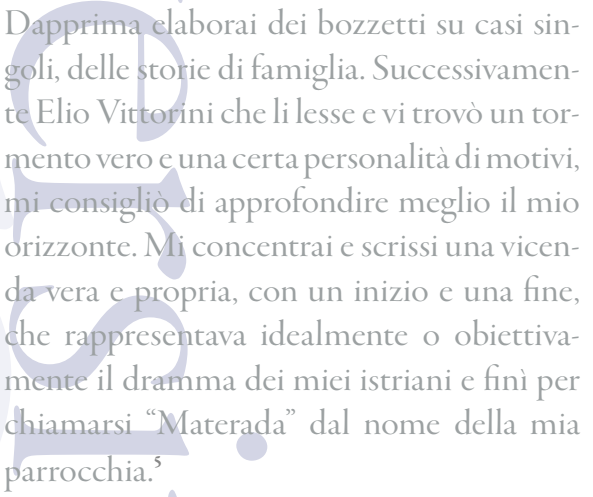

Pubblicato nel 1960 presso Mondadori, $M a$ terada è il libro d'esordio nel quale, appena venticinquenne, stimolato dal dovere civile di gridare le sorti della sua terra e della sua gente, Tomizza inizia il difficoltoso tentativo di ricreare, tramite la scrittura, sentita come esigenza biologica, l'unità tra la comunità slava e quella italiana, perduta in seguito alla lacerazione avvenuta nel secondo dopoguerra. Egli assume il compito di essere l'umile cantore delle umili res gestae di un mondo escluso dalla Storia, e pur riscattato da secoli di anonime sofferenze, un compito che è storico, ancor prima che letterario. Materada è il primo capitolo della Trilogia istriana (questo il titolo dato dalla Mondadori a un unico volume edito nel 1967, che comprende, oltre a Materada, La ragazza di Petrovia e Il bosco di acacie), nella quale lo scrittore sviscera la realtà dell'esodo istriano e ne esamina le tappe senza punte polemiche, bensì attraverso una rievocazione storico-documentaria oggettiva che diventa una vera e propria autobiografia collettiva, che sembrava non aspettasse altro che di essere raccontata, o come “espulsa” da sé. Com'è stato rilevato dalla criti-

Carmelo Aliberti, Fulvio Tomizza e la frontiera dell'anima (Foggia: Bastogi, 200 I), 7 . ca, in Materada Tomizza non si sottrae all'influsso dei maestri del realismo italiano, da Verga a Silone, a Tozzi, ma sono altrettanto evidenti le suggestioni di Pavese e Pratolini, ossia di un neorealismo ormai in crisi. Egli conserva, come evidenzia Carlo Bo,

la musica di quella stagione con tutte le in-
flessioni di un discorso che non vuole mai
essere personale e peraltro si dispone in una
visione più larga, più umana, senza per que-
sto perdere quelle che sono le prime qualità:
il senso della realtà, l’aderenza geografica, la
perfetta intuizione di un mondo in via di di-
sgregamento, meglio di un mondo in trasfe-
rimento.

Il romanzo si chiude nel momento in cui Franz, contadino istriano di Materada, come la maggior parte dei suoi compaesani, decide di abbandonare il paese e strappare così le radici che lo legano da generazioni a una terra aspra e fertile, ora negata e contesa. Materada è un'opera epica e corale, com'è stato evidenziato dalla critica, che attraverso la storia di una famiglia e di una proprietà frodata e inottenibile racconta il destino di un popolo diviso, alla ricerca di una nuova, definitiva identità, tra rancori, odi e sanguinose vendette. Quando anche per la famiglia di Franz Coslovich arriva l'ora della partenza, sono poche ormai le persone rimaste in paese: non c'è più nemmeno il sacerdote per celebrare la messa, sollevato dall' incarico dal nuovo regime. Allora qualcuno s'improvvisa prete per festeggiare, un'ultima volta prima di partire, il patrono del paese che si celebra ad agosto, la Madonna della Neve. È solo un ultimo momento di vita comunitaria, improvvisato e privo di solennità. Il romanzo si chiude con la mesta processione al cimitero del paese per dare l'estremo saluto ai morti. Con l'explicit affidato a una donna in procinto di partire, il «cerchio magico», che teneva salda la comunità, per un attimo si ricompone nella condivisione del dolore e nel rispetto per la morte.

6 Fulvio Tomizza, "Antologia critica", in Materada (Milano: Bompiani, 2000). 183 . 
Si uscì dalla chiesa e si entrò nel cimitero che è a due passi. Era mezzogiorno e la campana cominciò a suonare. [...] E già si sentivano da lontano le campane di Buje, poi quelle di Carsette, di Verteneglio, di Petrovia e di San Lorenzo. [...] Lerba del cimitero era alta e secca, e copriva tutte le tombe. Le donne avevano intonato il canto alla Madonna [...] Cessarono le altre campane; soltanto la nostra resistette ancora per poco. Poi mostrò di voler finire anch' essa: ormai dava soltanto qualche forte e singolo rintocco come scrollandosi tutta prima di morire. Anche il canto cessò. Ora non si sentiva che il caldo e i passi delle donne che strisciavano tra l'erba [... "Addio ai nostri morti" disse forte una donna. ${ }^{7}$

La struggente vicenda dell'esodo, «avvertito e sofferto come uno strappo indotto da qualcosa (i regimi politici) che si sovrappone alla libera volizione di una umanità corale $\gg,{ }^{8}$ sembra compiersi nel morire di quelle campane. Nell'avvio de La ragazza di Petrovia (1963) che, oltre ad essere il secondo capitolo della Trilogia istria$n a$, è un libro decisivo per la futura produzione narrativa di Tomizza e l'ideale continuazione di Materada, il suono mesto delle campane è sostituito dal rombo cupo dei camion, che con un'andatura traballante giungono carichi di profughi e delle loro masserizie al campo di raccolta loro assegnato. Il passo che segue è l'incipit del romanzo.

Vennero i camion e bloccarono i freni, si fermarono qui fra le baracche dai vari colori come arrivassero da competizioni diverse, vinti e insieme vincitori. Veramente dalla foga con cui avanzavano poteva sembrare che tutti indistintamente avessero vinto; ma la sconfitta venne fuori dopo, quando furono tutti indistintamente fermi sulla ghiaia, uno di qua, l'altro di là, visti dall'alto in tante

7 Fulvio Tomizza, Materada (Milano: Bompiani, 2000), 173.

8 Paolo Leoncini, "L'identità della terra. Lettura di Materada di Fulvio Tomizza", in L'esodo giuliano-dalmata nella letteratura, a cura di Giorgio Baroni e Cristina Benussi (Roma-Pisa, Fabrizio Serra Editore, 2014), 193. posizioni che non formavano una figura geometrica purchessia, fermi sotto il sole che picchiettava specchiandosi nelle pozzanghere, e nessuno si curava di levare le alte masserizie, né di abbassare le sponde o tirar giù il tendone.

Gli uomini stavano seduti lungo il gradino che accompagnava la bassa costruzione di docce e gabinetti al centro delle baracche. Fermi al sole, non si guardavano; ognuno aveva serrata nel pugno una chiave nuova. ${ }^{9}$

Le vicende narrate ne La ragazza di Petrovia si collocano in un momento cruciale della storia dell'Istria, quando l'esodo è una scelta imposta agli istriani e compiuta irreversibilmente. La «partenza snaturante» ${ }^{\text {10 }}$ è in gran parte già avvenuta. Il confine è stato varcato dalla maggior parte degli abitanti della penisola, tutta gente

$$
\begin{aligned}
& \text { provata da quegli ultimi mesi di costernazio- } \\
& \text { ne comune a quelli che erano in procinto di } \\
& \text { partire come a quelli che ormai si erano ras- } \\
& \text { segnati a restare: chiusi a tutte le speranze, } \\
& \text { erano convinti che il cerchio magico che li } \\
& \text { aveva tenuti uniti da sempre si fosse per sem- } \\
& \text { pre spezzato ad opera di una decisione pre- } \\
& \text { sa da due ministri, o di un nero destino, che } \\
& \text { tanto valeva partire quanto restare, in en- } \\
& \text { trambi i casi non rimaneva che chiudersi in } \\
& \text { se stessi }\left[. . . .{ }^{1 .}\right.
\end{aligned}
$$

Per tutti, sia per chi aveva deciso di partire sia per chi aveva scelto di restare, era iniziata un'umiliante via Crucis. Il «cerchio magico», che circondava e racchiudeva protettivo il contadino nel suo ambiente, si era definitivamente spezzato: si era franta l'alleanza sacra con la terra, che non potrà più ricomporsi. I protagonisti del romanzo, uomini di terra come Tomizza, avviliti ed esclusi per sempre dai loro campi e dalle loro stalle, sradicati dalla densità sacrale dell'arcaica civiltà contadina, appena giunti al Campoprofughi di Padriciano, sull'altopiano triestino, con ancora in mano la «chiave nuova», metafo-

9
10
11

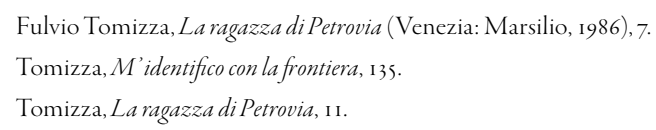


ra della nuova vita che stanno per affrontare, non sanno come atteggiarsi. Sono smarriti e disorientati, come si evince dal passo incipitario sopra citato, che presenta in maniera cinematografica una scena immobile e insieme in veloce movimento. ${ }^{12}$ Una volta sistemati nelle baracche loro assegnate e inseriti nella vita artificiale e ordinata del Campo, regolata da orari da rispettare e da attività da svolgere senza slancio, capiranno d'essere dei vinti: adattandosi al «nuovo ordine di idee» e a una «realtà nuova, cui volenti o nolenti dovevano sottoporsi», ${ }^{13}$ trascorreranno le giornate oscillando tra uno spossante senso di noia e di solitudine, coltivando non più i loro campi, com'erano soliti fare nella terra che hanno lasciato, seguendo il ritmo imposto solo dalla natura, ma quanto resta nella memoria della loro cultura contadina intrisa di umiltà. La vita nella campagna istriana era scandita da un'atemporalità che creava uguaglianza e condivisione, mediante usanze, riti e consuetudini. Ora, invece, la vita deve sottostare a nuove imposizioni e nuovi termini di tempo, ritmati non più dalla natura, ma da altri accadimenti, anche banali: dall'orario dei pasti alla mensa, dall'organizzazione interna del campo, dall'arrivo ogni giovedì del dentista e del medico per i bambini, dalla distribuzione gratis delle medicine e finanche dalle piccole beghe tra i profughi, provenienti da varie località dell'Istria. Al di là del rigido confine i profughi hanno lasciato un mondo conosciuto ed esperito. Privati dei propri punti di riferimento e delle proprie sicurezze i componenti della collettività rurale sono ora costretti a cercare in sé o al di fuori, ma sempre e comunque da soli, nuove possibilità di vita e nuove strategie di equilibrio. Subiscono una frustrante depauperazione, che essi vivono come conseguenza di una scelta fra alternative non conciliabili. Accomunati da un senso di fallimento e di straniamento, condannati a trascorrere giornate vuote e pregne di noia nel Campo «largo e solenne, intonato a un colore giallo-arancione e raccolto intorno all'alto fu-

\footnotetext{
i2 Tomizza non era estraneo all'ambiente cinematografico. Fu aiuto regista nel film sloveno girato a Lubiana, Attimi decisivi, che partecipò al festival di Venezia nel 1955.

13 Tomizza, La ragazza di Petrovia, 9.
}

maiolo della mensa», ${ }^{14}$ che li esclude dal resto del mondo e che subiscono come una dolorosa coazione, essi trascinano le loro esistenze segnate da una profonda solitudine interiore, turbati dalla condizione di precarietà e di incertezza per il futuro che non sanno come progettare tesi, almeno all'apparenza, a uniformarsi alle nuove abitudini. Ormai non rimane loro che «chiudersi in se stessi, nel piccolo giro dei propri rancori e dei propri interessi, chi in atto di sfida al mondo o all'Altissimo [...] chi in disperato e martellante silenzio». ${ }^{15}$ Da questo momento, e per il resto della vita, faranno parte di quella «famiglia smembrata i cui componenti si riconoscono nella custodia delle ceneri che si sono portati per il mondo». ${ }^{16}$ Nel discorso pronunciato il 27 ottobre del 1990 a San Donà di Piave in occasione della quinta edizione del Premio Nazionale dei Giovani Costantino Pavan per opere sulle culture locali, Tomizza ha tratteggiato puntualmente lo stato d'animo del contadino di Materada (ma potrebbe essere del contadino di Petrovia, o di Verteneglio...) nel momento in cui lascia la sua terra e l'ambiente rurale, dove si sentiva ed era sovrano, e delinea al contempo la condizione di estraneità che lo accompagnerà nella nuova realtà urbana.

$$
\begin{aligned}
& \text { Per lui quella sbarra sollevata, che chiude su } \\
& \text { un territorio e ne spalanca un altro, è un li- } \\
& \text { mite estremo che soltanto un’imposizio- } \\
& \text { ne, sia pure interiore, può rendere valicabi- } \\
& \text { le. Tutto (e sembrerebbe niente se a seguirlo } \\
& \text { sono la moglie e ifigli, il vecchio padre, il mo- } \\
& \text { bilio, l'ultimo raccolto, il bestiame), tutto è } \\
& \text { ugualmente rimasto alle sue spalle. Oltre, al } \\
& \text { dilà, sarà fondata un'altra vita, ma come pre- } \\
& \text { sa in prestito, che poteva essere assegnata al } \\
& \text { suo vicino e che pertanto non lo coinvolgerà } \\
& \text { mai interamente. Egli pagherà la sua estra- } \\
& \text { neità ricevendo meno agevolazioni di ogni } \\
& \text { altro profugo e tuttavia si sentirà immerite- } \\
& \text { vole di quelle ottenute; per la qual cosa sarà } \\
& \text { Tomizza,LaragazzadiPetrovia, 95. } \\
& \text { I5 Tomizza,LaragazzadiPetrovia, ir. } \\
& \text { i6 Fulvio Tomizza, "Un popolo troncato", in Alle spalle di Trieste } \\
& \text { (Milano: Bompiani), i2s. }
\end{aligned}
$$


costretto a dire cose che non sente, che non sono sue, si sforzerà anche lui di essere il profugo che non è, e ciò contribuirà a renderlo quello che invece è: nessuno, salvo a riemergere quando si incontrerà coi paesani, cosa che oramai avviene solo ai funerali. ${ }^{17}$

Ne La ragazza di Petrovia lo scandaglio interiore, lo scavo psicologico dei personaggi, che Tomizza amplierà secondo nuove linee evolutive ne L'albero dei sogni (1969), mette in luce la condizione di disagio, di sgomento e smarrimento dei profughi privati, come è stato per il padre di Tomizza, della vitalistica voglia esistenziale, trascinati dalla diaspora oltre il confine, via da una terra che è appartenuta loro per secoli e che consideravano la loro unica patria. Ma al di là di ogni frattura e di ogni rimpianto, la vita deve continuare e l'anima deve darsi pace, se non altro per «la tendenza congenita in ogni uomo e in ogni cosa a entrare nell'ordine delle cose $\gg,{ }^{18}$ sentenzia l'autore. Man mano che gli arrivi nel campo profughi si susseguono, con la lenta ambientazione, si dissolvono le strutture e i rapporti sociali del mondo rurale e se ne creano di altri. Anche tra i profughi c'è chi comincia la sua nuova vita integrandosi, come Gusto, che già insegue la promessa dell'assegnazione di un alloggio migliore con il soccorso delle autorità del campo: per altri la possibilità di riscatto è vista nell'opportunità di ottenere un lavoro che dia un senso alle loro giornate, li liberi dal clima avvilente in cui vivono e segni l'inizio di una stagione nuova della loro vita; per altri ancora, come per Valdo Stepancich, il protagonista maschile del romanzo che narra la sua parte in prima persona $\mathrm{e}$ si fa portavoce degli stati d'animo dei suoi compaesani, la soluzione è vista in una meditazione più alta, che riesca a dare un senso a ciò che sembra insensato e innaturale e riappacifichi l'uomo al suo destino. Pur di adeguarsi al nuovo contesto, Valdo sta diventando "altro" rispetto a quello che era al di là del confine. Per superare il proprio isolamento sceglie di cancellare qualsiasi segno distintivo che possa rivelare agli altri la sua

\footnotetext{
I7 Tomizza, $M$ 'identifico con la frontiera, I I-I2.

I8 Tomizza, La ragazza di Petrovia, 87.
}

identità di istriano (esemplificativo l'episodio in cui, attirato da una voce che tra la folla in tumulto maledice chi ha permesso agli esuli istriani di oltrepassare il confine e concede loro privilegi che altri non hanno, rinuncia a raccogliere le provviste uscite dalla borsa cadutagli di mano, tra le quali primeggia il tipico baccalà in bianco, che è il piatto d'obbligo di ogni istriano alla vigilia di Natale). Il cambiamento si è ormai verificato. Superando il confine fisico tra i due Stati, per rientrare «nell'ordine meraviglioso delle cose», l'esule è costretto a oltrepassare anche il confine psicologico e affettivo tra due mentalità, a staccarsi dalle tradizioni e dalle abitudini che si è lasciato alle spalle. Adattandosi alla nuova realtà che garantisce un alloggio, due pasti al giorno e un sussidio, in verità molto più di quanto abbia la gente del luogo che si trova talora in condizioni economiche di assoluta indigenza, appagato almeno in parte, Valdo si convince d'essere «compreso nell'ordine meraviglioso delle cose». ${ }^{19}$ Esemplificativo il passo che segue, tratto dalla terza parte del romanzo.
Era uno di quei pomeriggi invernali del tut to immobili, nei quali la luce e le tenebre convivono fin dopo l'ora del pranzo per ren- dere meno avvertibile poi il trapasso repenti- no dal giorno alla notte. Una giornata senza sole e senza vento, senza nebbia e senza piog- gia, in cui tutto, ogni cosa ogni animale ogni pianta, sembra trovarsi al suo giusto posto, nello stato più vero e più suo. [...] Salivo len- tamente la stradetta sassosa che porta sull'al- topiano e intorno a me tutto era silenzio. [...] Mi voltai verso la città che vedevo regola re, un po' fumosa e azzurra come attraverso un vetro sporco, e anch 'essa mi pareva d' im- provviso nel perfetto ordine delle cose e del creato; una città come tante altre al mondo, coi suoi palazzi, le vie, il mare, i teatri, le fab- briche, la gente che lavora e quella che ne- cessariamente non lavora. [...] E pensai che anche la mia presenza, il mio stesso ritorno dalla città dove avevo ritentato di presenta- re la domanda di assunzione [...], pensai che
19 Tomizza, La ragazza di Petrovia, 86

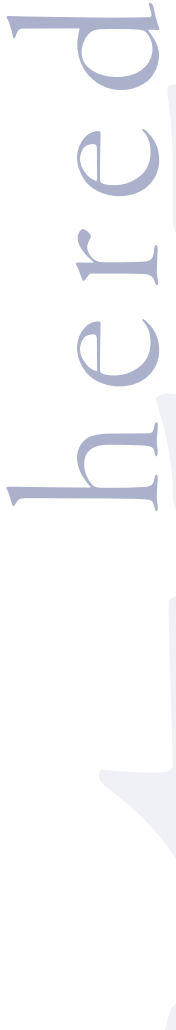


anche tutta la nostra faccenda s'inquadrava nell'ordine meraviglioso delle cose e che pur non partecipando direttamente di quel la meraviglia, rientrava tuttavia in quell'ordine semplicemente perché a essa necessario. Necessario quindi che un gruppo di gente venisse presa e caricata sui camion (anzi scegliesse da sé è salisse spontaneamente il suo camion) per essere trapiantata in una terra tanto simile alla sua ma all'opposto confine, dalla quale era sempre in grado di intravedere all'orizzonte le proprie colline che via via si sciolgono livide nel mare. [...] ed era per questo forse 'perché tutto pareva rientrare nella meravigliosa armonia delle cose] che io allora allungavo il passo per staccarmi il più possibile dalla città e avvicinarmi a quella baracca ormaí già un poco mia, forse perché aveva preso un po' del mio colore e dell'odore della mia pelle. Sapevo che lì mi sarei sentito di nuovo al mio giusto posto, nello stato più vero e più mio, ossia pienamente nell'ordine meraviglioso delle cose $[\ldots]^{20}$

Ne La ragazza di Petrovia il confine, considerato nelle sue varie dimensioni - fisica, sociale, psicologica, affettiva, interiore - è il perno su cui poggia la stessa strategia compositiva. L'opera si articola in due distinti piani narrativi che non si intersecano, come se fossero separati da una linea non valicabile che li divide, da un confine, appunto. Il mutamento stilistico e la difficoltà rappresentativa che l'autore affronta sapientemente nel suo secondo romanzo sembrano accompagnare il cambiamento della realtà che si propone agli esuli. Da una realtà nota $\mathrm{e}$ interpretabile come quella di Materada, e dalla narrazione delle istanze semplici dei protagonisti (la rivendicazione della proprietà, il risentimento nei confronti dello zio padrone, il sentimento ambiguo verso una nuova realtà, quella socialista, che mette in discussione i valori fondamentali del mondo contadino), si passa alla descrizione della condizione di alienazione vissuta dopo l'esodo, alla rappresentazione di una realtà sconosciuta e imprevedibile, che la gente sempli- ce della campagna non riesce a comprendere. La percezione del cambiamento accomuna tutti, ma ciascuno risponde con sensazioni proprie al mutamento: tutti i personaggi sono ormai, tra loro, degli "io-monadi". Nel momento in cui si oltrepassa la frontiera è come se il «cerchio magico» si spezzasse irrimediabilmente, e di conseguenza mutasse anche il carattere dell'individuo: si diventa diversi e come stranieri gli uni agli altri.

Di come siano cambiati i suoi compaesani una volta oltrepassato il confine si accorge la fragile Giustina, la ragazza di Petrovia, protagonista femminile del romanzo, la cui vicenda, raccontata in brani narrativi distinti da quelli in cui il protagonista è Valdo, l'uomo di Petrovia, è narrata in terza persona. Per buona parte del romanzo le due vicende seguono due percorsi differenti che non s'intersecano, e sono raccontate in spazi narrativi dedicati alternativamente ai due personaggi. Sono due storie parallele «che si sfiorano ma non si incontrano», scrive Cesare De Michelis nella postfazione, e aggiunge:

$$
\begin{aligned}
& \text { in realtà la struttura binaria che Tomizza co- } \\
& \text { struisce in un sapiente crescendo, dappri- } \\
& \text { ma contrapponendo le due vicende in due } \\
& \text { parti distinte e poi intrecciandole in una se- } \\
& \text { rie sempre più rapida di brevi e stringenti ca- } \\
& \text { pitoletti, sostiene il discorso ideologico che } \\
& \text { più gli sta a cuore, rompendo ogni volta la } \\
& \text { struggente malinconia che ci avvince e rapi- } \\
& \text { sce. }^{21}
\end{aligned}
$$

Solo a p. 136 dell'edizione dell'opera qui citata, a una fase avanzata dello snodarsi della vicenda, avviene l'incontro tra i due, quando Valdo si reca nella baracca di Gusto, presso il quale Giustina è ospite, per proporgli un lavoro.

Entrai da Gusto e come prima cosa vidi venirmi incontro quella ragazza che teneva una coperta in braccio e non sapeva dove posarla. Subito mi domandai quale motivo poteva aver indotto quella nostra ragazzetta silenziosa e ora più pallida in viso e gli occhi ancora più smarriti a trovarsi proprio nella

21 Cesare De Michelis, "Nota", in La ragazza di Petrovia (Venezia: Marsilio, 1986), 205. 
baracca di Gusto. E subito pensai a qualche disgrazia [...]. Ma vedevo gli altri tranquilli e allora ricordai la lontana parentela esistente tra Stefania [la moglie di Gusto] e il signor Marino [il padre di Giustina], entrambi dei Giurgevich. [...] Nell'andarmene, ora che ci ripenso, ebbi l'impressione che la ragazza mi stesse guardando con occhi supplichevoli, come chiedendomi di portarla via con me a quel posto di lavoro o dove volevo, quasi fosse in mia facoltà di prenderla in braccio e posarla in un luogo dove si sarebbe trovata meglio, in un'altra baracca o addirittura a Petrovia. ${ }^{22}$

Giustina ha oltrepassato il confine ed è giunta al Campo spinta da ragioni squisitamente affettive, sorretta dalla pia illusione di potersi inserire nel «cerchio magico», il solo ordine che conosce e dal quale l'alcolismo del padre Marino, rinnegato dai paesani, l'aveva esclusa. Desidera incontrare il figlio di Gusto, Vinicio, il padre del figlio che porta in grembo, che l'ha lasciata partendo per Trieste. Vinicio aveva «qualcosa del ragazzo cattivo, pronto a picchiarti senza ci sia una ragione e senza dimostrarsi neppure arrabbiato; anche sua madre e suo padre lo temevano». ${ }^{23}$ Dopo l'ultimo e decisivo incontro col giovane al Tabor, la collina prossima al paese col cucuzzolo «netto di roveri», ${ }^{24}$ dove «lui l'aveva visitata e le aveva lasciato qualcosa di sé», ${ }^{25}$ Giustina aveva vissuto un mese di smemoramento, fatto di gioia e di ricordi. Giunta al Campo vuole guardarlo per un istante fisso negli occhi «come una giovenca che aspetta la mazzata finale $\gg,{ }^{26}$ Legata a un costume arcaico e a sensi di colpa di radice cattolica, senza nessuno che possa difenderla o consolarla, sente fortemente il peso della colpa. Chiede il perdono di Dio per la sua «grande vergogna» (l'essersi data a Vinicio), per aver «osato e preteso per sé qualcosa», ${ }^{27}$ cerca di

\footnotetext{
22 Tomizza, La ragazza di Petrovia, 136, 137, 138.

23 Tomizza, La ragazza di Petrovia, 48-49.

24 Tomizza, La ragazza di Petrovia, 52.

25 Tomizza, La ragazza di Petrovia, 53.

26 Tomizza, La ragazza di Petrovia, 125.

27 Tomizza, La ragazza di Petrovia, 54
}

redimersi confessandosi al cugino sacerdote, ma non riesce ad andare fino in fondo: $\ll \mathrm{Ha}$ peccato sfidando non i roveri né le bestie né gli uomini, ma direttamente Dio; ha osato andare contro Lui e la sua regola e prendersi per sé quello che è riservato a Lui solo. Perché Dio è tutto quello che non si deve fare. E la punizione, a sua volta, ecco che le viene direttamente da Lui». ${ }^{28} \mathrm{Di}$ conseguenza Giustina «sente qualcosa di minaccioso gravarle sul capo per quella sua colpa; una mano terribilmente ferma». ${ }^{29}$

Per quella ragazza semplice è impossibile entrare nella realtà nuova e appena intuita durante il suo breve soggiorno al Campo profughi, molto diversa da quella lasciata a Petrovia. Anche se scossa dal senso della sua colpa, sola con l'intima sua verità, Giustina è pur consapevole di una sua più profonda dignità che la rende infine libera. Libera di decidere di ritornare a Petrovia, nonostante il permesso scaduto che avrebbe dovuto precluderle il rientro, libera di obbedire a quel suo istinto sentito come un dovere. Giustina:
[... sente ora distintamente che non potreb- be accettare la relegazione in quello sgabuz- zino né in alcun altro dei cento e cento che sono ordinatamente allineati al Campo; né potrebbe barattare la sua colpa con alcun tipo di pena che la escludesse dalla cornice del mandorlo, della casa, dell'orto e di Teresa [l'unica persona con la quale si confida, simi- le a lei perché come lei esclusa dai compaesa- ni dal «cerchio magico»]. Poiché d'improv- viso ha compreso l'esatto valore di quei contorni che sono i soli, gli unici al mondo a poter racchiudere i suoi giorni futuri [... Ed è esattamente questa considerazione [ol- tre alla nostalgia per il mondo lasciato al di là del confine letta negli occhi di Vinicio, e di tutti i profughi incontrati nel suo breve soggiorno al Campo] a far sì che non si sen- ta peggio e più in basso degli altri; la facol- tà che ha solo lei di poter prendere l'indoma- ni la corriera e scendere proprio davanti alle acacie di Gervasio. Che cos'è infatti codesto
28 Tomizza, La ragazza di Petrovia, 66
29 Tomizza, La ragazza di Petrovia, 66.

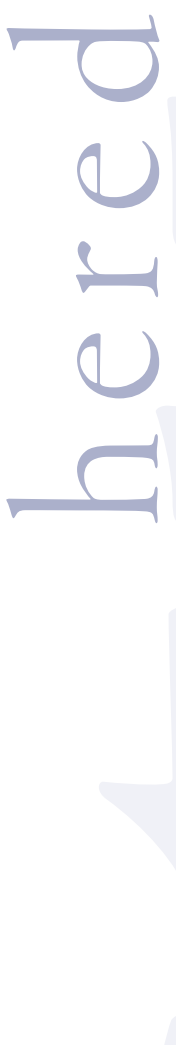


voler cambiare sgabuzzino o baracca in loro, questo voler raccogliere il più possibile gente di Petrovia da parte di quell'uomo [Valdo, che sta raccogliendo i profughi per qualche giornata di lavoro, da manovale o muratore], se non un disperato tentativo di avvicinarsi il più possibile a Petrovia? [...] È libera, domattina potrấ ringraziare e scendere in città e prendere la prima corriera senza neppure presentarsi dal cugino [il parente prete]. Ha la sensazione di stare a galla e guardare il cielo, senza alcuno sforzo, in un'acqua calda. ${ }^{30}$

Giustina non ha ancora acquisito una psicologia matura, spiazza il lettore per la sua fiducia adolescente: la sua innocenza e immaturità è motore e giustificazione delle sue azioni, che sono istintive prima che ragionate. La sua stessa capacità di interpretare esattamente gli avvenimenti è stravolta e sarà causa della sua tragica fine. Sono gli stessi tumulti tra i profughi e gli operai in sciopero, nei quali è coinvolto anche il figlio di Valdo, a permettere a Giustina di uscire impunemente dal Campo. ${ }^{31}$ Per un momento Giustina e Valdo s' incontrano, lui con in braccio il figlio ferito e sanguinante che cerca di portare in salvo, lei che corre verso la libertà. Delusa e smarrita, Giustina è infatti scappata dal Campo per ritornare a Petrovia, approfittando del disordine causato dalla zuffa tra profughi e scioperanti. Corre a perdifiato nella campagna che circonda il Campo, tra muri a secco, rovi e ginepri che pungono, alberi di nocciole e roveri. Vuole lasciarsi per sempre alle spalle quel mondo che non le appartiene e che sente estraneo. Prosegue nella corsa seguendo l'«invitante odore di stalle e di fieno umido», ${ }^{32}$ finché è convinta d'essere arrivata nel posto dove gli abitanti del Campo che, per una sorta di strano equivoco lei crede l'inseguano, «non possono più raggiungerla, perché quelle vigne e quei campi arati sono per sempre preclu-

\footnotetext{
30 Tomizza, La ragazza di Petrovia, I 46-1 47.

3I Pur di lavorare, i profughi avevano accettato di sostituire gli operai in sciopero, che si erano rivoltati contro coloro che consideravano dei crumiri e dei venduti. Nella zuffa rimase ferito il figlio di Valdo.

32 Tomizza, La ragazza di Petrovia, 195.
}

si alla loro vista $\gg .{ }^{33}$ Clandestina, anima inerme e ingenua che ingrossa la schiera dei vinti, Giustina si sente felice «per avercela fatta a fuggire proprio sotto gli occhi di loro che non si erano curati di chiudere il cancello o almeno di mettersi sulle sue tracce $\gg .{ }^{34}$ Il suo cammino ora è fatto di spazio e di sole. Non si ferma al posto di blocco da cui arrivano ordini secchi e minacciosi. Non obbedisce all'intimazione di arrestarsi e cade sotto le fucilate delle guardie. Muore tra un confine e l'altro, in terra di nessuno. La sua fine è appena accennata, come si evince dal passo che si riporta di seguito, così «come tutto appare evocato e accennato in questo racconto, così simile ad alcune narrazioni di autori nordamericani e degli italiani che ricostruiscono una forma di realismo tenendo conto di quel narrare stupito e reticente, che già in Faulkner era al limite della comprensione da parte del lettore. [...] La stessa narrazione, adottando il punto di vista di un personaggio incapace di percepire e interpretare esattamente la realtà e il procedere temporale, quasi come il Benjy di L'urlo e il furore, costringe il lettore a riflettere sulla probabile irrazionalità del reale o quanto meno su una sua intrinseca complessità $\gg .^{35}$

Fu infatti un largo sole quello che la accecò
improvvisamente dopo ch'ebbe udito la
stessa intimazione a fermarsi - stoj, stoj - ri-
petuta due volte dietro a un lontano cespu-
glio quasi con la stessa voce gutturale del
capo-reparto Branko, e che per lei suonò
nell'aria assordata dalle cicale come un cal-
do invito a proseguire, espresso in una lin-
gua non sua ma ora ancora più familiare del-
la sua. Eil sole siallargò smisuratamente fino
a comprendere in sé tutta l'aria e a coprire
tutto il cielo, che si fece di colpo rosso come
un geranio. ${ }^{36}$

Per scrivere La ragazza di Petrovia, come Tomizza rivela nel brano Le mie estati letterarie,

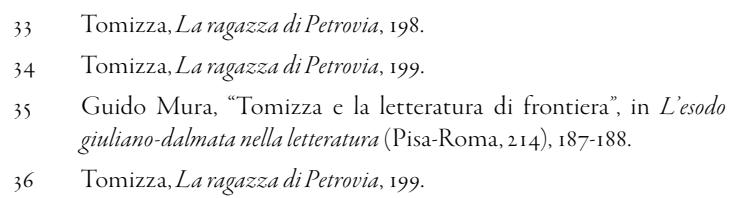


inserito nel volume omonimo citato in apertura, «sacrificai tutte le ferie aziendali [all'epoca Tomizza era impiegato presso la Rai di Trieste], allungate dai recuperi delle giornate festive nelle quali avevo lavorato». ${ }^{37} \mathrm{E}$ aggiunge:

\section{Mi stabilii nel villaggio carsico di Gropada, non lontano da Padriciano, affittando una camera; studiai i luoghi ancora più aspri dei nostri e abitati da sloveni; ripresi a frequen- tare i miei materadesi finiti nelle baracche del Campo, ed elaborai la vicenda esemplare di Giustina, ragazza rimasta incinta allo sca- dere dell'estate delle partenze, la quale vin- ce a stento la timidezza portata agli estre- mi dall'intima scoperta e va alla ricerca del corresponsabile, ma non ha il coraggio di af frontarlo anche perché respinta dal cambia- mento intervenuto nei compaesani. ${ }^{38}$}

L'autore termina il passo con una minuta descrizione nella quale svela il rituale che segue nel momento in cui si accinge a scrivere: «Come mi accade quasi sempre per i progetti letterari, segnai su un foglio il tracciato della azione, coi luoghi e i percorsi dei singoli personaggi, e, dopo aver accostato un tavolino alla finestra della stanza d'affitto, avervi deposto un paio di quaderni, la boccetta d'inchiostro e l'indispensabile vocabolario, mi ci immersi compiendo e raccontando l'itinerario»..9 A sedici anni dalla scomparsa, nell'anno in cui avrebbe compiuto ottant'anni, ci piace immaginare Tomizza così, ancora intento a scrivere nella sua casa in Istria davanti alla finestra aperta su quel paesaggio che tanto amava, così simile di qua e di là del confine. Da uomo che proviene da una civiltà di campagna e coglie in profondità la vita misteriosa della natura, Tomizza la percepiva con panica religiosità, sentendosi dentro un ordine delle cose che fa parte di una perfezione insondabile e a noi sconosciuta. Nel brano Il rapporto con la divinità confessa: «Non credo che l'universo e l'esistenza uma-

37 Tomizza, "Le mie estati letterarie", in Le mie estati letterarie. Lungo le tracce della memoria (Venezia: Marsilio, 2009), I3 I-132.

38 Tomizza, "Le mie estati letterarie", I32.

39 Tomizza, "Le mie estati letterarie", 132 na si riducano a sola materia ma neppure riesco ad aver fede in un'entità superiore che ci sovrasti. Rimango assai spesso incantato dalla natura, impressionato da fenomeni atmosferici pur noti, commosso da manifestazioni di tenerezza, innocenza e grazia da parte dei miei simili come pure degli animali», ${ }^{40}$ e prosegue: $\ll$ La contemplazione della natura ci preserva maggiormente dallo scatenamento degli impulsi egoistici e a me offre l'occasione di raffigurarsi un rapporto con Dio». ${ }^{41}$ Nello stesso brano conclude:

$$
\begin{aligned}
& \text { fra tutti i paesaggi noi preferiamo quelli fa- } \\
& \text { miliari, con i quali la nostra esistenza si sia già } \\
& \text { misurata. [...] Molte volte d'estate in Istria, } \\
& \text { ad un incrocio di strade bianche o accostan- } \\
& \text { domi a un villaggio, nel silenzio teso dell'o- } \\
& \text { ra meridiana, ho vissuto istanti in cui ho av- } \\
& \text { vertito come un brivido di eternità. La mia } \\
& \text { aspirazione è di pervenire a simili momenti } \\
& \text { quanto più spesso. Scrivo appunto per que- } \\
& \text { sto. }{ }^{42}
\end{aligned}
$$

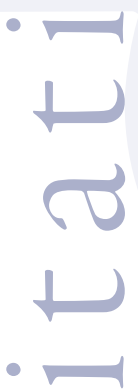

Uomo di frontiera, ma oltre i confini, Tomizza credeva veramente e sinceramente nella diversità come ricchezza, nella permeabilità dei confini e nella possibilità di superarli: il mondo avrebbe ancora bisogno di lui per costruire con umiltà, modestia e convinzione, e senza chiudersi in egoistiche autosufficienze, contatti e rapporti più umani, rispettosi delle culture e delle identità. Durante il suo breve transito terreno si è assicurata l'eternità con i suoi romanzi: superando la contingenza, essi oltrepassano il suo e il nostro tempo e "s' infuturano".

\section{Povzetek}

V članku je razčlenjen roman La ragazza di Petrovia pisatelja Fulvia Tomizze (1935-1999), ki skupaj z Materado (1960) in Il bosco di acacie (1967) tvorijo $\gg$ istrsko trilogijo «, v kateri avtor do podrobnosti secira realnost istrskega eksodusa brez polemičnih not, a z zgodovinsko dokumentirano objektivno uprizoritvijo, ki preraste $\mathrm{v}$

\footnotetext{
$40 \quad$ Fulvio Tomizza, "Rapporto con la divinità", in Le mie estati letterarie. Lungo le tracce della memoria, (Venezia: Marsilio, 2009), I59.

4I Tomizza, "Rapporto con la divinità", I60.

42 Tomizza, "Rapporto con la divinità", 160
}

$(2)$


pravo kolektivno avtobiografijo. Drugi roman trilogije La ragazza di Petrovia (1963) je v bistvu nadaljevanje $M a$ terade, a je obenem tudi ključni roman za nadaljnjo literarno ustvarjanje istrskega avtorja. Dogajanje, opisano v romanu, doseže namreč odločilni trenutek v zgodovini Istre, ko postane eksodus vsiljena in nepovratna izbira za Istrane. Prišlo je tako do številnih »prisiljenih odhodov $\ll$. Velika večina prebivalcev Istre se je tako odločila za prečkanje meje in »čarobni $\mathrm{krog}_{\ll}$, $\mathrm{ki} \mathrm{je} \mathrm{varoval} \mathrm{in}$ ščitil kmete pri njihovem delu, se je dokončno pretrgal. Psihološko raziskovanje likov, ki ga bo avtor še poglobil v novem evolucijskem nadaljevanju v L'albero dei sogni (1969), izpostavlja nelagodje, razočaranje in izgubo beguncev, ki so bili oropani življenjske sile in so bili poklicani čez mejo, daleč stran od zemlje, ki jim je stoletja pripadala. Od poznane in doumljive realnosti opisane $v$ Materadi, preide avtor v La ragazza di Petrovia v opis alienacije, ki so jo doživeli Istrani po eksodusu vse do reprezentacije nepoznane in nenapovedane realnosti, ki je preprosti ljudje s kmetov niso mogli doumeti. Percepcija spremembe je sicer jasna vsakomur, a vsak nanjo odgovarja različno: vsi opisani liki so $» j a z-e n o \ll$. Ko prestopijo mejo, se zanje »čarobni krog « kakor da razblini, in kot posledica, se tudi posamezni liki spreminjajo: vsak postane drugačen in kakor tujec eden drugemu.

\section{Summary}

The essay examines the novel La ragazza di Petrovia written by Fulvio Tomizza (1935-1999), which with Materada (1960) and Il bosco di acacie (1967) constitutes the «Istrian trilogy», in which the writer dissects the reality of the Istrian exodus without polemical points, but through an objective historical-documentary re-enactment, which becomes a real collective autobiography. La ragazza di Petrovia (1963), the second novel of the trilogy, is the ideal continuation of Materada, but it is also a decisive book for the future narrative production of the Istrian author. The events narrated in the novel are at a crucial moment in the history of Istria, when the exodus is a choice imposed on the Istrians and irreversibly accomplished. The "distorting departure" has largely occurred. The border has been crossed by most of the inhabitants of the peninsula and the "magic circle", which surrounded and protected the peasant in its environment, has definitely broken off. The psychological excavation of the characters, which the writer will expand according to new evo- lutionary lines in Lalbero dei sogni (1969), highlights the condition of discomfort, dismay and loss of refugees deprived of vitalistic existential desire and dragged across the border, via from a land that has belonged to them for centuries. From a known and interpretable reality like the one described in Materada, in La ragazza di Petrovia we go to the description of the condition of alienation experienced by the Istrians after the exodus, to the representation of an unknown and unpredictable reality that the simple people of the countryside can not understand. The perception of change is common to everyone, but each responds with feelings of change: all the characters are now "I-monads". When you cross the border, it is as if the "magic circle" is irretrievably broken off, and as a consequence the character of the individual also changes: one becomes different and as strangers one to another.

\section{Bibliografia}

Aliberti, Carmelo. Fulvio Tomizza e la frontiera dell'anima. Foggia: Bastogi, $200 \mathrm{r}$.

De Michelis, Cesare. "Nota”. In La ragazza di Petrovia, 205. Venezia: Marsilio, 1986.

De Michelis, Cesare. "Introduzione". In Le mie estati letterarie. Lungo le tracce della memoria, Fulvio Tomizza, 8-ı4. Venezia: Marsilio, 2009.

Leoncini, Paolo. "L'identità della terra. Lettura di Materada di Fulvio Tomizza”. In L'esodo giuliano-dalmata nella letteratura, a cura di Giorgio Baroni e Cristina Benussi, 193198. Roma-Pisa: Fabrizio Serra Editore, 2014.

Mura, Guido. "Tomizza e la letteratura di frontiera”. In L'esodo giuliano-dalmata nella letteratura, a cura di Giorgio Baroni e Cristina Benussi, I87-188. Roma-Pisa: Fabrizio Serra Editore, 20I 4.

Tomizza, Fulvio. La ragazza di Petrovia. Venezia: Marsilio, 1986.

Tomizza, Fulvio. Destino di frontiera. Genova: Marietti Editore, 1992.

Tomizza, Fulvio. “Un popolo troncato”. In Alle spalle di Trieste, I25-I32. Milano: Bompiani, 1995. 
Tomizza, Fulvio. M'identifico con la frontiera.

San Donà del Piave: Biblioteca civica, 1999.

Tomizza, Fulvio. “Antologia critica”. In

Materada, I83. Milano: Bompiani, 2000.

Tomizza, Fulvio. Materada. Milano: Bompiani, 2000.

Tomizza, Fulvio. "Le mie estati letterarie”. In Le mie estati letterarie. Lungo le tracce della memoria, I3I-I32. Venezia: Marsilio, 2009.

Tomizza, Fulvio. "Rapporto con la divinità". In Le mie estati letterarie. Lungo le tracce della memoria, I59-160. Venezia: Marsilio, 2009.
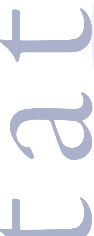

-
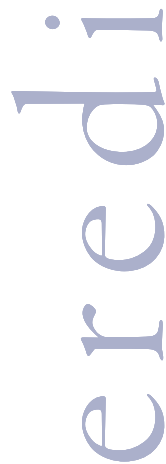


\title{
Girolamo Muzio, letterato Capodistriano
}

\author{
Nives Zudič Antonič, Anita Dessardo
}

In questo articolo verrà presentata l'opera di Girolamo Muzio, autore capodistriano di famiglia e d'affetti. Muzio era un uomo che oggi potremmo definire "di regime”, allineato con le strutture di potere. Infatti, verso la metà del Cinquecento, si trovò nella tipica posizione di servitore e di letterato, quando oramai la corte diventava sempre più centro del potere politico, mettendo così in crisi la figura dell' intellettuale, visto come maestro di civiltà. Nell'articolo viene illustrata la sua ampia produzione letteraria che comprende diversi ambiti: da quello religioso, alla questione della lingua e alle regole del comportamento.

Parole chiave: Girolamo Muzio, Controriforma, letterati capodistriani, il "martello degli eretici", Il Duello.

V članku so predstavljena dela Girolama Muzia, avtorja, ki izhaja iz koprske družine in je na Koper bil zelo navezan. Muzio je bil osebnost, ki ga lahko danes imenujemo » človek režima«, naklonjen takratni oblasti. Sredi i6. stoletja se uveljavi v vlogi dvornega privrženca in učenjaka, prav v času, ko je dvor vedno bolj postajal sedež politične moči. Tako je žal zastrt lik izobraženca kot učitelja civilizirane družbe. Članek predstavlja ves avtorjev literarni opus, ki zajema različna področja: od verskih do jezikovnih vprašanj in tudi pravil olike v družbi.

Ključne besede: Girolamo Muzio, protireformacija, koprski učenjaki, »kladivo za krivoverce «,Dvoboj.

$\mathrm{N}$

el vasto panorama degli autori istriani o che si considerarono tali, non si può non parlare di Girolamo Muzio, capodistriano di famiglia e d'affetti. A molti, purtroppo, sconosciuto o poco considerato. Si tratta di un autore ingiustamente sottovalutato che paga il suo allineamento alla curia e la sua lotta alla riforma. Il "martello degli eretici", come veniva chiamato, è una figura che a prima vista potrebbe sembrare meno affascinante del Vergerio e di coloro che si fecero carico della riforma protestante. Muzio era un uomo che oggi potremmo definire "di regime", allineato con le strutture di potere, in pratica può essere definito un cortigiano.
Infatti, verso la metà del Cinquecento, si trovò nella tipica posizione di servitore e di letterato, quando oramai la corte diventava sempre più centro del potere politico, mettendo così in crisi la figura dell' intellettuale. Visto come maestro di civiltà, Muzio svolse diverse funzioni di segretario al servizio dell'uno o dell'altro signore, sempre però subordinato al potere assoluto. Girando per le corti e frequentando molta gente, divenne particolarmente esperto in materia cavalleresca, così che nobili di tutta l'Europa lo consultarono per districare svariate querele.

La sua produzione letteraria fu molto ampia. Si cimentò in diversi campi, scrivendo sulla religione, sulla questione della lingua - che in 
quel periodo rivestiva un ruolo di primaria importanza - e sulle regole del comportamento. Coltivò, inoltre, la lirica, la forma epistolare, tentando anche l'epica che poi abbandonò. L'opera che lo rese famoso in tutta l'Europa fu il trattato intitolato il Duello.

Nonostante la sua cospicua produzione, la notorietà raggiunta e il buon grado di conservazione delle sue opere, sono stati in pochi ad occuparsi della figura di Girolamo Muzio.

\section{L'inquieto Cinquecento istriano}

\section{Il Cinquecento mise in luce alcune delle figure} più significative e d'alto livello morale, nonché intellettuale, del panorama istriano. Queste rivestirono un notevole ruolo nelle vicende politiche ed ecclesiastiche di quel periodo non solo a livello regionale, ma anche in un contesto più ampio. La loro abbondanza talvolta ci fa mettere in secondo piano personaggi che meriterebbero ben altra attenzione. Si deve rilevare che la vita spirituale istriana non si può certo esaurire nello studio di figure come Pier Paolo Vergerio il Giovane, Baldo Lupatino, Flaccio Illirico o Pietro Bonomo, come sembrerebbe dagli studi finora pubblicati in materia.

Sin dall'antichità, il sentimento che dominò fra gli istriani fu il desiderio, o meglio il bisogno spirituale di libertà, per il quale seppur sottomessi, combatterono più volte. Non fu solo la Riforma, l'unico elemento che fece scaturire nuove idee, ma è necessario considerare pure il manifestarsi di tutti quei problemi culturali, politici, economici e religiosi, che emersero ben prima. L'Umanesimo fu così il mezzo ideale per un riscatto non solo culturale, ma anche civile. Fu questo, uno dei motivi per cui gli umanisti istriani furono numerosi.

Esaminando attentamente i documenti ecclesiastici e politici dell'epoca, è evidente come nel

La Biblioteca centrale di Capodistria conserva un'edizione del Duello del 1585 .

2 Fulvio Salimbeni. "Fonti e studi sulla storia religiosa dell' Istria nel XVI secolo," in L'umanesimo in Istria, cur. Vittore Branca e Sante Graciotti (Firenze: Olschki, 1983), 167.

3 Francesco Semi, Istria e Dalmazia. Uomini e tempi. Istria e Fiume (Udine: Del Bianco, 1991).
XVI secolo si evolse, impetuosamente, quell'irrequietezza che si trovava alla base della vita istriana, non solo nel Quattrocento e all'inizio del Cinquecento, ma già alla fine del Trecento. ${ }^{4}$

La storiografia istriana ha creato un'immagine della storia moderna "tanto compatta e monolitica, tutta veneziana e italiana che, per quanto fascinosa e suggestiva, è decisamente sviante e fuorviante; e l'adesione popolare alla Riforma protestante è la prova evidente d'un malcontento latente, inconfessato, in parte inconscio contro la Dominante, anche se si devono ammettere" molte altre concause che hanno spinto a tale scelta di constatazioni dei valori ufficiali.

In ogni modo, osservandolo nel suo insieme, il quadro della letteratura istriana del Cinquecento offre un panorama sociale e culturale interessante e apparentemente contraddittorio: da un lato scrittori protestanti, come Vergerio il Giovane, Flaccio, Lupatino e fra Giulio Morato da Capodistria, dall'altro invece Girolamo Muzio Giustinopolitano, difensore della Curia romana e definito "martello degli eretici", il cittanovese Antonio Pantera, capodistriani come Giovanni Zarotti e Vincenzo Metelli. ${ }^{6}$

Nonèda trascurareche Capodistriafun importante centro culturale, dove, già nel $\mathrm{I} 478$, sorse un'accademia, la Compagnia della Calza, che dopo aver abbandonato gli eserciti cavallereschi dei suoi primi anni, si trasformò ben presto in una società letteraria, che ai tempi della riforma mutò nome in Desiosi e proibì ai suoi iscritti qualsiasi discussione su argomenti religiosi. A questo punto il Muzio accusò tutti i membri d'eresia e di convivenza con il Vergerio. Non si sa con esattezza se questo fatto fosse vero o meno, dimostra però la divisione dell'ambiente istriano: da una parte innovatori, dall'altra, conservatori. Lo stato attuale degli studi in materia non è ancora riuscito a chiarire se anche nelle altre cittadine, a Pirano, a Pola, o altrove, dovunque esi-

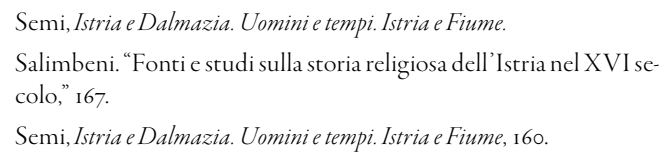


stessero accademie, succedeva lo stesso che fra $\mathrm{i}$ Desiosi. Le beghe capodistriane però sembrano indicare un certo stato d'animo caratteristico.

\section{La Controriforma in Istria}

In Istria, dominata in gran parte dalla Repubblica di Venezia e in parte dagli Arciduchi d'Asburgo, ci fu un forte influsso del luteranesimo. Le continue lotte fra l'Impero e Venezia devastarono l'Istria, influendo in modo negativo sull'andamento economico, aggravato anche dalle epidemie e dalle scorrerie dei Turchi. Le idee luterane si propagarono in questo territorio mediante sacerdoti locali e tramite predicatori luterani che giungevano da altre province. Intorno al 1520 aderivano alla Riforma non solo letterati ed ecclesiastici, ma persino donne e bambini. Questo entusiasmo cominciò in una specie d'Accademia per prepararsi, successivamente, in tutta la provincia conquistando sia le classi colte sia quelle popolari. Ben presto dalle stamperie di Venezia, prima che la "Santa Inquisizione" potesse imporre il suo veto, varcarono il confine gli scritti protestanti, che non si fermarono in Istria, ma si diffusero anche lungo la Dalmazia. Anche il vescovo di Trieste, Pietro Bonomo, ebbe una dose di responsabilità nell'importazione della "merce sassonica".

In Istria la Riforma diede quei frutti che altrove scarseggiavano, ma l'Inquisizione e le vicende politiche sfatarono le rosee prospettive, così la penisola fu costretta a chinarsi al gioco delle vecchie tradizioni. Nella seconda metà del XVI secolo l'eresia protestante si sviluppò rapidamente, e contemporaneamente si sviluppò anche la lotta dell'Inquisizione romana per contrastarne il passo. Primož Trubar svolse un ruolo importante nella diffusione dell'eresia luterana e anche Pier Paolo Vergerio il Giovane, seppur in Germania, teneva d'occhio il Friuli, tentando di convincere i giovani friulani a partire alla volta della Germania. Pier Paolo Vergerio, divenuto vescovo di Capodistria, tornò in patria nel 1544

Semi, Istria e Dalmazia. Uomini e tempi. Istria e Fiume, I6 I.

8 Antonio Miculian, "Il Santo Ufficio e la riforma protestante in Istria," in Atti del Centro di ricerche storiche, Vol. XI (Rovigno-Trieste: Centro di Ricerche Storiche di Rovigno, 1980-8I), 215-230. e nel giro di pochi anni, con l'aiuto anche del gruppo ereticale piranese, diffuse segretamente il luteranesimo in tutta l'Istria. Infatti, d'accordo con il fratello Gian Battista, propagò fra il clero e fra i cittadini le nuove dottrine, diffondendo manoscritti, lettere, rinnegando le confessioni dei peccati, ecc. Solo cinque anni più tardi Pier Paolo venne spogliato della dignità episcopale.'

Al proliferare della riforma si era opposto anche papa Paolo IV, ma a livello istriano il vero grande aiuto alla curia romana fu dato dall'opera svolta da Girolamo Muzio, che in seguito alla pubblicazione delle Vergeriane e a causa della polemica con il Vergerio, fu ritenuto il vero salvatore del cattolicesimo in Istria. Le Vergeriane rappresentano il capolavoro dell'epoca per quel che riguarda la storia ecclesiastica della diocesi di Capodistria. $^{\text {Io }}$

\section{Muzio e la Controriforma}

Girolamo Muzio ebbe il suo primo approccio con il luteranesimo nel 1545, quando accompagnò il marchese del Vasto alla corte di Carlo V, che allora si trovava a Worms in Germania. S'informò sulla dottrina e i costumi degli innovatori e si convinse che le dottrine protestanti fossero eretiche e che fosse suo obbligo impedire la diffusione della riforma in Italia. ${ }^{\text {II }}$

In un gruppo di lettere che appartengono a un periodo poco conosciuto della vita del Muzio fra il 1553 ed il 1558 , conservate fra le carte del cardinale Gian Pietro Carafa, membro dell'Inquisizione, appare evidente che il Muzio agiva come spia dell'Inquisizione e anche come agente provocatore, assumendo alle volte pure un atteggiamento di superiorità, tendendo a esagerare, senza cattiveria, ma per ambizione, i mali o le colpe nelle quali s'imbatteva. ${ }^{\mathrm{I}}$

\footnotetext{
9 Miculian, "Il Santo Ufficio e la riforma protestante in Istria," 215 230.

Io Miculian, "Il Santo Ufficio e la riforma protestante in Istria," I73230.

I I Miculian, "Il Santo Ufficio e la riforma protestante in Istria," I73230.

I2 Miculian, "Il Santo Ufficio e la riforma protestante in Istria," I73230.
} 
Tra queste lettere sono interessanti quelle indirizzate ad alcuni concittadini di Capodistria, e si potrebbero classificare come un'appendice alle Vergeriane. Da esse sappiamo che nel I533 alcuni dotti cittadini di Capodistria si erano uniti per formare un'accademia, come tante che si fondavano in Italia, con il nome di accademici desiosi, decidendo che non si doveva menzionare la religione per impedire qualsiasi contesa o disputa. Naturalmente Muzio interpretò nel peggiore dei modi la loro decisione e subito scrisse, da Venezia, la sua prima lettera agli accademici che considerarono l'intervento inutile e scandaloso. ${ }^{13}$

L'autore spesso, nella morale e nelle controversie teologiche, si dimostrò contraddittorio con se stesso. Nei suoi scritti più volte criticò, detestando quello che pure lui stesso praticava. Ad esempio, nel Trattato della comunione de' laici e delle mogli de' chierici (pubblicato con le Vergeriane), lodò e sostenne la continenza, seppur anche lui viveva in concubinato e fu amante di Tullia D'Aragona. ${ }^{14}$

Nel 1533 pubblicò i Tre testimonifedeli, dedicato alla duchessa Vittoria Farnese, dove mostrò quali erano le dottrine nelle chiese d'Europa, d'Africa e d'Asia nel secondo, terzo e quarto secolo dopo Cristo, spiegando le frodi d'Erasmo. ${ }^{\text {Is }}$

Sostenne, invece, l'autorità del concilio con varie opere. Scrisse il Bulligero riprovato (I562), la De Romana Ecclesia (1563), l'Eretico infuriato (I562), la Cattolica disciplina de' Principi (I562), l'Antidoto cristiano ( 1562 ), che parla delle menzogne che si trovano nelle prediche di Bernardino Ochino. Contro di lui aveva scritto anche le Mentite ochiniane (155I). ${ }^{16}$

Quando morì papa Pio IV nel 1566, Muzio si affidò a un altro potente protettore, papa Pio $\mathrm{V}$

\footnotetext{
I3 Pio Paschini, "Episodi della Controriforma in lettere inedite di Girolamo Muzio," in Atti e Memorie della società istiana di archeologia e storia patria, Vol. XXXIX-fascicolo I (Trieste: Società istriana di archeologia e storia patria, 1927), 349-350.

I4 Pietro Stancovich, "Biografia degli uomini distinti dell'Istria," in Atti del Centro di Ricerche Storiche, Vol.3 (Rovigno-Trieste: Centro di Ricerche Storiche di Rovigno, 1972).

is Paolo Giaxich, Vita di Girolamo Muzio (Trieste: J. Papasch\&Tip., I847), 52 .

I6 Giaxich, Vita di Girolamo Muzio, 58-59
}

che gli concesse una grossa provvigione. Nel 1570 scrisse l'Istoria Sacra, nella quale lotta contro gli errori e le frodi con cui gli eretici cercavano di offuscare le verità dei Vangeli. Scrisse inoltre: Difesa della messa, de' santi, del papato, contro le bestemmie di Pietro Viretro (1565), la Beata Vergine incoronata (1567), il Coro pontificale (1570), Lettere cattoliche (1571), la Selva odorifera (1572). ${ }^{17}$

\section{La questione della lingua italiana}

Nei primi decenni del XVI secolo, abbandonata l'idea umanistica di usare il latino come lingua letteraria, iniziarono accesi dibattiti intorno alla lingua che miravano alla ricerca e alla determinazione del tipo di lingua letteraria che avrebbero dovuto usare tutti gli scrittori d'Italia e a fissare le regole grammaticali. ${ }^{18}$

Già Dante, nel De vulgari eloquentia si era posto l'impegno di indicare agli scrittori in volgare un modello di lingua italiana, valido per tutti gli autori, al di là della frammentazione geografica e politico-culturale che presentava già da allora l'Italia. Tale modello doveva essere una koinè linguistica e cioè una lingua comune in cui venivano a mescolarsi i diversi volgari italiani nei loro aspetti più "illustri” e cioè più nobili, depurati dai più evidenti elementi di rozzezza plebea, sia in campo lessicale (il vocabolario) sia morfologico e sintattico. Dante è stato perciò il primo grande scrittore italiano a prefigurare una lingua unitaria di estensione "nazionale". Tuttavia, è evidente il fatto che, nella concretezza della sua scrittura, soprattutto nella "Commedia", Dante rimane in gran parte fedele al fondo toscano-fiorentino della lingua materna e il "volgare illustre" resta un modello ideale astratto, lontano da ogni possibilità di realizzazione concreta. ${ }^{\mathrm{I}}$

A cominciare dal Petrarca che, come affermano alcuni critici, esercitò una dittatura linguistica involontaria attraverso i secoli successivi, si afferma sempre più il modello del fiorentino illustre e si apre, a partire dal 'soo, un dibattito

\footnotetext{
I7 Giaxich, Vita di Girolamo Muzio, 58-59.

I8 Alberto Asor Rosa, Sintesi di storia della letteratura italiana (Firenze: La Nuova Italia, 1978), 98-99.

19 Nives Zudič Antonič, Storia e Antologia della letteratura italiana di Capodistria, Isola e Pirano (Capodistria: Unione italiana, 2014), 86.
} 
a più voci sulla lingua italiana, parlata e scritta, che si spinge fino al nostro tempo. ${ }^{20}$

Per tutto il Cinquecento la "questione della lingua" occupa un posto centrale. Si tratta soprattutto di proporre un codice linguistico per gli scrittori, un modello cioè di lingua scritta (non parlata) nobile e adatto a temi elevati quali l'amore spirituale, la fede religiosa, le gesta eroiche, ecc. Il più importante in tal senso è: "Le prose della volgar lingua" del veneziano Pietro Bembo. Nell'opera, tre libri in forma di dialogo (genere prediletto dai trattatisti del 'soo), si sostiene la seguente tesi: la lingua degli scrittori (a differenza di quella di Dante che appare al Bembo troppo carica di forme plebee, di rozzezze, di neologismi astrusi) doveva basarsi sul fiorentino colto: quello usato dal Petrarca per la poesia e da Boccaccio per la prosa. ${ }^{21}$

La tesi del Bembo incontrò subito forti opposizioni. Ne erano contrari soprattutto coloro che pur considerando l'importanza del fiorentino, non ne accettavano la preminenza e preferivano una lingua più variegata che prendesse spunto dalle forme delle varie parlate d'Italia. Si trattava infatti del ritorno alla tesi dantesca, cioè a quella della koinè, ad essa si rifaceva Baldassar Castiglione, con la sua opera il Cortegiano, e Giangiorgio Trissino, il principale avversario del Bembo, veneto pure lui, il quale, nel I529, pubblicò un dialogo, il Castellano, in cui sostanzialmente ripropone la teoria dantesca. Attorno a queste due tesi, da una parte il "fiorentinismo bembesco" e dall'altra la "lingua italiana" del Trissino, si raccolsero tutti gli altri letterati che intervennero nel dibattito sulla lingua da posizioni diverse. Chi volendo inserire nel modello bembesco anche termini tratti dalla lingua fiorentina parlata, chi affermando che la lingua da usare avrebbe dovuto essere quella toscana. Alla fine però vinse la tesi del Bembo, e la lingua italiana letteraria, fino alla metà del Settecento, era quella basata sul modello dei due grandi letterati

20 Zudič Antonič, Storia e Antologia della letteratura italiana di Capodistria, Isola e Pirano, 86.

2 I Zudič Antonič, Storia e Antologia della letteratura italiana di Capodistria, Isola e Pirano, 86 del Trecento e andava studiata attraverso i libri e la tradizione letteraria. ${ }^{22}$

\section{Girolamo Muzio e la questione della lingua}

Anche nella nostra regione, molti letterati affrontarono la questione della lingua italiana, in particolar modo tra di loro si distinse Girolamo Muzio che studiò le teorie bembesche ed era suo fermo sostenitore.

Muzio iniziò probabilmente ad occuparsi della questione della lingua durante un suo viaggio in Dalmazia e precisamente sull'isola d'Arbe dove si recò nel I5I3. Nell' isola dalmata d'Arbe, Muzio discuteva con Antonio Mezzabarba, discreto poeta veneziano e buon raccoglitore di rime antiche, delle regole della lingua italiana e gli fece probabilmente conoscere le teorie di Bembo. Inoltre, quando si trovò al servizio di Pietro Bonomo, ebbe l'opportunità di entrare in contatto e leggere un libro di grammatica del dalmata Francesco Fortunio, ${ }^{23}$ e da Trieste dove si trovava al servizio del vescovo Pietro Bonomo, Muzio ne scriveva con grande interesse ad Aurelio Vergerio:

\section{È stato mandato al vescovo mio un libro di grammatica volgare, di un messer Francesco dalmatino; la quale a me è stata cara di vede- re, perché egli insegna di molte cose, e della ortografia, e della proprietà della lingua, del- la variazion de’ nomi e de’ verbi.[.... E dob- biam sperar di vedere che la lingua in questo non si fermerà, che' ne avremo anche degli altri scrittori. ${ }^{24}$}

Più tardi intervenne al dibattito con vari scritti linguistici composti tra il 1533 e il 1574 e

22 Nives Zudič Antonič. "Girolamo Muzio e la questione della lingua italiana," in Hieronimo Mutio Iustinopolitano: Operette morali (Giolito, in Vinegia 1550), Le Vergeriane (Giolito, in Vinegia I550), Egloghe (Giolito, in Vinegia 1550), Le battaglie (Dusinelli, in Vinegia I582), Il duello (Compagnia de gli Uniti, in Venetia 1585), Lettere (Sermartelli, in Firenze 1590), cur. Petre Štoka e Ivan Markovič (Capodistria: Biblioteca centrale Srečko Vilhar, 2013), 79-93.

23 La grammatica di Francesco Fortunio Regole grammaticali della volgarlingua (I516) era considerata la prima grammatica italiana a stampa.

24 Girolamo Muzio, Lettere inedite di Girolamo Muzio Giustinopolitano: pubblicate nel IV centenario della sua nascita (Capodistria: Comune, 1846), i I. 
pubblicati postumi dal figlio Giulio Cesare con il titolo di Battaglie in difesa dell'italica lingua (I582). ${ }^{25}$

Nel 1530 Muzio si recò a Parigi con il conte Rangone. In questa città conobbe Luigi Alamanni con cui poté affrontare il tema che gli stava particolarmente a cuore: l'uso della lingua italiana.

Nel 1535 si recò a Ferrara, dove ebbe l'opportunità di conoscere due letterati fiorentini, Bartolomeo Cavalcanti e Gabriele Cesano e le loro opinioni sulla lingua. I due letterati fiorentini erano grandi ammiratori dello stile di Machiavelli e criticavano quello di Boccaccio. Muzio affermò il contrario e nella sua opera le Battaglie, riconobbe ogni grazia dello stile al Boccaccio. ${ }^{2}$

E per tornare al Boccaccio, istimo io che alcuno non viva oggi, che in questa lingua scriva in prosa con alcuna lode, che da altro volgare scrittore che da lui abbia imparato a scrivere. E se di me mi fosse lecito alcuna cosa dire, io direi che io ho pure alcuna volta fatto prova di scrivere alcuna cosa: ho scritto di molte e di varie lettere; ho scritto in suggetto di duello; ho scritto alcuna cosa morale; et a materie di più dignità sono ancora trapassato. Né ho io alcuna cosa scritto con alcuna diligenza, che io scritta non l'abbia in quella lingua che dalle novelle del Boccaccio ho imparata. Né infino ad ora mi pento di averla imparata tale. Non mi siano queste parole di me apposte a vizio, che io per altro a dirle non mi sono condutto, se non per argomento: che io tale dalla imitazione del Boccaccio in tante maniere di dire mi sono avanzato, non si doverà negare che gli uomini di rara dottrina e di chiaro ingegno non siano per trattar con quella ogni altissimo suggetto. $^{27}$

25 "Il Muzio grammatico, secondo un libro recente," Pagine istriane n.6 (1909): 132-133.

26 Nives Zudič Antonič, Storia e Antologia della letteratura italiana di Capodistria, Isola e Pirano, 98.

27 Girolamo Muzio, Battaglie di Hieronimo Mutio giustinopolitano, per diffesa dell'italica lingua, con alcune lettere a gl'infrascritti nobili spiriti (Venezia, 1582), ir.
Il Muzio ammira lo stile di Boccaccio e non apprezza quello del Machiavelli, a differenza di quanto affermano messer Gabriello e messer Cesano che dicono che Machiavelli sia più dotato di grazia e di eleganza. Secondo il Muzio invece il Machiavelli non scrive bene e lui pertanto non ha mai preso spunto dalle sue opere.

E dico che de' libri del Macchiavelli già è gran tempo che me ne vennero alcuni in mano, et avendone nella lezion di poche righe il suo stilo e la sua lingua notata, gli gittai da parte, come quegli da' quali io non pensava di poter raccogliere cosa di tanta utilità di quanto danno potrebbe essere stato quel suo dire alle mie scritture. [...] Io non so trovar nelle parole di lui cosa che comportabile mi paia in scrittore che voglia con lode alcuna cosa scrivere. Se riguardo alla forma del dire, non so come dir si possa più bassamente. Se cerco degli ornamenti, non ne trovo niuno: anzi mi pare egli esser tutto secco, e digiuno di ogni leggiadria. Poi nella lingua egli è tale, che oltra l'usar molte parole latine, là dove non men belle ne averebbe avute delle volgari, e nella variazione e nella proprietà de' verbi egli è tutto cieco; usa male i nomi, e peggio i pronomi; non sa ben collocare né articoli né adverbii: et in somma tanto sa delle osservazioni della lingua, quanto chi non ne sa niente. ${ }^{28}$

-

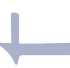

Le Battaglie in difesa dell'italica lingua, è l'opera di Muzio che, escludendo il settore religioso, poetico e cavalleresco, si può oggi ritenere quella di maggiore rilevanza culturale.

L’opera, concepita forse già nel I530, fu pubblicata solo nel 1582 , accompagnata inoltre da lettere indirizzate ai maggiori esponenti che si occuparono della questione della lingua. ${ }^{29}$

Secondo Bonora, in questi scritti Muzio diede prova migliore del suo acume, sostenendo l'italianità del volgare, rifacendosi ad una lingua colta, da apprendere attraverso lo studio severo

28 Muzio, Battaglie di Hieronimo Mutio giustinopolitano, per diffesa dell'italica lingua, con alcune lettere a gl'infrascritti nobili spiriti, $4 \mathrm{r}$.

29 Aldo Cherini e Paolo Grio, Le famiglie di Capodistria: notizie storiche ed araldiche (Trieste: Famea Capodistriana, 1998), 17ı. 
degli antichi scrittori. Riconosce, inoltre, l'importanza degli scrittori moderni d'origine non toscana, in particolare dell'Ariosto e persino degli scrittori dialettali. ${ }^{30}$

\section{Come nasce la lingua letteraria}

Per quanto riguarda la questione della lingua, come abbiamo già affermato, Muzio si rifà alle teorie del Bembo, ed è concorde con il fatto che ogni lingua ha una sua parabola di sviluppo, salendo via via alla sua perfezione. Pertanto anche la lingua italiana è destinata ad una tale ascesa verso la sua perfezione espressiva e gli scrittori devono promuovere tale svolgimento rifacendosi alla più alta tradizione del passato. Perciò devono prendere a modello il Petrarca e il Boccaccio, che hanno dimostrato con le loro opere il grande valore del volgare italiano e cercare di perfezionare la loro lingua.

Nelle lettere e soprattutto nella raccolta che prende il nome di Battaglie in difesa dell'italica lingua Muzio sostiene la teoria fondamentale di Bembo, e precisamente che la lingua letteraria non nasce o si governa secondo l'uso dei parlanti, ma si sviluppa e deriva da una tradizione letteraria, cioè mediante l'opera degli scrittori. Inoltre spiega che non è importante essere nati a Firenze $\mathrm{o}$ in Toscana per poter scrivere bene, ma che per scrivere bene bisogna imparare dai libri. Secondo Muzio per apprendere bene una lingua bisogna studiarla attentamente attraverso la lettura di grandi opere e fare sempre attenzione alla propria scrittura. Pertanto, secondo lui, anche coloro che non sono nati a Firenze o in Toscana, impegnandosi, possono scrivere bene. ${ }^{32}$

Enel vero le lingue, le vere lingue, non si imparano dalla mamma, e non dal babbo, ma dalle scritture: e là dove voi altri volete (voi dicendo intendo di dire a coloro che così sentono) che dal parlare a scrivere si impa-

30 Ettore Bonora, "Il classicismo dal Bembo al Guarini," in Storia della Letteratura Italiana, vol. IV, Il Cinquecento (Milano: Garzanti, 1966), 184 .

$31 \quad$ Nives Zudič Antonič. "Girolamo Muzio e la questione della lingua italiana," 83

32 Nives Zudič Antonič. "Girolamo Muzio e la questione della lingua italiana," 83. ri, ho io da Cicerone imparato che dal leggere e dallo scrivere si impara a parlare. Ma per meglio intendere qual via si debbia tenere per conseguir dirittamente questa più nuova lingua, avviso che sia ben fatto che dalle altre più antiche se ne debbia prendere l'essempio. Epertanto, se volete conoscere quanto poco giovi l'esser nato toscano per volere toscanamente scrivere, ricordivi che Virgilio fu mantovano, Catullo veronese, Orazio venusino, Terenzio africano, e che Marco Tullio non fu romano. Da cui vogliam noi dire che quegli stranieri apprendessero la romana lin gua? Da' libri $[\ldots]^{33}$

Muzio prosegue dando una descrizione di se stesso e del suo scrivere in italiano, dicendo che gli studiosi fiorentini lo ritenevano incapace di scrivere bene perché non era nato a Firenze. ${ }^{34}$

E prima dico che io sono per origine della città di Iustinopoli, volgarmente detta Capodistria, e dagli antichi appellata Egida, lontana dal Carnaro, Ch'Italia chiude, e suoi termini bagna, intorno ad ottanta miglia. Nacqui in Padova e fra in Padova, in Vinegia, in Capodistria, in Dalmazia et in Alamagna vissi in fino alla età di trenta anni. Appresso conversai in Lombardia, in Piemonte, in Francia, et in Fiandra; e ne aveva forse quaranta prima che Fiorenza mi vedesse, et a mettere insieme tutto il tempo che in più volte stato vi sono, non so se egli passasse un anno. Sì che né io vi son nato, né da fanciullo allevato: e che in me non sia indicio alcuno di fiorentina ria, assai si mostra a chi mi sente favellare. Laonde per la coloro ragione si viene a conchiudere che io bene non posso scrivere. ${ }^{35}$

Lo scrittore prosegue poi dicendo che anche gli scrittori istriani, come quelli fiorentini, hanno appreso la lingua italiana dalle loro madri e si fanno capire da tutti coloro che parlano italiano,

33 Muzio, Battaglie di Hieronimo Mutio giustinopolitano, per diffesa dell' 'italica lingua, con alcune lettere a gl' infrascritti nobili spiriti, $4 \mathrm{r}$.

34 Nives Zudič Antonič. "Girolamo Muzio e la questione della lingua italiana," 87

35 Muzio, Battaglie di Hieronimo Mutio giustinopolitano, per diffesa dell'italica lingua, con alcune lettere a gl' infrascritti nobili spiriti, $34 \mathrm{r}$. 
pur non usando la pronuncia fiorentina; inoltre Muzio afferma che gli scrittori istriani e lui pure, hanno migliorato la loro conoscenza della lingua italiana attraverso i libri e lo fanno meglio dei fiorentini che pensano di sapere perfettamente la lingua e di non avere bisogno di migliorarla. ${ }^{36}$

Abbiamo anche noi succhiata la lingua italiana dalle poppe delle balie e delle madri, e dal popolo e da' cittadini delle nostre città la abbiamo appresa: e con questa nostra lingua, et io e degli altri andiamo per tutta Italia parlandola. Et io, uno fra gli altri, dal Varo all'Arsa la ho corsa tutta, e per tutto sono stato inteso: e si mi sentito parlare, e se da loro è stata intesa la mia favella, quantunque ella non mi gorgogliasse nella strozza alla fiorentina. Da' libri ci vantiamo noi di apprendere a 'dirittamente scrivere'. [...] Da' libri impariamo noi a bene scrivere, e più agevolmente impariamo noi che i Fiorentini, né gli altri Toscani, perciò che come noi ci mettiamo a voler dar opera allo studio dello scrivere, così ci persuadiamo di non saperne nulla; e perciò negli animi nostri, come in tavole monde, si figurano le bellezze e le purità della lingua, in chi vuol faticare, e sa studiare; e questi sono molto pochi. ${ }^{37}$

Muzio si occupò nell'arco dell'intera vita della questione della lingua, e soprattutto si adoperò in difesa di chi, non essendo nato a Firenze, poteva dimostrare come lui di essere un buon conoscitore della lingua italiana, grazie alla lettura e al costante impegno. Albino Zenatti, invitato dal municipio di Capodistria a pubblicare alcune lettere inedite di Girolamo Muzio nel quarto Congresso della lega nazionale, in occasione del quarto centenario della sua nascita disse di lui le seguenti parole: "Fra i molti letterati che illustrarono Capodistria, nessuno, in vero, si occupò de-

36 Nives Zudič Antonič. "Girolamo Muzio e la questione della lingua italiana," 87.

37 Muzio, Battaglie di Hieronimo Mutio giustinopolitano, per diffesa dell' italica lingua, con alcune lettere a gl' infrascritti nobili spiriti, 39r.

gli studi intorno alla nostra lingua più o meglio del Muzio". ${ }^{8}$

\section{Le opere di Girolamo Muzio \\ Il Duello}

Il trattato Duello di Girolamo Muzio fu stampato per la prima volta a Venezia nel I550, assieme alle Risposte cavalleresche e immediatamente ebbe un enorme successo editoriale non solo in Italia, ma in tutta Europa. Con quest'opera, divenne l'autore di scienza cavalleresca più noto del secolo.

Il suo testo fu considerato un'opera innovativa, perché scritta in volgare, da un letterato o meglio da un cortigiano e non da un uomo di legge o d'armi, suscitando tra il pubblico disinteresse per i precedenti trattati. ${ }^{39}$

Il Muzio fu "duellista" e "duellante", secondo il senso delle voci stabilito all'epoca da un altro trattatista de Il Duello, Giovambattista Pigna:

"Duellista sarà colui che scriverà di duello: il quale fondandosi su questo suggetto e da esso essendo nominato, farà il duello essere scienza. Duellante [...] chiunque entri in duello: e da questa voce, come da quella che è suo mestiero, il nome piglierà" ${ }^{40}$

"Duellante", divenne, seppur "in punta di penna" nel momento in cui si apprestò ad assumere - per conto d'Alfonso d'Avalos Marchese del Vasto, luogotenente imperiale a Milano, l'ufficio di "duellista". ${ }^{41}$

Ben presto in molti si affidarono alle sue consulenze per risolvere le diverse querele in "suggetto di honore". L'autore stesso le menzionò nella sua opera le Vergeriane. Inoltre le diverse consulenze furono pubblicate nell'opera le Risposte cavalleresche.

38 Albino Zenatti, Lettere inedite di Girolamo Muzio Giustinopolitano: pubblicate nel IV centenario della sua nascita (Capodistria: Comune, I846), 5 .

39 Francesco Erspamer, La biblioteca di Don Ferrante. Duello e onore nella cultura del Cinquecento (Roma: Bulzoni, 1982), 82.

Giovambattista Pigna, Il duello (Venezia: Valgrisi, I554), I45.

$4^{1} \quad$ Luciana Borsetto. "L'Ufficio di scrivere in suggetto di honore'. Girolamo Muzio 'duellante' duellista'," Acta Histriae IX (2000): $14 \mathrm{I}$. 
IlDuello era diventato "la soluzione finale di tutte le controversie insorte 'per cagion di honore”. Le sue furono semplici opinioni e pareri su argomenti che gli venivano sottoposti. ${ }^{22}$ Per scrivere la sua opera, quindi, non dovette far altro che mettere per iscritto il suo sapere specialistico che aveva acquisito, in quanto uomo di corte, e che aveva approfondito con le proprie ricerche personali. È Muzio stesso a dichiararlo nella dedicatoria a Emanuele Filiberto:

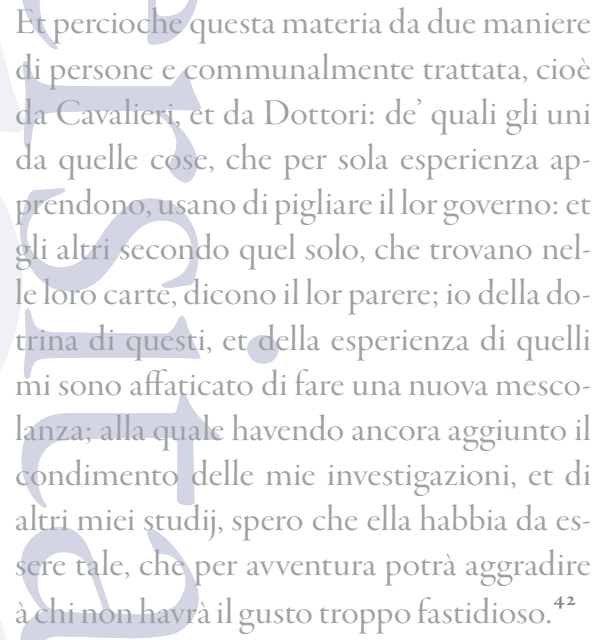

L'autore duellò con la penna contro coloro che non rispettavano le regole cavalleresche, che non rispettavano la fede cristiana, in nome della lingua italiana e in nome del papato. ${ }^{43}$

Con quest'opera voleva porgere ai cavalieri uno strumento efficace affinché potessero con onore districare le questioni cavalleresche. Il trattato presentava il duello come un cerimoniale di norme, di consuetudini allo scopo di disciplinarne l'uso. Il suo intento era nobile; considerando che sarebbe stato impossibile abolirlo, voleva almeno diminuirne l'uso e soprattutto impedirne l'abuso. $^{44}$

Secondo l'autore, il duello, non doveva venir praticato per sopraffazione o vendetta, ma come

42 Girolamo Muzio, Il duello del Mutio Iustinopolitano, con le risposte cavalleresche (Venetia: Compagnia degli Uniti, I585), 3.

43 Borsetto, "L'Ufficio di scrivere 'in suggetto di honore'. Girolamo Muzio 'duellante' duellista'," I4I.

44 Giaxich, Vita di Girolamo Muzio, 47. Erspamer, La biblioteca di Don Ferrante. Duello e onore nella cultura del Cinquecento, I 12. "prova della verità" nonché come legittima difesa nei "confronti dell' ingiuria subita". 45

L'obiettivo dell'autore era duplice: “descrivere l'arbitrio che governava a suo tempo la Pratica perversa del combattimento privato dei nuovi cavalieri, dibattuti tra ingiuria e 'mentita', tra infamia e onore, tra offesa e vendetta, volti principalmente al conseguimento della comune approvazione, e sottoporlo al vero costume della cavalleria”. Nella dedicatoria a Emanuele Filiberto leggiamo:

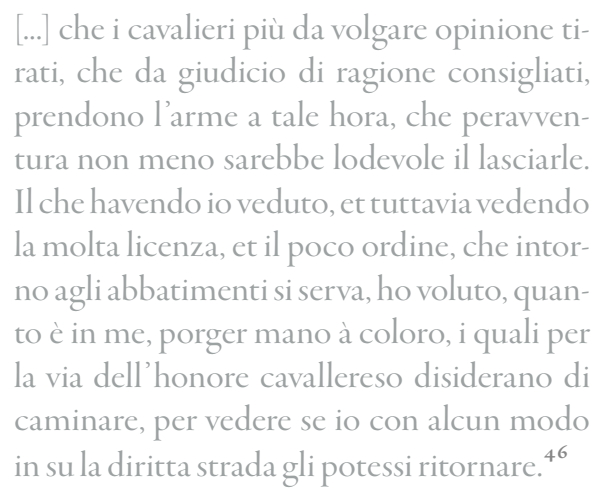

S'impegnò anche a proporre denominazioni specifiche, importando alcuni termini come "attore", "reo", dicendo con orgoglio di essere stato il primo, a parlare di "mentite". Gli scrittori usavano in generale un lessico specifico, affatto originale, destinato ad un pubblico eterogeneo, quindi doveva venir compreso pure da persone poco colte. $^{47}$

Muzio trattò d'ingiurie, delle mentite, dell'attore, del reo, dei cartelli, del campo, esplicando i loro significati per una corretta utilizzazione. Dichiarò che per vendetta i signori non dovevano concedere il campo, spiegò come si arrivava al duello "per delitto" e teorizzò su come doveva essere il "risentimento onorevole" e a "quali gradi della nobiltà" era consentito combattere. Stabilì chi era il "reo" e chi l'“attore", come si configurava l'“ingiuria” e come il "ca-

\footnotetext{
45 Borsetto, "L'Ufficio di scrivere 'in suggetto di honore'. Girolamo Muzio 'duellante' 'duellista," I 4 I.

Muzio, Il duello del Mutio Iustinopolitano, con le risposte cavalleresche, 3 .

47 Erspamer, La biblioteca di Don Ferrante. Duello e onore nella cultura del Cinquecento, 130-136; Borsetto, "L'Ufficio di scrivere 'in suggetto di honore'. Girolamo Muzio 'duellante' 'duellista'," 147.
} 
rico", sotto che titoli si dovevano congegnare le "mentite", sotto che forma dovevano venir concesse le "patenti di campo" e quali armi usare negli "steccati". Muzio, così, riformò il moderno duello. "Notando, et elevando" gli abusi che lo rendevano crimine, sottoponendolo a nuove leggi. $^{48}$

In realtà, quanto si può dedurre dalle missive che Muzio scrisse ad amici e nemici, pare che iniziò a scrivere l'opera, soprattutto perché sollecitato dai propri signori e padroni, ovvero gli fu imposto. Ciò è quanto traspare nella dedicatoria:

$$
\begin{aligned}
& {[\ldots .] \text { à prender questa honorevole fatica non }} \\
& \text { picciolo sprone mi è stato (illus. Prencipe) } \\
& \text { l'havere io veduto quanto il gentilissimo } \\
& \text { amico vostro fosse desideroso, che io alcu- } \\
& \text { na cosa scrivessi in questo suggetto (che nel } \\
& \text { tempo, nel quale io mandato dal mio Signor } \\
& \text { Marchese a Nizza di Provenza àil servire il S. } \\
& \text { Duca vostro padre, et voi, non una sola volta } \\
& \text { da voi imposto mi fu, che dovendovi io man- } \\
& \text { dare delle mie scritture, ve ne mandassi in } \\
& \text { materia di Duello). Per tal cagione già vi ap- } \\
& \text { prestai io, et hora ho pubblicati questi miei } \\
& \text { libri, giudicando che le cose scritte in sug- } \\
& \text { getto di onore ad honorato Prencipe otti- } \\
& \text { mamente si convengono. }{ }^{49}
\end{aligned}
$$

Per rispondere alle polemiche che il suo libro aveva provocato, progettò inoltre di realizzare un libro particolare di Questioni di Duello, proponendosi di rispondere a coloro che si "erano dilettati di trafiggerlo", ma la censura del 1563 ne bloccò la realizzazione. Il suo nuovo testo seguì le sorti che erano state riservate anche ad altri trattati inerenti allo stesso tema, tuttavia il trattato Il Duello, fino al 1585 , continuò ad essere pubblicato. ${ }^{\text {so }}$

I censori però impedirono all'autore di portare a termine l'opera con cui avrebbe risposto a

\footnotetext{
48 Borsetto, "L'Ufficio di scrivere 'in suggetto di honore'. Girolamo Muzio 'duellante' duellista', I48.

49 Borsetto, "L'Ufficio di scrivere 'in suggetto di honore'. Girolamo Muzio 'duellante' "duellista', I 4 8-I 49.

50 Erspamer, La biblioteca di Don Ferrante. Duello e onore nella cultura del Cinquecento, 63.
}

tutti coloro che lo avevano attaccato, accusandolo "di aver discettato su tutto, di essersi occupato di vili soggetti e indegni di esser messi in scrittura, di aver condotto gli uomini a morte, di aver voluto trattare, da 'huomo secolare, et di corte', materie pertinenti alla cattolica disciplina; di aver desunto il suo sapere dalla scienza degli altri, usurpando una fama immeritata".

"Allineate su un unico piano, l'icona del Muzio 'duellante' che ci rinviano le sue opere nell'ultimo scorcio del secolo, si sovrappone del tutto a quella del Muzio 'duellista', emblemi entrambe dell'unica, ininterrotta fatica da lui compiuta nel suo ossequio ai poteri secolari e cattolici del tempo: l'“ufficio di scrivere in suggetto di honore"'.52

La sua fama di "duellante" terminò con la sua morte nel 1576 , quella di scrittore invece no. Infatti, Manzoni lo cita nella sua opera I Promessi Sposi, inserendolo nella biblioteca del personaggio di don Ferrante. ${ }^{53}$

\section{Le lettere}

In generale la lettera del Cinquecento (in particolare quella del Muzio) non fu vincolata da nessuna necessità di tempo o di luogo, ma al tempo indeterminato della comunicazione letteraria. Muzio fece ampio uso di questo strumento di comunicazione. Il suo "luogo" fu quello soggettivo della lettura e della rilettura, tanto che lui stesso incitava i lettori a leggere e a rileggere una stessa lettera, in modo da farla diventare lunga a piacere, quanto vorremmo noi. ${ }^{54}$

Nella dedicatoria a Vincenzo Fedeli delle Lettere (denominate dall'autore secolari, per distinguerle dalle cattoliche) in tre libri (il quarto venne pubblicato nel 1590 , dopo la morte dell'au-

\footnotetext{
5I Borsetto, "L’Ufficio di scrivere 'in suggetto di honore'. Girolamo Muzio 'duellante' 'duellista', I5 1 .

52 Borsetto, "L'Ufficio di scrivere 'in suggetto di honore'. Girolamo Muzio 'duellante' 'duellista," I55

53 Alessandro Manzoni, I Promessi Sposi (Milano: Principato, 1976), Capitolo XXVII, 496

54 Luciana Borsetto, "Introduzione," in Muzio Girolamo: Lettere. Rist.anastat. (Bologna: Forni, 1985), XIII.

$\checkmark$

$\sqrt{n}$

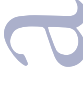

$\sqrt{ }$


tore), è palese la nozione fondamentale da cui traeva origine l'intera raccolta. ${ }^{55}$

\section{Certissima cosa è, che lo scrivere delle lette- ré non per altro è stato intodutto, se non per mantenener viva la humana conversatione, la quale dalla lontananza essendo interrotta, senza quelle se ne verrebbe del tutto à mori- re. [...] le lettere sono esse le mantenitrici del- la conversazione $[\ldots]^{56}$}

Le lettere del Muzio dimostrano il suo sapere su questioni largamente dibattute nelle corti di quel periodo: l'amore, l'astrologia e in particolare la lingua. Quelle di Muzio possono essere anche argomentazioni morali e didattiche, o semplicemente digressioni su luoghi o su personaggi. Tutto ciò ci riporta alla figura dell'erudito e dell'intellettuale del Cinquecento, in grado di discutere e di approfondire i più disparati discorsi. Le lettere servirono però a Muzio come veicolo privilegiato dei suoi vari duelli su carta di cortigiano-scrittore, per condannare o per assolvere, per ricusare o per smentire, per difendere gli altri o se stesso. ${ }^{57}$

Le Vergeriane e le Catholiche possono essere qualificate come vere e proprie dispute a distanza, composte allo scopo di smascherare coloro che si dimostrarono contrari a tutto ciò che esse contenevano. ${ }^{58}$

Volendo fare una ripartizione delle lettere di Muzio va detto che all'inizio i temi trattati furono l'amore e l'amicizia mentre in seguito discusse temi più specifici come la lingua, l'onore, la cavalleria e le armi in particolare. Durante il Concilio di Trento, invece, diventarono lettere istruttorie e didattiche sulla formazione del buon principe cattolico. In questo modo, però, si persero le funzioni vere e proprie di questo modello letterario, seguendo la linea dell'argomentazione tipica del trattato. Sono in forma più

\footnotetext{
55 Borsetto, "Introduzione," IX.

56 Muzio, Il duello del Mutio Iustinopolitano, con le risposte cavalleresche, 1585 .

57 Borsetto, "Introduzione," XIX; Borsetto, "L'Ufficio di scrivere 'in suggetto di honore'. Girolamo Muzio 'duellante" duellista,", 152.

Borsetto, "Introduzione," LV
}

58 lunga, così l'autore si vede costretto a normalizzare l'eccessiva lunghezza. ${ }^{59}$

La forma epistolare, quasi universalmente utilizzata dal Muzio, diventò come già detto la "forma stessa del suo scrivere", utilizzata anche nelle Risposte cavalleresche, pubblicate separatamente o a seguito del Duello, e in alcuni scritti, pubblicati sotto il titolo di Operette morali e di Avvertimenti morali. Per ultimo, ma non per importanza, da ricordare ancora un'altra raccolta dal titolo: Battaglie in difesa dell' italica lingua. ${ }^{60}$ Lettere inedite

Il municipio di Capodistria invitò Albino Zenatti a pubblicare alcune lettere inedite di Girolamo Muzio nel quarto Congresso della lega nazionale, in occasione del quarto centenario della nascita di quel "valoroso letterato", che nacque a Padova. Il volume è un' interessante fonte per approfondire la vita e la personalità di Girolamo Muzio.

Come dice Zenatti: "Fra i molti letterati che illustrarono Capodistria, nessuno, in vero, si occupò degli studi intorno alla nostra lingua più o meglio del Muzio". ${ }^{61}$ Dalle regioni del Veneto, nei primi anni del Cinquecento partirono le teorie che fecero definitivamente trionfare il volgare sul latino, e la lingua di Dante e Petrarca divenne veramente lingua letteraria della nazione intera. Sicuramente il merito principale del movimento cinquecentesco a favore del volgare, spetta al veneziano Pietro Bembo.

Nell' isola dalmata d'Arbe, il Muzio discuteva con Antonio Mezzabarba, discreto poeta veneziano e buon raccoglitore di rime antiche, delle regole della lingua italiana. Era stata da poco pubblicata l'operetta grammaticale di Francesco Fortunio e da Trieste dove si trovava al servizio del vescovo Pietro Bonomo, Muzio ne scriveva con grande interesse ad Aurelio Vergerio:

\footnotetext{
È stato mandato al vescovo mio un libro di grammatica volgare, di un messer Francesco

Borsetto, "Introduzione," LV.

60 Per quanto riguarda la lingua Muzio favori la tesi di Dante e Trissino. Borsetto, "Introduzione," LV.

6I Zenatti, Lettere inedite di Girolamo Muzio Giustinopolitano: pubblicate nel IV centenario della sua nascita, 5.
} 
dalmatino; la quale a me è stata cara di vedere, perché egli insegna di molte cose, e della ortografia, e della proprietà della lingua, della variazion de' nomi e de' verbi.[.... E dobbiam sperar di vedere che la lingua in questo non si fermerà, che' ne avremo anche degli altri scrittori. ${ }^{62}$

Albino Zenatti definisce il libro come un semplice saggio di molte lettere inedite.

Complessivamente ne contiene 24, scritte dopo i sessant'anni, quando in seguito a una gravissima malattia, avvenne quella profonda conversione dell'animo del Muzio, trasformandolo in un dotto e serissimo moralista e teologo. Leggendo la sua biografia è chiaro che fu amico di vescovi, di patriarchi, familiare di cardinali e di papi, di due santi, per la precisione di Carlo Borromeo e Pio $\mathrm{V}^{6}$.

Tra i testi più interessanti del volume si possono considerare quelli che compose a Roma, tutto impegnato a rivedere e a rassettare i grandi scrittori al servizio della censura ecclesiastica. Il suo intento fu quello di salvare il più possibile e il meglio di scrittori e poeti. Questo incarico era assegnato il più delle volte ai frati, con i quali Muzio non aveva un buon rapporto.

Nella sua opera le Battaglie, riconobbe ogni grazia dello stile al Boccaccio, sulla quale non volle metterci sopra le mani. Lo fece invece nei Discorsi e nell'Arte della guerra di Machiavelli. Pur apprezzandolo meno come scrittore, $\mathrm{Mu}$ zio si dimostrò comunque diligente e prudente nel "sistemare" il suo lavoro visto che si rendeva conto della "sconvenienza" e della "sconcezza" di questi procedimenti. ${ }^{64}$ Scriveva al Duca d'Urbino:

Ho pensato che essi danno questa impresa ad alcuno, la potranno dare a qualche parte che ne farà quello che ha fatto un altro delle novelle del Boccaccio, il quale da un fra-

62 Muzio, Lettere inedite di Girolamo Muzio Giustinopolitano: pubblicate nel IV centenario della sua nascita, I I.

63 Zenatti, Lettere inedite di Girolamo Muzio Giustinopolitano: pubblicate nel IV centenario della sua nascita, 8-9.

64 Benedetto Croce, "Scritti di storia e politica," in Poeti e scrittori del pieno Rinascimento. Vol. I (Bari: Laterza, 1945), 205. te è stato non, come dicono, censurato ma tonsurato, in maniera che lo hanno fatto rimaner toso: ché ne ha levate ventisei novelle intere e molti squarci soppresso qua e là. E poi lo hanno dato a me, che debba rassettarlo e legarlo assieme là dove essi lo hanno guasto e disciolto! Dalla qual cosa io non sono per prenderne fatica alcuna, se non mi rimettono la impresa a me di correggerlo in tal modo, che lo netterà di tutte le cose che sono dette con poca reverenza di Dio; e per sodisfare ancora loro, leverò via tutte quelle cose che in generale sono dette contro i frati; che se si volesse levar tutto quello che è detto contro ogni particolare, ci resterebbe poco da leggere di quel libro! ${ }^{65}$

-

Nelle lettere indirizzate al duca è curiosa la profonda confidenza con la quale scrive al suo $\mathrm{Si}$ gnore. In ogni modo la lista dei principi che giovarono e si affezionarono al Muzio, a cominciare dal Marchese del Vasto, per finire con Francesco de' Medici, fu molto lunga. Ai lettori capodistriani saranno sicuramente più interessanti e care le lettere che scrisse al nipote Maurizio, nelle quali Muzio difese il suo poema, L'Egida, scritto in gloria di Capodistria. L'autore era dispiaciuto al notare che la sua opera era poco apprezzata dai suoi concittadini. L'Egida, secondo Albino Zenatti, si staccava dai soliti poemi dell'epoca ed era la dimostrazione del profondo affetto che Muzio nutriva per la sua terra. ${ }^{66}$

\section{La lirica, la poetica, il poema epico e gli scritti} sul comportamento

Al centro della lirica di Muzio si colloca il suo amore per la bella e raffinata cortigiana Tullia d'Aragona a cui dedica sonetti, canzoni e parecchie egloghe.

Le Egloghe ${ }^{67}$ sono divise in cinque libri: Le Amorose, Le Marchesane, Le Illustri, Le Lugubri,

65 Muzio, Lettere inedite di Girolamo Muzio Giustinopolitano: pubblicate nel IV centenario della sua nascita, 30-3I.

66 Zenatti, Lettere inedite di Girolamo Muzio Giustinopolitano:pubblicate nel IV centenario della sua nascita .

67 Componimento poetico solitamente di argomento pastorale o di forma amebea. 
le Varie. Nelle Amorose celebra Tullia d'Aragona con "espressioni teneramente avanzate" prima col nome di Tirennia, esaltata anche nelle sue Rime, più di quel che aveva fatto Bernardo Tasso, poi, invece, sotto il nome di Talia. ${ }^{68}$

Lo afferma pure lui stesso in una lettera a un amico:

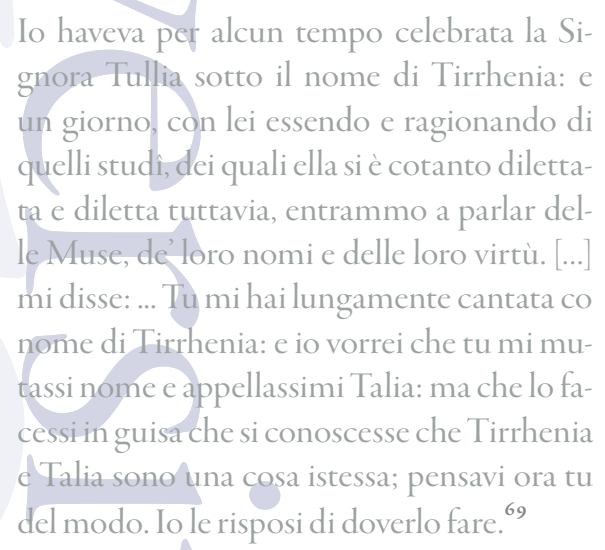

Le egloghe del secondo libro parlano del marchese Alfonso d'Avalos, dei mali della guerra, degli amori del marchese e di sua moglie. Il terzo libro tributa onori ai suoi protettori. Il quarto contiene egloghe funebri che sono le più commoventi: piange la morte di Luigi Gonzaga, deplora la scomparsa di vari suoi protettori e amici, si lamenta per la morte di Argia, sorella di Tullia d'Aragona e, infine, della sua amante Chiara, sotto il nome di Clori, celebrata già in vita.

Nelle Rime diverse, che paragona alle Odi di Orazio, celebra, con canzoni e sonetti, le sue "due donne molto amate", "l'una d'umili condizioni”, Chiara, l'altra, invece, la celebre Tullia d'Aragona.

Nell'Arte poetica, opera divisa in tre libri e molto lodata dal Varchi, l'autore volle imitare l'Arte poetica di Orazio. Nel primo libro attacca coloro che sostengono che per scrivere poesie basti "il naturale" e che non è un'arte che si possa imparare; nel secondo spiega come dare grandezza alle cose "minute", mettendo al primo posto

\footnotetext{
68 Stancovich, "Biografia degli uomini distinti dell' Istria," 7 I.

69 Muzio, Lettere inedite di Girolamo Muzio Giustinopolitano: pubblica te nel IV centenario della sua nascita, I I.
}

Virgilio davanti a Omero e Ovidio; infine, nel terzo parla della lingua italiana, dei diversi tipi di poesia, dello stile e delle metafore. ${ }^{\circ}$

L'Egida (1572), invece, è un poema eroico in dieci libri in versi sciolti, nel quale narra, usando pure elementi mitologici, la favolosa origine di Capodistria; con quest'opera celebra quella che considerava la sua città.

Muzio si occupò anche di norme sociali. La lingua italiana da lungo tempo ha una parola specifica per definire il complesso delle regole per il corretto comportamento sociale, quella di "galateo" che richiama il titolo dell'opera più famosa di Giovanni della Casa, il Galateo, overo de' costumi. In quest'opera con chiari esempi si era proposto il modello di ciò "che si convenga di fare per poter, in comunicando et in usando con le genti, esser costumato e piacevole e di bella maniera".

Le opere che Muzio scrisse su questo tema sono: Il Gentiluomo che consiste in tre dialoghi e parla della nobiltà: come si acquista, conserva e perde; inoltre da dove deriva. Distingue la nobiltà degli uomini, delle donne, delle persone "private" e "de' signori", nonché quella delle armi e delle lettere e si pone il problema quale sia la "maggiore". Scrisse, inoltre, l'operetta il Cavaliero, le Operette morali e gli Avvertimenti morali. ${ }^{73}$

\section{Conclusione}

Dopo una lunga e intensa vita, passata al servizio di numerosi uomini importanti, dopo aver stilato una miriade d'opere, seppur continuamente in viaggio, a causa di diversi incarichi che gli erano stati assegnati, si ritrovò alla fine malato, senza mezzi, abbandonato da tutti, ospite di un amico. La sua amarezza traspare chiaramente in una lettera, scritta poco prima di morire:

\footnotetext{
$70 \quad$ Stancovich, "Biografia degli uomini distinti dell’ Istria," 73-75.

71 Il poemetto narra la contesa tra Poseidone e Pallade Atene e la trasformazione dello scudo (o dell' "egida”) della dea, caduta in mare, nell' isoletta su cui sarebbe sorta Capodistria.

72 Inge Botteri, Galateo e Galatei (Roma: Bulzoni, I999), I I.

73 Stancovich, "Biografia degli uomini distinti dell'Istria," 8I.
} 
Io sto alcuna volta pensando alla mia passata vita, et alle Corti de' Prencipi dove io sono vivuto, et che ' I Marchese del Vasto mi mandò al Duca Hercole di Ferrara, et che'i Duca d'Urbino mi tolse a Don Ferrando, et che Papa Pio quarto, et poi il quinto mi tolsero al Duca d'Urbino; le quali cose mi persuadono che io sia stato qualche cosa: ma, vedendo poi che mi hanno lasciati povero, entro in altra opinione. Considerando poi che infino ad hor quindici volumi di mie opere con approbation si leggono, et che di cose cavalleresche, di morali, et di catholiche non so se altri habbia scritto più cose (per non dir meglio) di me, ritorno in fantasia di meritar pur qualche cosa. Et, se ben non fossi hora più atto alle fatiche; come soldato veterano dovrei almen essere mantenuto, come si fa alcuna volta de' cani et de' cavalli, che si pascono et si da' loro sepoltura. ${ }^{74}$

La sorte degli uomini di cultura nel Cinquecento era ingrata. Costretti a cercare i favori dei nobili facoltosi, erano sempre in balia degli umori dei loro mecenati.

Girolamo Muzio lasciò un'impronta nella storia letteraria del suo secolo e anche nella lingua italiana. Ciò gli valse onori e celebrità, ma non lo risparmiò dalle vicissitudini della vita. La sua opera più importante, Il Duello, contribuì non poco alla diffusione della lingua letteraria volgare. Assieme a Machiavelli che scrisse $I l$ principe contribuì in maniera fondamentale alla diffusione di un genere letterario di carattere politico-scientifico.

\section{Povzetek}

V široki panorami istrskih avtorjev je nemogoče obiti Girolama Muzia, Koprčana po duši in po družinskem izvoru. Gre za po krivici podcenjenega avtorja, ki je bil pozabljen zaradi svoje politične naklonjenosti Cerkvi in svojega boja za protireformacijo. »Kladivo za krivoverce $\ll$, kot je bil imenovan, se na prvi pogled predstavi kot manj privlačna figura od Vergerija in ostalih, ki pa so se približali protestantski reformi. Muzio je bil oseb-

74 Zenatti, Lettere inedite di Girolamo Muzio Giustinopolitano: pubblicate nel IV centenario della sua nascita, 74 . nost, ki bi jo lahko danes definirali kot »človek režima«, ker je bil lojalen do oblasti, ki so takrat vladale; resnici na ljubo pa bi ga lahko imeli tudi za laskača. Sredi i6. stoletja se uveljavi v vlogi dvornega privrženca in učenjaka, prav v času, ko je dvor vedno bolj postajal sedež politične moči. Tako je žal zastrt lik izobraženca kot učitelja civilizirane družbe. Muzio je izvrševal različne naloge kot tajnik v službi enega ali drugega gospodarja, čeprav je bil vedno podložen najvišji avtoriteti. Ker je obiskoval različne dvore in srečeval različne ljudi, je kmalu postal velik poznavalec viteških spretnosti, tako da so se aristokrati iz različnih krajev Evrope obračali nanj za nasvete. Njegova literarna produkcija je bila zelo obširna. Pisal je o najrazličnejših vsebinah, o veri, o vprašanju jezika - kar je bilo poglavitnega pomena v tistem času - in o pravilih bontona. Ob tem se je posvečal tudi pisanju poezije, pisem in se preizkusil tudi v epiki, ki pa jo je kasneje opustil. Delo, po katerem je zaslovel po celi Evropi, je nosilo naslov: IlDuello (Dvoboj).

Ključne besede: Girolamo Muzio, protireformacija, koprski učenjaki, »kladivo za krivoverce «, Dvoboj.

\section{Summary}

In the vast panorama of the Istrian authors, it is impossible not to discuss Girolamo Muzio, a Capodistrian by family and affection. This is an unjustly underestimated author, who pays for his political support to the curia and his struggle for reform. The "hammer of the heretics", as he was called, is a figure that may at first seem less fascinating than Vergerio and those who took charge of Protestant reform. Muzio was a man who could today be defined as a person "of the regime", loyal to the structures in power at the time; in reality he can be called a flatterer.

Towards the middle of the sixteenth century, he found himself in the typical position of a servant and literate at a time when the court was becoming more the centre of political power, thus causing a crisis for an intellectual who was seen as a master of civilisation; Muzio conducted different functions as a secretary at the service of one or other master, although always subservient to the ultimate authority. Visiting courts and meeting many people, he became particularly skilled in chivalrous matters, so noblemen from all over Europe consulted him to resolve various issues. His literary production was extensive. He dealt with diverse fields, writing on religion, 
on the question of language - which was becoming of primary importance in the period - and on rules of etiquette. In addition, he cultivated the lyric, an epistolary form, and also experimented with an epic, which he later abandoned. The work that made him famous throughout Europe was the treatise entitled: IlDuello (The Duel). Keywords: Girolamo Muzio, Counter-Reformation, Capodistrian writers, the "hammer of the heretics", The Duel.

\section{Bibliografia}

Bonora, Ettore. "Il classicismo dal Bembo al Guarini." In Storia della Letteratura Italiana. Il Cinquecento. Vol. IV. Milano: Garzanti, 1966.

Borsetto, Luciana. “Introduzione”. In Muzio Girolamo: Lettere. (Ristampa anastatica dell'edizione Sermartelli I590). Bologna: Forni, 1985.

Borsetto, Luciana. "L'Ufficio di scrivere 'in suggetto di honore'. Girolamo Muzio 'duellante' 'duellista'." Acta Histriae, IX (2000): I39-158.

Botteri, Inge. Galateo e Galatei. Roma: Bulzoni, 1999.

Cherini, Aldo e Paolo Grio. Le famiglie di Capodistria: notizie storiche ed araldiche. Trieste: Famea Capodistriana, 1998.

Croce, Benedetto. "Scritti di storia e politica." In Poeti e scrittori del pieno Rinascimento. Vol. I. Bari: Laterza, 1945.

Di Brazzano, Stefano. "Girolamo Muzio e Pietro Bonomo.” In Atti e memorie della Società Istriana di Archeologia e Storia Patria. Vol. 99. Trieste, 1999.

Dionisotti, Carlo. "La letteratura nell'età del Concilio di Trento.” In Geografia e storia della letteratura italiana. Torino, 1967.

Erspamer, Francesco. La biblioteca di Don Ferrante. Duello e onore nella cultura del Cinquecento. Roma: Bulzoni, 1982.

Giaxich, Paolo. Vita di Girolamo Muzio. Trieste: J. Papasch\&Tip., I847.

Givanardi, Claudio. La teoria cortigiana. Roma: Bulzoni, 1998.
Maier, Bruno. “Girolamo Muzio.” In Enciclopedia monografica del FriuliVenezia Giulia. Udine: Istituto per l'enciclopedia del Friuli - Venezia Giulia, 1979.

Manzoni, Alessandro. I Promessi Sposi. Milano: Principato, 1976.

Miculian, Antonio. "Contributo alla storia della riforma protestante in Istria.” In Atti del Centro di Ricerche storiche. Vol. X. 215230. Rovigno: Centro di Ricerche Storiche, 1980.

Miculian, Antonio. "La controriforma in Istria: Il concilio di Trento e il ruolo dei gesuiti." In Atti del Centro di Ricerche storiche. Vol. XXIX, 200-226. Rovigno-Trieste: Centro di Ricerche Storiche di Rovigno, 1999.

Miculian, Antonio. "Il Santo Ufficio e la riforma protestante in Istria." In Atti del Centro di ricerche storiche, Vol. XI, 215230. Rovigno-Trieste: Centro di Ricerche Storiche di Rovigno, 1980-8I.

Monti, Silvana. L'età del Rinascimento. Palermo: Palumbo, i979.

Morpurgo, Alessandro. "Girolamo Muzio. Lettura tenuta nel Gabinetto di Minerva." Estratto all'Archeografo Triestino, vol.XIII, fasc.I. Trieste: Archeografo Triestino, I893. Muzio, Girolamo. Lettere. Venezia: Gioito, I55I. Muzio, Girolamo. Battaglie di Hieronimo Mutio giustinopolitano, per diffesa dell'italica lingua, con alcune lettere a gl'infrascritti nobili spiriti. Venezia, 1582.

Muzio, Girolamo. Il duello del Mutio Iustinopolitano, con le risposte cavalleresche. Venezia: Compagnia degli Uniti, 1585.

Muzio, Girolamo. Lettere inedite di Girolamo Muzio Giustinopolitano: pubblicate nel IV centenario della sua nascita. Capodistria: Comune, i846.

Muzio Girolamo. Lettere. Rist.anastat. Bologna: Fomi, 1985.

Pagine istriane n.6. "Il Muzio grammatico, secondo un libro recente." Capodistria, 1909. 
Paschini, Pio. "Episodi della Controriforma in lettere inedite di Girolamo Muzio." In Atti e Memorie della società istiana di archeologia e storia patria, XXXIXfascicolo I, 354-36I, Trieste: Società istriana di archeologia e storia patria, 1927.

Pigna, Giovan Battista. Il duello. Venezia: Valgrisi, 1554 .

Salimbeni, Fulvio. "Fonti e studi sulla storia religiosa dell'Istria nel XVI secolo." In L'umanesimo in Istria, cur. Vittore Branca e Sante Graciotti. 165-179. Firenze: Leo S. Olschki, 1983.

Semi, Francesco. Istria e Dalmazia. Uomini e tempi. Istria e Fiume. Vol. I. Udine: Del Bianco, I99I.

Stancovich, Pietro. "Biografia degli uomini distinti dell'Istria." In Atti del Centro di Ricerche Storiche di Rovigno, Vol.3. Rovigno-Trieste: Centro di Ricerche Storiche di Rovigno, 1972.

Zenatti, Albino. Lettere inedite di Girolamo Muzio Giustinopolitano: pubblicate nel IV centenario della sua nascita. Capodistria: Comune, I846. 


\title{
Diffusione del dramma pastorale in Istria
}

\author{
Nives Zudič Antonič
}

Nell'articolo, partendo dall'origine e dalla diffusione del dramma pastorale in Italia, viene presentata la diffusione di questo componimento poetico in Istria. Nell'articolo vengono pertanto presentati alcuni degli autori istriani che si sono cimentati nella stesura di questo tipo di componimento poetico e viene fatta pure l'analisi di alcune delle loro opere più significative. Tra gli autori che vengono presi in esame troviamo: Girolamo Vida, Ottonello de’ Belli e Giovan Battista Brati.

Parole chiave: dramma pastorale, fiaba pastorale, poesia idilliaca, egloga, idillio.

V članku najprej predstavimo izvor in širjenje pastoralne igre v Italiji, v nadaljevanju pa predstavimo širjenje te zvrsti v Istri. V članku predstavljamo tri najpomembnejše istrske pisce pastoralnih iger in nekaj njihovih najvidnejših del, ki smo jih analizirali. Predstavljeni avtorji so: Girolamo Vida, Ottonello de Belli in Giovan Battista Brati.

Ključne besede: pastoralna igra, idilična poezija, ekloga, idila.

D all'idea di ampliare l'egloga dialogata, assai cara ai poeti del secondo Quattrocento, in egloga drammatica, con personaggi in veste di pastori, nacque, e presto entrò in voga negli ambienti colti del Cinquecento, un nuovo genere letterario: il dramma pastorale. Pur avendo origine dai testi degli autori classici come Teocrito e Virgilio, questa composizione si distanzia dalla norma aristotelica e occupa uno spazio intermedio fra la tragedia e la commedia, spesso intrecciando alla comicità della commedia la serietà della tragedia e dando a vicende tristi conclusione lieta. In Italia il dramma (o favola) pastorale fece la sua prima prova ufficiale con il Sacrificio (1554) di Agostino Beccari a Ferrara, ma al livello della vera poesia si elevò soltanto con l'Aminta di Tasso e con il Pastor Fido di Battista Guarini. E proprio sull'esempio di questi due autori e dei loro componimenti poetici che si ispirano pure gli autori di drammi pastorali in Istria.

\section{La nascita della favola pastorale drammatica}

Nell'ambito del rinnovato classicismo rinascimentale e del gusto raffinato e mondano delle corti, accanto al ritorno alle vecchie forme del teatro classico, l'idillio pastorale trova una sua appropriata collocazione, colorandosi di elementi nuovi, rispetto al passato più autobiografici e patetici e richiamandosi all'egloga dialogata e quindi avviandosi a diventare favola pastorale drammatica o dramma pastorale. L'idillio pastorale in volgare si diffuse largamente nel Rinascimento, specialmente dopo l'Arcadia di Sannazzaro. Esso è l'espressione dell'eterno bisogno umano di fuga dalla realtà storica (che è necessariamente lotta, conflitto, e quindi sofferenza) per evadere, almeno idealmente, in un mondo pacifico, sereno, remoto dagli affanni della città. Il so-

\footnotetext{
L'idillio ha una lunga tradizione dal greco-siculo Teocrito alle Bucoliche di Virgilio.
} 
gno, cioè, di una vita felice dei campi e dei pastori, paradiso terrestre al di là della storia, che gli uomini avrebbero perduto per l'invenzione della cosiddetta civiltá. In tal senso la poesia idillica divenne sempre più sinonimo di poesia agreste e pastorale.

Il dramma pastorale rispetta le unità del teatro classico e la sua caratteristica è quella di rappresentare vicende tristi che però si concludono con un lieto fine, soddisfando le esigenze dell'artista rinascimentale, perché la massima aspirazione del poeta di corte cinquecentesco è il sogno di sublimazione e rispecchiamento del proprio travaglio esistenziale, proiettato in un mondo consapevolmente ormai ritenuto fittizio e artificiale, e insieme espressione idealizzata del dramma della passione. Da ciò l'esigenza del travestimento teatrale dei personaggi della corte, in cui gli stessi cortigiani si rappresentano e si contemplano come su un palcoscenico. ${ }^{3}$

Di uno sviluppo drammatico dell'egloga, che diventa sempre più complessa, assumendo motivi della commedia, della tragedia e della farsa, si possono seguire le tracce sin dai primi decenni del Cinquecento; ma di un vero e proprio dramma pastorale non si può parlare prima del I554, quando fu recitato a Ferrara il Sacrificio di Agostino Beccari, ferrarese (I510 c. - I590), in cui le semplici scene pastorali si sviluppano in regolare assetto drammatico e in cinque atti.

In Italia i più importanti drammi pastorali del Cinquecento sono l'Aminta del Tasso e il Pastor fido, del ferrarese Battista Guarini (1538I6I2). L'Aminta è una favola pastorale rappresentata nel luglio del 1573 nell' isola di Belvedere sul Po, davanti alla corte estense.

Gli studiosi hanno segnalato tutte le fonti di questa favola: Teocrito, Mosco, Virgilio, Ovidio, Petrarca, Poliziano, Sannazzaro, ecc. Si tratta quindi di un'opera molto letteraria per il contenuto, ma quello che è più importante è il tono tutto personale con cui la materia è raccontata e liricamente espressa. Inoltre, è rilevante il fatto

2 Mario Sansone, Disegno storico della letteratura italiana (Milano: Principato, 1963).

3 Alberto Asor Rosa, Storia della letteratura italiana (Firenze: La Nuova Italia, 1985). che i personaggi sono un travestimento pastorale di certe figure della corte estense: Licori è Lucrezia Bendidio, Elpino il vecchio innamorato di Licori, è il Pigna, sotto l'aspetto di Batto si nasconde il Guarini, ecc. ${ }^{4}$

L'Aminta è, per così dire, la corte che contempla se stessa staccandosi momentaneamente dalla realtà e rifugiandosi in un sogno di bellezza e di armonia naturale. $\grave{E}$ ancora un prodotto del Rinascimento maturo, che però rivela i segni dell'imminente decadenza. La sensualità, l'erotismo sono al centro della fragile vicenda. Si veda il coro dell'Atto I che celebra l'eden primitivo: "O bella età dell'oro...", in cui il piacere era il massimo fine della vita, e la regola "se piace, ei lice"; ' ma già un velo di malinconia attenua la gioia di vivere e godere, e il dramma manca di azione e si stempera in effusione lirica. ${ }^{6}$

Il Pastor Fido (I590), dramma pastorale o, meglio, tragicommedia come l'autore stesso preferiva chiamarlo, perché si proponeva di fondere gli elementi della tragedia e della commedia classica. Infatti, egli deriva dalla tragedia la statura eroica di certi personaggi e la drammaticità, spesso solo fittizia, dell'intrecciarsi di eventi sorprendenti, e dalla commedia il programmato smorzarsi e il sorridente e garbato sciogliersi delle passioni nella grazia dell'idillio.'

Il suo scopo, come afferma Guarini, non è ammaestrare moraleggiando, ma solo dilettare $\mathrm{i}$ suoi lettori; e siccome non c'è diletto senza sofferenza, come non c'è corpo senza ombra, mescola il tragico e l'elegiaco col comico, per creare tensioni e attesa cui deve seguire appagamento e rilassatezza. ${ }^{8}$

È evidente l'intenzione del Guarini di superare l'Aminta del Tasso, ma l'Aminta è un'opera di maggior respiro sentimentale e unità espressiva e stilistica rispetto a quella del Guarini, dove, tuttavia, per il gusto della magnificenza orna-

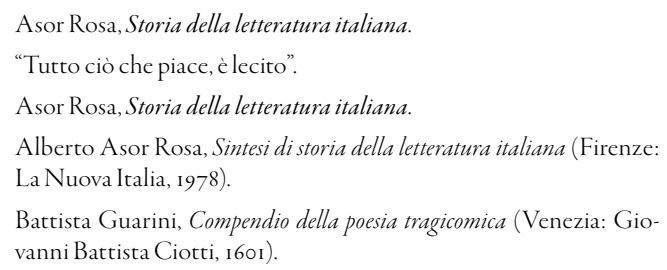


mentale e per il risalto che hanno i momenti lirici su quelli descrittivi, già prelude alla grande poesia e alla musica barocca. Anche l'erotismo e la celebrazione della pura sensualità sono elementi dominanti in questo dramma pastorale che indulge al piacere senza problemi e scrupoli moralistici.?

Va comunque ricordato che sia il Guarini che il Tasso sono uomini del loro tempo: ambedue uomini di corte, e partecipi di quel sogno di fuga dalla rumorosità mondana, nella pace idilliaco-campestre che era un connotato tipico della cultura cortigiana.

\section{L'ispirazione idillica e pastorale dell'Arcadia}

Nell'ottobre del 1690 a Roma, un gruppo di poeti e intellettuali si costituirono in una nuova accademia cui dettero il nome di Arcadia. I maggiori ispiratori e iniziatori di tale movimento, che si richiamava all'antica poesia idillica, bucolica e pastorale, furono Giovan Mario Crescimbeni e Gian Vincenzo Gravina.

I poeti aderenti all'Arcadia predilessero, in opposizione al gusto barocco ancora dominante, un linguaggio d'ispirazione classicistica volutamente semplice e lineare, adatto al genere della poesia bucolica, in cui cortigiani e dame (come nell'Aminta tassiana) travestiti in pastori, pastorelle e ninfe si muovevano su uno sfondo campestre sereno, tipico della tradizione idillica, simboleggiante l'antico sogno di fuga dalla triste realtà della vita. ${ }^{10}$

Acutamente il Gravina definì l'Arcadia: "un sogno in vista della ragione", riassumendo abilmente in una sigla la matrice razionalistica (ma di stampo moderato) di questa poetica.

Immagini campestri molto convenzionali costituiscono il palcoscenico su cui si atteggiano in pose languide e sospirose amanti e amate fra parrucche e trine che, nei momenti poetici più fortunati, sospendono in una nube soffusa di ciprie e profumi i poetici segni di una società

9 Natalino Sapegno, Compendio distoria della letteratura italiana $(\mathrm{Fi}-$ renze: La Nuova Italia, 1951).

Io Asor Rosa, Storia della letteratura italiana. elegante e colta, sensibile alle galanterie e svenevolezze studiate dell'ambiente cortigiano e curiale. $^{\text {II }}$

Il gusto cui abbiamo accennato del travestimento, induce i poeti a darsi degli pseudonimi idillico-pastorali. Le donne amate, coerentemente, si chiamano Filli, Nice, Nerina, nome che incontriamo, p. es., in queste strofe di Paolo Rolli (da L'Inverno, quinto libro delle sue Rime): ${ }^{\mathrm{I2}}$

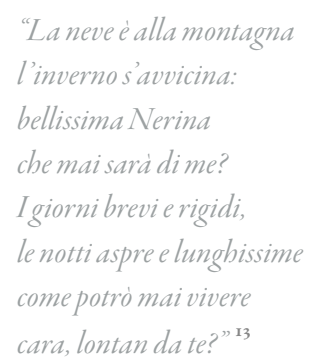

La semplicità proposta dagli Arcadi è certamente raggiunta in questi versi. La successione di settenari intreccia abilmente quella musica insieme saltellante e sospirosa che si ritroverà nel Metastasio, e che è connotato saliente caratteristico dei poeti arcadici, fra i quali Carlo Innocenzo Frugoni, Giovan Battista Zappi, Aurelio Bertola. Dello Zappi c'è da dire che l'eccesso di dolcezza delle sue liriche gli meritò l'attributo datogli dal Baretti di inzuccheratissimo. ${ }^{14}$ Ed è questo, infatti, il limite della poetica e del linguaggio arcadici, anche se in essi è tuttavia riconoscibile spesso uno schietto amore per la Natura e l'aspirazione a uno stile di vita sereno e remoto dalle convenzioni tormentose della civiltà urbana.

\section{Il dramma pastorale in Istria}

In Istria il dramma pastorale è legato per lo più alle Accademie, che furono un segno distintivo dell'età rinascimentale. Esse comparvero dapprima come semplici associazioni erudite, per trasformarsi successivamente in un sodalizio dotato di norme e leggi particolari. La caratteristica

\footnotetext{
I I Asor Rosa, Storia della letteratura italiana..

I2 Quello delle stagioni fu un genere diffuso nel Settecento.

I3 Paolo Rolli, Dépoetici componimenti del Signor Paolo Rolli: divisi in trelibri (Venezia: Bartolommeo Occhi, 176I), 229.

14 Asor Rosa, Storia della letteratura italiana.
} 
che accomunava questi circoli di dotti era lo studio delle discipline scientifiche e letterarie. La loro diffusione fu una conseguenza del risveglio culturale e della rinnovata vita intellettuale e sociale.

A Capodistria, principale centro urbano dell'Istria, che annoverava le più importanti istituzioni culturali, le accademie comparvero nell'ultimo quarto del XV secolo, proprio come nel resto d'Italia. Dal I 478 al 1567 era attiva la Compagnia della Calza (all' inizio prevalsero gli esercizi cavallereschi ma si trasformò poi in sodalizio letterario). Importante anche l'Accademia dei Desiosi, sorta nel 1553 per iniziativa di un gruppo di intellettuali, si sciolse l'anno successivo perché sospettata di eresia da Girolamo $\mathrm{Mu}-$ zio. Nel 1554 essa si tramutò in Accademia Palladiana o dei Palladi (fu chiusa nel 1637) e ebbe tra i suoi aderenti: Santorio Santorio, che ne fu per qualche tempo "principe"; Girolamo Vida, Ottonello de Belli, Guido de Belli, Giacomo Zarotti, Annibale Grisonio, Mario Vida, Nicolò Manzuoli. ${ }^{15}$ I membri che ne facevano parte, seguendo il genere allora in voga, proponevano perlopiù drammi pastorali. Pietro Pola presentò l'Ardor di Amore e la commedia I giusti inganni, Girolamo Vida la Filliria e il dialogo Il Sileno, Ottonello de' Belli Le selve incoronate e il poemetto satirico Lo scolare, Giovan Battista Brati scrisse il dramma pastorale La ninfa del Formio$n e^{16}$

Nel 1646 fu fondata l'Accademia dei Risor$t i$ che con alterne vicende rimase in vita sino al I806. Vi facevano parte: Giuseppe e Cristoforo Gravisi, Domenico Manzioli, Antonio Grisoni, Giacomo de Belli, Gavardo Gavardo, Cristoforo Tarsia, Giuseppe Bonzio, Moretti e Alvise Manzioli. Questo sodalizio accolse anche il medico Girolamo Vergerio, poi professore nelle università di Pisa e Padova e Cesare Zarotti, medico, poeta, epigrammista. Nel 1739 al suo interno vi fu una scissione promossa da Girolamo Gravisi e dal cugino Gian Rinaldo Carli e fu fondata l' $A c$ -

\footnotetext{
I5 Baccio Ziliotto, Accademie e accademici di Capodistria (1478-1807) (Trieste: Arti grafiche L. Smolars \& nipote, 1944).

I6 Nives Zudič Antonič, Storia e antologia di Capodistria, Isola e Pirano (Capodistria: Unione Italiana, 20 I4)
}

cademia degli Operosi (1739-1742). Essa desiderava dare un contributo nuovo e concentrò l'attenzione soprattutto sugli studi di storia antica, ma ebbe vita breve poiché i suoi giovani membri lasciarono la città per frequentare l'università a $\mathrm{Pa}$ dova, compresi i due promotori (Carli nel 1740 fu accolto nell'Accademia dei Ricovrati della città veneta). Fu rifondata nel 1763 come una sorta di cenacolo privato di giovani poeti; ne fu promotore Dionisio Gravisi e si estinse con la sua prematura morte (I767). ${ }^{17}$

\section{Gli autori istriani di drammi pastorali e poesie di ambientazione agreste}

Come abbiamo detto nel paragrafo precedente, un aspetto particolare della letteratura istriana del Cinquecento e del Seicento è costituita dalle Accademie, che si collegano per più riguardi al movimento umanistico, ma che hanno una loro specifica autonomia e uniscono a una componente culturale una componente salottiera e mondana, apparendo espressione caratteristica della società nobiliare e, comunque, di una cultura elitaria e aristocratica. Proprio in questi luoghi pertanto gli intellettuali amavano discutere di letteratura e presentare le proprie opere.

Nel Cinquecento uno dei primi autori di un'egloga pastorale fu il capodistriano Pietro Pola, autore di diverse commedie e di un'egloga pastorale. Girolamo Vida nel 1585 scrive la favola pastorale o boschereccia Filliria che racconta la storia di Nelirio innamorato di Filliria, una ninfa che gli sfugge. L'opera venne rappresentata per la prima volta dall'autore a Capodistria il 27 gennaio del I585; il cav. march. Giovanni Niccolò Gravisi di Capodistria creò le scene per lo spettacolo. ${ }^{18}$ Nello stesso anno l'opera fu rappresentata a Padova, di seguito a Venezia nel 1587 e nuovamente a Padova nel i621. Per quest'opera, Girolamo Vida fu eletto membro dell'Accademia Olimpica di Vicenza.

Il dramma pastorale è un componimento poetico spesso usato dagli autori italiani. Da un

\footnotetext{
I7 Baccio Ziliotti, Storia letteraria di Trieste e dell'Istria (Trieste: La Editoriale Libraria, 1924)

I8 Nives Zudič Antonič, Storia e antologia di Capodistria, Isola e Pirano.
} 
punto di vista retorico, ciò che accomuna questi drammi è la strutturazione in cinque atti e l'osservazione delle unità di tempo, luogo e azione; lo scenario prescelto è quello dell'Arcadia o della Grecia antica o dell'Italia (nel nostro caso anche quello dell'Istria), quasi tutti sono in versi endecasillabi. Un altro elemento distintivo è la struttura dell' intrigo, uno schema complesso, con un notevole numero di personaggi solitamente presentati in coppie, in cui casi amorosi si intrecciano l'un l'altro. Gli autori istriani per scrivere le loro opere si rifanno ai lavori dei grandi scrittori italiani, di cui sono grandi ammiratori. A tal proposito lo scrittore inglese Richard Hughues che nel 1927 soggiornò a Capodistria a proposito dei drammi pastorali istriani del Cinquecento disse: "Nulla di originale; in tutta l'Europa nel Cinquecento si cantavano satiri e ninfe, ma se tutta la poesia istriana di quel secolo è così, parlerei d'imitazione di opere classiche [...]."'

Altro autore capodistriano di drammi pastorali è Ottonello de' Belli che compose il dramma pastorale Le selve incoronate (pubblicate dagli eredi dopo la sua morte, nel 1673 a Venezia). Le selve incoronate è una "tragicommedia", cioè un misto di tragedia e commedia che si rifà al dramma pastorale Pastor Fido del Guarini. L'opera mantiene l'unità di tempo e di luogo ed è composta di cinque atti.

L'autore, come il Guarini, fonde nella sua tragicommedia elementi della tragedia e della commedia classica. Egli deriva dalla tragedia la statura "eroica" di certi personaggi e la drammaticità, spesso solo fittizia, dell'intrecciarsi di eventi sorprendenti, e dalla commedia il programmato smorzarsi e il sorridente e garbato sciogliersi delle passioni nella grazia dell'idillio.

Giovan Battista Brati è autore del dramma pastorale La ninfa del Formione (1617), ${ }^{2 \circ}$ che venne considerata la sua opera migliore, anche se $\mathrm{i}$ critici esprimono giudizi poco favorevoli. La fiaba narra la storia di Mirzio pastore innamorato

I9 Francesco Semi. Istria e Dalmazia: uomini e tempi. Istria e Fiume, 2 I 5.

20 Formione: antico nome del fiume Risano di Lidia, una fanciulla che rifiuta il suo amore, ${ }^{21}$ per farle cambiare idea Mirzio decide di raccontarle la tragica storia della ninfa Dori. La bellissima ninfa Dori abitava sulle sponde del fiume Formione.

\section{Diquesto ameno, egrato, \\ lusinghiero soggiorno, \\ fortunato girdin, stanza amorosa. \\ Stanza ben certo degna \\ De'Semidei gentili, \\ $V$ 'era Vergine bella, \\ Nobilposseditrice: \\ DORIgentil nomata, \\ Che qualdal'oro hà il nome: \\ Cosid'oro ha le chiome \\ Eralagiovinetta \\ De la bella età sua su quel confine, \\ Che pius s'appressa all'acerbetto Aprile; \\ Bella sine' anni, \\ Ch'Angioletta sembrava in forma humana \\ Scesa dal Ciel qua in terra, \\ Perfar del Cielo amato \\ Disuebellezze, innamorar la Terra.}

Nel suo giardino, che si trovava lungo le rive del fiume, la ninfa Dori coltivava dei bellissimi fiori, inoltre pescava nel fiume, nelle vicinanze di quelle sponde andava a caccia e non si curava dell'amore.

\section{Etalhora colveltro \\ Seguir difera fuggitival'ormè, \\ Ospiando il covile \\ De le timide lepri, e de conigli, \\ Òcon la canna, el'hamo \\ Turbar nel' acqua a' pesciriposo. \\ Òco'l visco, ò co'llaccio, \\ Tender à vaghi augelli insidie ascose. ${ }^{23}$}

Il pastore Eurindo era innamorato di Dori e un mattino, mentre lei pescava, le si avvicinò e le dichiarò il suo amore. Ma Dori, che aveva dedi-

\footnotetext{
21 Il tema della resistenza all'a more è un tópos della letteratura idillica. Nell'Aminta del Tasso, p. e. è la ninfa Silvia che si vorrebbe sottrare all'amore, che è non solo legge di Natura, ma anche forza d'ingentilimento'.

22 Giovan Battista Brati, La ninfa del Formione (Venezia: 1619), 5-6.

23 Giovan Battista Brati, La ninfa del Formione, 7-8.
} 
cato a Diana la propria verginità, pregò la dea di difenderla dal giovane. Diana la trasformò in acqua, mentre Zeffiro col suo dolce vento, e Apollo con la sua potenza, agitarono le onde del Formione: e le piccole stille "mirabilmente fersi/ picciol globi di sale".

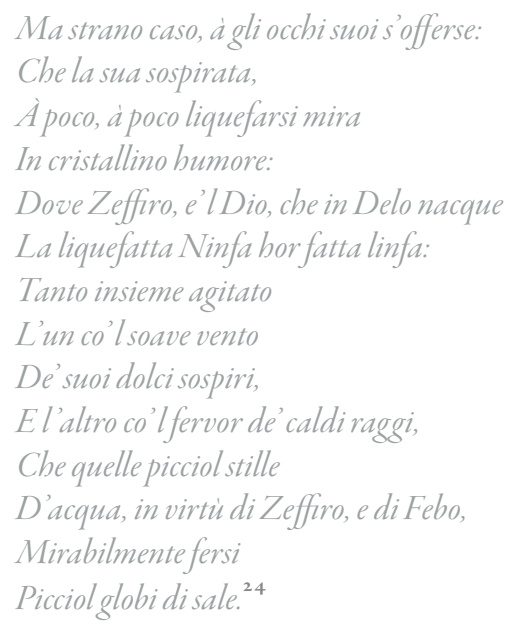

Eurindo allora, aiutato da Nereidi, raccolse quei granelli che da quel giorno divennero condimento del cibo. Alla fine del racconto di Mirzio scende la sera e così si conclude pure la fiaba del Brati.

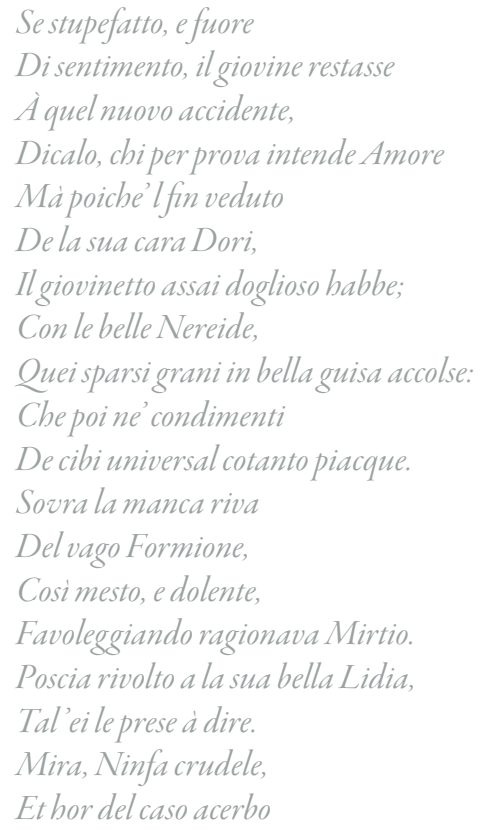

Di Dori, impara a le sue spese, o bella,

A non insuperbire,

Con tra Amor; tu che troppo

Di tua beltà sai de la schiva, tale

De le donne superbe è la mercede:

Tu gradisci il mio affetto, e mentre il giorno

Fè con la notte tregua,

Silentio imporse al ragionar', e tacque.

Nel dramma pastorale il poeta oltre a raccontare la storia dei due innamorati presenta una descrizione molto accurata del paesaggio primaverile lungo il corso del fiume Formione (odierno Risano) e rifacendosi all'esempio della ballata di Angelo Poliziano I'mi trovai, fanciulle presenta tutti i fiori che ci sono nei prati che si trovano lungo il corso del fiume. Anche qui però come nella ballata di Poliziano la rosa viene presentata come la regina di tutti i fiori.

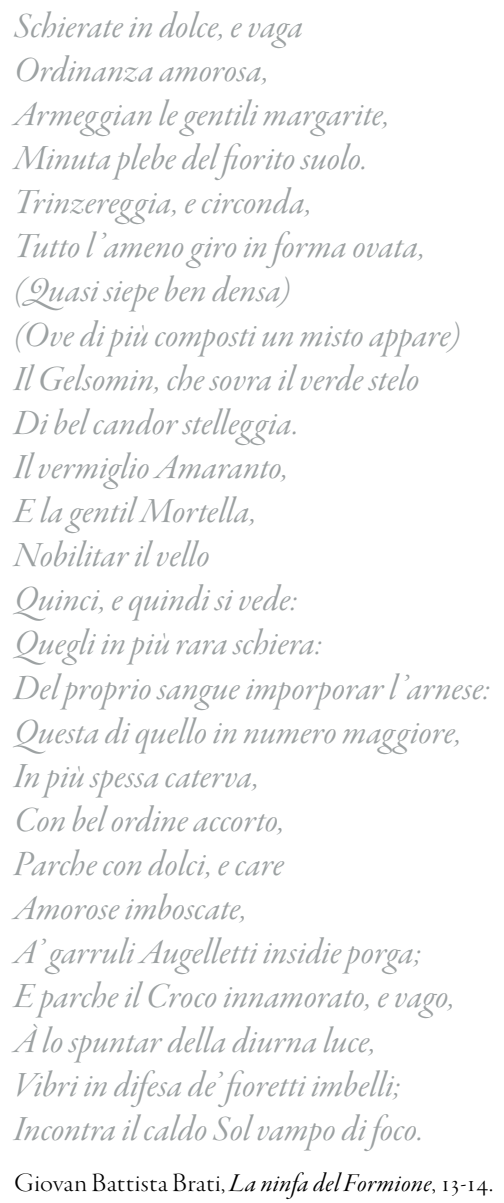

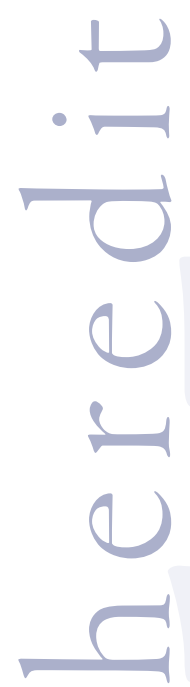




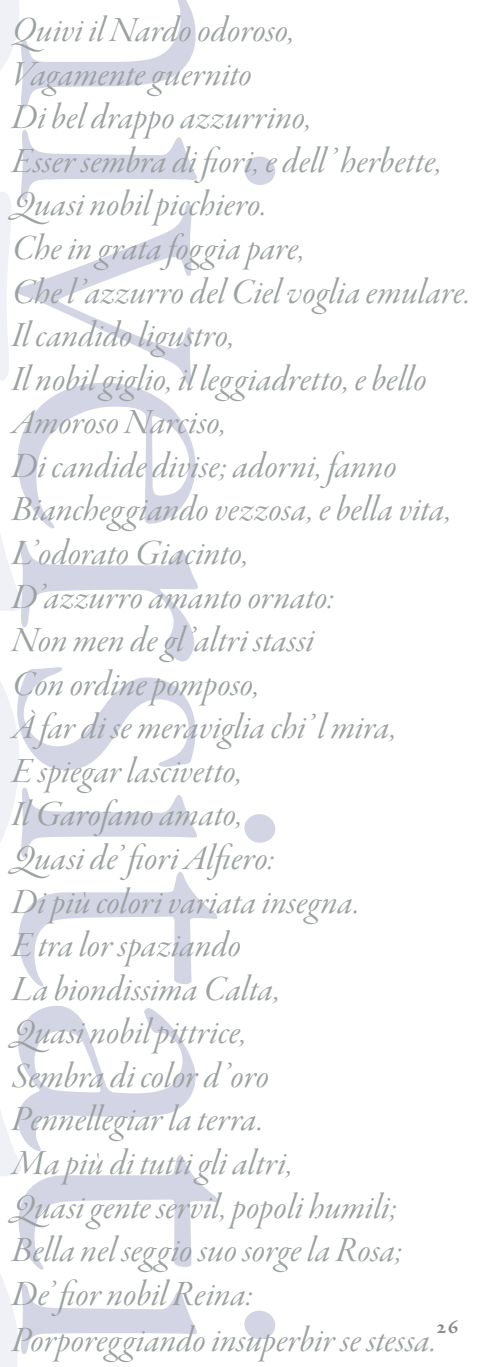

Il motivo dei fiori e in particolar misura della rosa ha numerosi riscontri nella produzione degli autori dei drammi pastorali in Istria. Spontaneo è il rimando alla ballata del Poliziano: comune ai due testi è il tema della poesia d'amore che si confonde con la natura fiorita, il rilievo dato alle notazioni cromatiche (i versi presentati sopra rappresentano un autentico catalogo dei colori del prato), l'importanza di trovarsi in un paesaggio primaverile fiorito.

Mentre però il Poliziano nella sua ballata parla della raccolta dei fiori da parte della donna per farne una ghirlanda che l'avrebbe poi adornata, Brati si rifà alla descrizione dei fiori fino ad arrivare alla rosa come regina tra tutti per presentare l'ambiente in cui vive la protagonista del suo dramma. Per queste opere gli autori si rifanno a due modelli classici: un testo greco del retore Libanio, in cui Venere, in riva al fiume Scamandro, sceglie fra tutti i fiori le rose, con cui si adorna prima del giudizio di Pride; e un anonimo carme latino De rosis. Va inoltre ricordato che il Poliziano dedica il capitolo XI della prima centuria dei suoi Miscellanea al motivo di Venere e della rosa, ripercorrendo diverse attestazioni classiche, latine e greche (compreso lo stesso Libanio) inerenti alla tradizione che lega questo fiore all'amore. ${ }^{2}$

Al di là delle fonti e dell' ispirazione, l'originalità dell'opera di Brati sta proprio nella descrizione così minuziosa del paesaggio lungo le rive del Risano e della descrizione leggendaria dell'origine del sale, elemento tanto prezioso per la sua regione.

Nel Settecento in Istria la tradizione dei drammi pastorali viene ripresa da alcuni autori attraverso la composizione di egloghe pastorali o composizioni poetiche che si rifanno all'idillio. Vanno qui ricordati Girolamo Gravisi e suo figlio Dionisio e Giuseppe Bonzio. Giuseppe Bonzio poeta capodistriano, fece parte dell'Accademia dei Risorti tra il 1754 e il 1755 (il suo nome accademico fu Tirsi). Il poeta scrive un libro di poesie assieme a Dionisio Gravisi Poesie liriche che verrà pubblicato dopo la sua morte nel I77I dalla contessa Santa Borisi Gavardo. Nella prefazione al libro, la donna, parlando dei versi del Bonzio dice che "questi si sollevano dalla bassa nojosa turba dei vuoti verseggiatori..." si nota inoltre nei suoi versi una somiglianza ai versi del Chiabrera che fu promotore dell'indirizzo dell'Arcadia classicheggiante e imitò la vacua grandiosità dell'ode pindarica. ${ }^{29}$ La contes-

Riccardo Bruscagli, Gino Tellini Vittorio Corsano Lucia Denarosi e Silvia Fiaschi, Itinerari dell 'invenzione 2. Umanesimo e Rinascimento. Autori, temi, crocevia della letteratura italiana ed europea (Firenze: Sansoni per la scuola, 2002).

28 Santa Borisi Gavardo, "Prefazione," in Poesie liriche dei signori Giuseppe Bonzio e marchese Dionisio Gravisi nobiligiustinopolitani. Giuseppe Bonzio e Dionisio Gravisi, (Venezia, 1771), 3.

29 Nives Zudič Antonič, Storia e antologia di Capodistria, Isola e Pirano. 
sa inoltre spiega che il Bonzio fu imitatore pure di Benedetto Menzini che fu, come specifica lei "uno dei primi, che alle itale muse abbia restituito l'antico decoro oscurato ed offeso dai falsi vezzi dello scorso secolo, in cui egli visse". ${ }^{\circ} \mathrm{La}$ donna dice inoltre che le poesie del Bonzio sono talmente ben scritte e "animate da fuoco poetico" che favoriscono la lettura.

Gli intellettuali che frequentavano l'Accademia dei Risorti solitamente amavano proporre dei problemi su cui discutere e ragionare. Nell'Egloga pastorale tratta dall'opera Poesie liriche Giuseppe Bonzio presenta un'opera scritta assieme a Girolamo Gravisi su imitazione di Virgilio. Il testo presenta un dialogo in cui Alindo (Girolamo Gravisi) e Tirsi (Giuseppe Bonzio) si pongono il problema se sia più vantaggioso avere un animo guerriero o pacifico.

Dionisio Gravisi dal 1763 , quando era studente nel collegio dei nobili di Capodistria, fu uno dei rinnovatori dell'Accademia degli Operosi, fondata da suo padre trent'anni prima. Già all'età di sedici anni scriveva poesie e collaborava alle Accademie locali. Le sue poesie in linea di massima rispecchiavano la malinconia della sua sofferente giovinezza e il presentimento della morte prematura. ${ }^{3 \mathrm{I}}$ Le sue poesie, come già menzionato sopra, vennero pubblicate assieme a quelle del poeta capodistriano Giuseppe Bonzio dalla contessa Santa Borisi Gavardo. La contessa, nella prefazione al libro di poesie, parlando del poeta, dirà che Dionisio Gravisi è "fortunato seguace della lirica scuola aperta in Grecia, e fatta rinascere in Roma da Orazio nell'aureo secolo di Augusto", ${ }^{2}$ pure lui come il Bonzio sono seguaci del Chiabrera e dell'indirizzo dell'Arcadia classicheggiante. La contessa Borisi Gavardo inoltre lo considera seguace pure del poeta Frugoni e lo Stancovich, nella sua Bibliografia degli uomini illustri dell'Istria, dirà che "le poesie del marchese Dioniso piacciono, allettano, e ricolmano l'animo di un pieno, a cui nulla più resta da desiderare" (1829).

\footnotetext{
30 Gavardo, "Prefazione."

3 I Baccio Ziliotti, Storia letteraria di Trieste e dell'Istria.

32 Gavardo, "Prefazione," 3.
}

Nella poesia L'Armonia il poeta si rifà al componimento pastorale che è l'indirizzo tipico della poesia arcadica. Questo mondo arcadico, spesso così ricco di grazia e di delicatezza fine e superficiale, trovò il suo modo proprio di espressione nella canzonetta in cui si continua l'anacreontica chiabresca, che è propria gloria e, nella sua particolare intonazione, vera creazione d'Arcadia. $^{33}$

La canzone L'Armonia di Dionisio Gravisi, composta da strofe con ritmo facile, e disposta ad accogliere il rivestimento musicale, è un componimento poetico di grazia, di psicologia amorosa facile e squisita insieme. In questo testo si possono intravedere le caratteristiche classicheggianti del Chiabrera.
[...] In mezzo a cuiverdeggerà sublime
L'alma fronde di Pallade Risorta ${ }^{34}$
Che rediviva di nascenti germi
Tanta ora in Pindo di sè parte ingombra.
Mobil dai rami penderan le cetre
Che faran dolce ai venticelli invito,
E desteranno, se movendo, un suono
Di concorde armonia; là presso cinto
Di musco, e canne, il Formion divise
Verserà in rami dalla facil' urna
L'acque cui lungo a fabbricar lor nido
Verran candidi Cigni, aerea Torma,
E un nuovo canto tempreranno, un nuovo
Meonio Fonte risonar faranno. ${ }^{35}$

Nell'altra canzonetta Alla barchetta, che 1 conduce Egle alla campagna Dionisio Gravisi descrive il viaggio in barca che porta Egle $^{36} \mathrm{da} \mathrm{Ca-}$ podistria alla contrada campestre di Arzioli dove la famiglia del poeta aveva una villa.

\footnotetext{
33 Bruno Maier, Letteratura italiana dell' Istria dalle origini al Novecento (Trieste: Edizioni Italo Svevo, 1996).

34 Pianta di Olivo rinascente, esposta al Sole, col motto di far rivivere (rediviva) l'impresa dell'antica Accademia dei Risorti a Capodistria.

35 Giuseppe Bonzio e Dionisio Gravisi, Poesie liriche dei signori Giuseppe Bonzio e marchese Dionisio Gravisi nobili giustinopolitani (Venezia, 1771), 236-237.

36 Egle è il nome accademico di Dionisio Gravisi.
} 
] O tu Risan, che moder

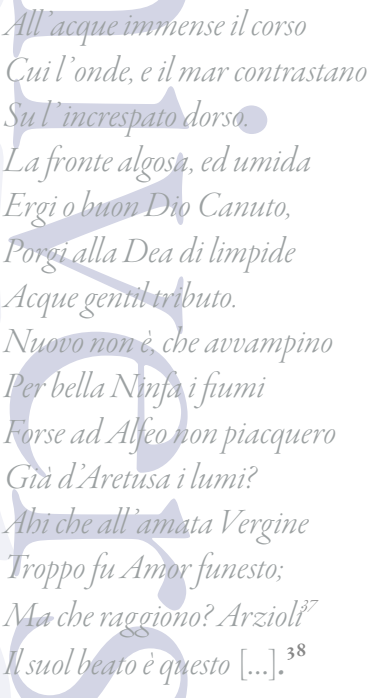

In questa canzone il poeta si rifà al gusto della finzione pastorale e alla trasfigurazione fiabesca del paesaggio. I versi del Gravisi riportano a un senso di misura che si oppone agli eccessi dello stile barocco, puntando piuttosto alla raffinatezza e alla leggiadria della forma. ${ }^{39}$ Nei suoi versi, pertanto, possiamo intravedere il gusto barocco classicheggiante della poesia chiabresca.

Come il Chiabrera anche il Gravisi fece uso di soggetti tratti dai classici greco-ellenistici usando un sistema metrico-linguistico che gli consentì una musicalità chiara e leggera del verso, portando la sua canzonetta a quella caratteristica votata al grazioso.

\section{Conclusione}

Nonostante i critici esprimessero opinioni poco lusinghiere nei confronti degli istriani autori di drammi pastorali, sottolineando che, in genere, detti autori proponevano opere dalla scarsa originalità e di imitazione, va tuttavia considerato che la loro presenza è un'importante testimonianza per la letteratura della regione istriana.

37 Arzioli, contrada campestre, disgiunta per breve tratto di mare da Capodistria, dove c'era una villa dell'Autore.

38 Giuseppe Bonzio e Dionisio Gravisi, Poesie liriche dei signori Giuseppe Bonzio e marchese Dionisio Gravisi nobili giustinopolitani, 236-237.

39 Bruno Maier, Letteratura italiana dell'Istria dalle origini al Novecento.
Ne sono dimostrazione opere quali Filliria, di Girolamo Visa, Le selve incoronate, di Ottonello de' Belli, La ninfa del Formione, di Giovan Battista Brati, che, pur essendo imitazioni delle opere di importanti letterati italiani autori di drammi pastorali, quali Guarini e Tasso, presentano un importante elemento originale riscontrabile nella descrizione dell'ambiente. Quest'ultimo, infatti, è un ambiente locale che, pur rifacendosi alle descrizioni dei grandi autori del Rinascimento italiano, mantiene le caratteristiche e le peculiarità della regione istriana.

\section{Povzetek}

Nova literarna zvrst pastoralne lirike se je razvila iz ideje, da bi razširili eklogo v obliki dialoga, ki je bila posebno pri srcu pesnikom petnajstega stoletja, $\mathrm{v}$ dramatično eklogo s pevci v vlogi pastirjev: nova literarna zvrst je kmalu postala zelo popularna in se razširila v kulturnih krogih šestnajstega stoletja. Čeprav je njej nastanek vezan na klasične avtorje, predvsem na Teokrita in Vergilija, pesniki pastoralne lirike ne spoštujejo aristotelskih norm, ker združujejo bodisi nekatere značilnosti tragedije kot komedije, saj večkrat začinijo resnobo tragičnih dogodkov s komičnim humorjem ali pa pripišejo srečen konec žalostnim dogodkom.

V Italiji je bila pastoralna lirika prvič predstavljena v Ferrari z delom Sacrificio (1554) Agostina Beccarija, svoj višek žlahtne poezije pa je doseglas Tassejevo Aminto in z delom Battista Guarinija Pastor Fido. In ravno oba omenjena pesnika in njuni pesnitvi sta navdihnila pesnike pastoralne lirike v Istri. V Istri je bila pastoralna lirika še najbolj prisotna v Akademijah, ki so imela pomembno vlogo v času renesanse. Ta središča, ki so bila sicer bolj povezana s humanističnim gibanjem, so pa imela specifično avtonomijo, so prepletala neresne in posvetne tematike s kulturnimi kot karakteristična značilnost aristokratske družbe in, elitne, aristokratske kulture. Ravno v teh krogih so istrski intelektualci radi razpravljali o literaturi in predstavljali svoja dela.

Med avtorji, ki so opisani v članku gre omeniti: Koprčana Pietra Polo, ki je bil prvi avtor pastirske ekloge v šestnajstem stoletju; Girolamo Vida je leta I586 napisal Fillirio, pastoralno zgodbo ali boschereccio; leta 1673 je bila objavljena pastoralna drama Le selve incoronate Koprčana Ottonella de’ Bellija; leta I6ı7 je Giovan Battista Bra- 
ti napisal pastoralno dramo La ninfa del Formione. Članek omenja še druge pisce, kot so bili Girolamo Gravisi, njegov sin Dionisio, in Giuseppe Bonzio, ki je nadaljeval tradicijo pastoralne drame v osemnajstem stoletju v Istri s pastoralnimi eklogami ali pesniškimi kompozicijami, povezanimi zidilami.

Ključne besede: pastoralna igra, idilična poezija, ekloga, idila

\section{Summary}

From the idea of expanding an eclogue in dialogues, very dear to the poets of the second half of the fifteenth century, into a dramatic eclogue, with characters in the roles of shepherds, a new literary genre was born which soon became popular among the educated circles of the sixteenth century: pastoral drama. Although originating from the texts of Classical authors such as Theocritus and Virgil, this form does not conform to the Aristotelian norm, and occupies an intermediate space between tragedy and comedy, often interweaving the seriousness of tragedy with the humour of comedy, and giving unhappy events a happy ending. In Italy, pastoral drama (or fable) made its first appearance in Ferrarra with Sacrificio (1554) by Agostino Beccari; however, it rose to the level of genuine poetry only with the Aminta by Tasso, and with the Pastor Fido by Battista Guarini. In fact, it is the example of these two authors and their poetic compositions that also inspired the authors of pastoral drama in Istria. In Istria, pastoral drama is mostly related to the Academies, which were a distinctive feature of the Renaissance period. These centres, which were connected more to the humanistic movement, but have a specific autonomy, combine a frivolous and worldly component with a cultural one, appearing as a characteristic expression of aristocratic society and, of an elite and aristocratic culture. It is precisely in these places, therefore, that Istrian intellectuals enjoyed discussing literature and presenting their works.

Among the authors presented in the article are: the Capodistrian, Pietro Pola, who was the first author of a pastoral eclogue in the sixteenth century; in ${ }^{5} 85$ Girolamo Vida, wrote Filliria, a pastoral fable or boschereccia; in 1673 the pastoral drama Le selve incoronate by the Capodistrian Ottonello de'Belli was published; in 1617 Giovan Battista Brati wrote the pastoral drama La ninfa del Formione. The article also cites some authors, such as Gi- rolamo Gravisi, his son Dionisio, and Giuseppe Bonzio, who continued the tradition of pastoral drama in the eighteenth century in Istria by writing pastoral eclogues or poetic compositions that relate to idyll.

Keywords: pastoral drama, pastoral fable, idyllic poetry, eclogue, idyll.

\section{Bibliografia}

Asor Rosa, Alberto. Sintesi di storia della letteratura italiana. Firenze: La Nuova Italia, 1978 .

Asor Rosa, Alberto. Storia della letteratura italiana. Firenze: La Nuova Italia, 1985.

Borisi Gavardo, Santa. "Prefazione.” In Poesie liriche dei signori Giuseppe Bonzio e marchese Dionisio Gravisi nobili giustinopolitani, Giuseppe Bonzio e Dionisio Gravisi, 2-5. Venezia, I77I.

Bonzio, Giuseppe, e Dionisio Gravisi. Poesie liriche dei signori Giuseppe Bonzio e marchese Dionisio Gravisi nobili giustinopolitani. Venezia, I77I.
$\downarrow$
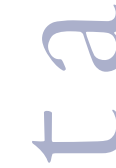

Brati, Giovan Battista. La ninfa del Formione. Venezia, I6I9.

Bruscagli, Riccardo, Gino Tellini, Vittorio Corsano, Lucia Denarosi, e Silvia Fiaschi. Itinerari dell'invenzione 2. Umanesimo e Rinascimento. Autori, temi, crocevia della letteratura italiana ed europea. Firenze: Sansoni per la scuola, 2002.

De'Belli, Ottonello. Le selve incoronate. Tragicomedia Boschereccia del signor D. Ottonello de Belli nobile giustinopolitano. Venezia, 1673.

Guarini, Battista. Compendio della poesia tragicomica. Venezia: Giovanni Battista Ciotti, I6or.

Maier, Bruno. Letteratura italiana dell'Istria dalle origini al Novecento. Trieste: Edizioni Italo Svevo, 1996.

Rolli, Paolo. De’ poetici componimenti del Signor Paolo Rolli: divisi in tre libri. Venezia: Bartolommeo Occhi, I77I.

Sansone, Mario. Disegno storico della letteratura italiana. Milano: Principato, 1963. 
Sapegno, Natalino. Compendio di storia della letteratura italiana. Firenze: La Nuova Italia, I95I.

Semi, Francesco. Istria e Dalmazia: uomini e tempi. Istria e Fiume. Udine: Del Bianco Editore, 1991.

Stancovich, Pietro. Biografia degli uomini distinti dell'Istria del canonico Pietro Stancovich. Tomo secondo. Trieste: Presso Gio. Marenigh Tipografia, I829.

Ziliotti, Baccio. Storia letteraria di Trieste e dell'Istria. Trieste: La Editoriale Libraria, 1924.

Ziliotto, Baccio. Accademie e accademici di Capodistria (1478-1807). Trieste: Arti grafiche L. Smolars \& nipote, 1944.

Zudič Antonič, Nives. Storia e antologia di Capodistria, Isola e Pirano. Capodistria: Unione Italiana, 2014.

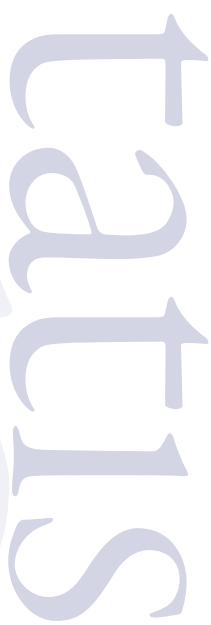


-

r

$\downarrow$

G

1

-

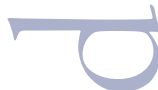

( )

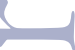

(U)

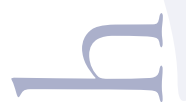




\title{
Lingua e identità nel carteggio degli intellettuali fiumani (1960-1987)
}

\author{
Corinna Gerbaz Giuliano, Maja Đurdulov
}

Il saggio prende in esame alcuni scambi epistolari intercorsi tra gli intellettuali fiumani Osvaldo Ramous, Antonio Widmar e Enrico Morovich dai quali si evince il rapporto con la loro identità. Questa è determinata dal singolare ambiente multiculturale e multilingue in cui sono nati e si sono formati. Il lavoro esamina le complessità che emergono dall' identità multiculturale degli autori fiumani di lingua italiana in un periodo di significative trasformazioni politiche, linguistiche e culturali a Fiume.

Parole chiave: circoli culturali a Fiume, lingua italiana, identità interculturale, Fiume

Članek obravnava korespondenco med reškimi intelektualci Osvaldom Ramousem, Antoniom Widmarjem in Enricom Morovichem, iz katere je razbrati odnos, ki ga imajo do svoje identitete. Njihova identiteta je namreč zaznamovana z medkulturnim in večjezičnim okoljem, v katerem so se rodili in odraščali. Delo analizira predvsem kompleksnost medkulturne identitete reških avtorjev italijanskega jezika v obdobju pomenljivih političnih, jezikovnih in kulturnih sprememb na Reki.

Ključne besede: kulturni krogi na Reki, italijanski jezik, medkulturna identiteta, Reka

Tercorsi culturali di Osvaldo Ramous, Antonio Widmar ed Enrico Morovich, voci illustri del cosiddetto circolo letterario fiumano, e le loro corrispondenze epistolari costituiscono una materia ancora per molti versi da studiare. Il presente contributo si soffermerà, in particolare, su ciò che emerge dal fitto carteggio tra $\mathrm{i}$ tre letterati e che attesta la preziosa eredità di un vivace mondo culturale che ha interessato la città di Fiume. Nella fattispecie si cercherà di mettere in rilievo la necessità, avvertita da Ramous, Widmar e Morovich, di conservare e archiviare il proprio registro linguistico e culturale, ricco e variegato. Per quanto concerne il discorso identitario, va sottolineato che il loro è stato un percorso piuttosto tormentato, simile e diverso al contempo, ma è proprio alla luce di questa considerazione che si è voluto indagare sulla sensibilità di questi intellettuali fiumani nei confron- ti del proprio nucleo identitario che emerge in particolare dalle loro corrispondenze private. Il processo di formazione dell'identità non è di pertinenza esclusiva delle discipline socio-antropologiche, ma implica indubbiamente il discorso letterario ed è in questa prospettiva che si è cercato di analizzare il senso di appartenenza all'entità collettiva dei tre autori fiumani filtrata da ciò che emerge dalle loro lettere.

Ramous, Widmar e Morovich nascono agli inizi del Novecento a Fiume, in una città di mare e di frontiera, che, al di là dell'elemento di instabilità racchiuso nell'accezione del termine, delinea una storia culturale ricchissima, fatta di rimandi, di compenetrazione culturale e linguistica.

Tutti e tre gli autori nascono in un ambiente pluriculturale e mistilingue e si inseriscono a pieno titolo nella koinè mitteleuropea, in quel cro- 
cevia di popoli e culture che funge da sostrato culturale alla città di Fiume. Il capoluogo quarnerino situato a ridosso del mare Adriatico può essere inteso come una sorta di collante che ha unito sia i litorali che gli entroterra ma, oltre ad unire, ha inevitabilmente prodotto scissioni tra $\mathrm{i}$ vari popoli dando vita a una storia molto movimentata, come lo è stata del resto tutta la storia dell'area balcanica

$$
\begin{aligned}
& \text { che è in gran parte la storia delle grandi po- } \\
& \text { tenze che si sono continuamente contese il } \\
& \text { dominio dei territori dell'odierna Repubbli- } \\
& \text { ca e hanno cercato di espandersi attraverso } \\
& \text { le sue strategiche vie d'accesso naturali. Ma è } \\
& \text { anche la storia della resistenza degli slavi del } \\
& \text { sud agli attacchi contro la loro indipenden- } \\
& \text { za e il loro carattere nazionale e, nello stesso } \\
& \text { tempo, della lotta di questi popoli per raffor- } \\
& \text { zare la loro posizione e dei tentativi degli uni } \\
& \text { di unificare, assorbire o dominare gli altri. }
\end{aligned}
$$

A prescindere dai pesanti momenti di instabilità $\mathrm{e}$ tensione che queste terre hanno vissuto, vanno ricordati i momenti di notevole crescita economico-sociale e culturale, basti ricordare il periodo della reggenza austro-ungarica, che in particolare per la città di Fiume ha significato diventare il secondo porto dell'Impero, incrementando così le attività commerciali e industriali, seguite da un considerevole progresso in chiave socio-culturale il che ha portato a consolidare l'aspetto multiculturale e in particolare di convivenza della città quarnerina. Una sorte analoga la ebbero anche i centri più rilevanti sia in terra istriana sia in quella dalmata, basti pensare alla Spalato di cui ci narra Enzo Bettiza. In questo quadro multietnico il concetto di cittadinanza a Fiume è ed è sempre stato sinonimo di apertura culturale e linguistica e soprattutto di tolleranza reciproca. Antonio Widmar, Osvaldo Ramous e Enrico Morovich sono intellettuali fiumani dal respiro cosmopolita, uomini di frontiera, personalità dall'identità plurima. Ci risulta indispen-

I Henry Clifford Darby, Robert William Seton-Watson, Phyllis Auty, Robert George Dalrympl Laffan e Stephen Clissold, Storia della Jugoslavia. Gli slavi del sud dalle origini a oggi (Torino: Einaudi, 1969), 13-14 sabile spendere alcune parole per tentare di circoscrivere (per quanto sia possibile) il concetto di identità plurima. Che cos'è in effetti l'identità plurima? Cerchiamo di spiegarlo affidandoci al saggio di Edmond Jabés Uno straniero con, sotto il braccio, un libro di piccolo formato, ${ }^{2}$ un libro autobiografico nel quale l'autore mette in scena il personaggio dello Straniero che si fonde con il narratore. Jabés in effetti racconta se stesso, è declinato alla prima persona. Chi è dunque lo Straniero di Jabés? È l'Io che incontra l'Altro, l'estraneo, il forestiero; è l' Io che incontra se stesso nelle sembianze di uno straniero. Dunque lo straniero siamo noi stessi. Sottolinea Pier Aldo Rovatti nella postfazione all'opera:

$$
\begin{aligned}
& \text { per Jabés si tratta, mediante un esercizio } \\
& \text { (che non può avere a che fare con la parola), } \\
& \text { cioè una ricerca e un travaglio, e in definitiva } \\
& \text { precisamente attraverso una messa a repen- } \\
& \text { taglio della propria soggettività, di 'diven- } \\
& \text { tare stranieri' [... . Jabés sa che questo Stra- } \\
& \text { niero, che noi vediamo solo di spalle, non è } \\
& \text { fuori di noi. Lo è solo nella finzione narra- } \\
& \text { tiva: per incamminarci davvero sulla strada } \\
& \text { dell'io-straniero si tratta certo di riconosce- } \\
& \text { re la passività-responsabilità dell'io, ma poi } \\
& \text { e prima di tutto si tratta di realizzare il fatto } \\
& \text { che quello Straniero che intravvedo e che mi } \\
& \text { sfugge sono io stesso. }
\end{aligned}
$$
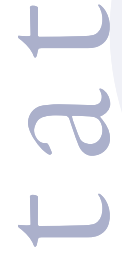

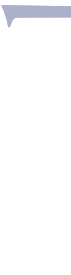

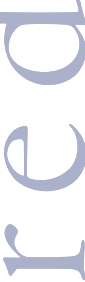

E per $\mathrm{i}$ tre autori in questione l'incontro dell'Io con se stesso nelle sembianze di uno Straniero rappresenta una condizione di partenza dalla quale si sviluppa la loro identità plurima che li fa diventare cittadini del mondo.

La città quarnerina, crogiuolo di etnie e culture diverse dai tempi più remoti, punta sulla formazione di un sostrato intellettuale multiculturale e plurilingue che si adopera nel manifestare la propria specificità, nel cancellare eventuali giudizi di parte dimostrando di meritare a pieno titolo il coinvolgimento negli aspetti culturali di mato (Milano: SE, I99I).

Pier Aldo Rovatti, "L'io straniero e il silenzio della parola", in Uno straniero con, sotto il braccio, un libro di piccolo formato, a cura di Edmond Jabès (Milano: SE, I991), I 40. 
rilievo. Dentro a questo quadro si muovono personaggi diversi tra di loro, ma concordi nell'affidare al discorso culturale la missione di costruire ponti tra culture differenti. Il ruolo degli intellettuali e dei mediatori culturali fiumani che si impegnano nell'avvicinare letterature diverse e si cimentano in traduzioni da una lingua all'altra, diviene un anello di congiunzione importante all'interno di un quadro pluriculturale, che di fatto incarna lo spirito della città quarnerina. Ed è proprio questa specificità del retroterra culturale fiumano a suscitare l'interesse degli studiosi ad ampia scala.

Sono molti i nomi di intellettuali fumani a cui va riconosciuto il merito di aver tessuto una così ricca storia culturale, tra questi spiccano quelli di Widmar, Ramous e Morovich. La scrittura è insieme la base della realtà sociale, della nostra coscienza e del nostro pensiero e la pratica letteraria si presta per definizione a funzione di archivio della memoria. Se siamo concordi nell'affermare che nella memoria di un popolo è intrinseco il concetto d'identità, allora le corrispondenze epistolari divengono materiale prezioso per indagare specifici periodi storici e forme di pensiero. All'interno della storia della gente di confine intessuta da rimandi, alti e bassi, scontri e conflitti, i carteggi diventano materiale pregiato per ricucire i lembi della storia con la $S$ maiuscola. I pensieri, gli stati d'animo e le posizioni a volte molto dure nei confronti di specifiche vicende storiche che emergono dai carteggi ci permettono di interpretare momenti storici particolari. Partendo dal presupposto che la memoria debba essere intesa come categoria indispensabile per capire il presente, allora il narrare allargato al discorso confidenziale delle lettere va inteso come parte integrante dell'esistenza umana che è «come la vita, esiste di per sé, è internazionale, trans-storica, trans-culturale $\gg .{ }^{4}$ La letteratura di confine e soprattutto i carteggi tra gli intellettuali costituiscono piattaforme per conoscere realtà diverse, proiezioni di vita da cui emergono valori, mentalità, culture a contatto

4 Roland Barthes, "Introduzione all'analisi strutturale dei racconti", in L'analisi del racconto (Milano: Bompiani, 1996), 7 e storie divise. Il terreno entro il quale gli intellettuali si muovono non è esclusivamente quello della memoria individuale, bensì è quello della memoria collettiva di un popolo. «Il fenomeno della memoria, nella molteplicità dei suoi aspetti, non è solo interdisciplinare, nel senso di non poter essere oggetto di una sola disciplina, ma anche controverso e contradditorio all' interno delle singole discipline» ${ }^{5}$ e le vicende storiche che hanno interessato Fiume, l'Istria e le isole, privandole in gran parte della componente italiana, sono divenute oggetto di riflessione letteraria, e non solo, in virtù del condizionamento reciproco che esiste tra letteratura e storia hanno fortemente delineato il discorso letterario.

Ma nel considerare il fenomeno della memoria collettiva nella sua diversità e contraddittorietà dobbiamo inevitabilmente fare i conti anche con la memoria del dolore. Sottolinea Nelida Milani che «l'identità personale è fondata sulla memoria, sulla propria autobiografia. Anche la sofferenza ha un ruolo nell'identità, un ruolo positivo» ${ }^{6}$ e la storia dell'area istro-quarnerina è fatta anche della memoria del dolore, è un valore del codice genetico dei suoi abitanti. «La memoria dà la capacità agli individui di aver coscienza di permanere se stessi attraverso il tempo e attraverso tutte le fratture dell'esperienza. Quindi l'identità personale viene connessa a una fondazione orizzontale, la quale mette in relazione gli istanti, le ore, i giorni della nostra esistenza con tutto l'arco della nostra vita organica. Quella della memoria collettiva è soltanto un'analogia».

La memoria rappresenta un terreno d'indagine di grandissima attualità. «Il terreno della memoria è dinamico, conflittuale, un luogo in cui i ricordi non giacciono statici in successione [...] ma sono legati ad affetti, appartenenze, giudizi, valori, interessi» ${ }^{8}$ e il carteggio, inteso quale

\footnotetext{
5 Aleida Assmann, Ricordare. Forme e mutamenti della memoria culturale (Bologna: Il Mulino, 2002), 17 .

6 Nelida Milani, "Appartenenza e separazione”, Civiltà istriana, ricerche eproposte. Etnia extra serie, n.I (1998): 289. Milani, “Appartenenza e separazione," 289.

8 Paolo Jedlowski, Il senso del passato. Per una sociologia della memoria (Milano: Franco Angeli, 1991), 9.
} 
parte integrante nella ricostruzione della memoria collettiva di un popolo, diventa un elemento di forza improsciugabile.

\section{Antonio Widmar}

Sono proprio gli affetti, i giudizi, le appartenenze e i valori che emergono dal carteggio tra Osvaldo Ramous e Antonio Widmar.

Antonio Widmar nasce a Fiume nel r899e muore a Chiavari nel 1980. Poeta, prosatore, pubblicista e traduttore. A conclusione degli studi letterari compiuti a Bologna, fa ritorno nella sua città. I primi vent'anni del secolo scorso lo vedono protagonista di interessanti iniziative culturali promosse dai periodici letterari "La Fiumanella" e "Delta". A partire dal 1926 ha inizio la sua parentesi ungherese; rimarrà a Budapest fino alla fine della seconda guerra mondiale, dove allaccerà rapporti d'amicizia con l'intellighenzia ungherese. Nel 1943 si rifiuterà di aderire alla Repubblica Sociale di Mussolini e nel 1944 sarà deportato assieme ad altri funzionari dell'ambasciata italiana in Germania. Ritornerà a Budapest e si lancerà nell'attività umanitaria, lavoro illegale che gli procurerà non pochi problemi. All'ingresso delle truppe sovietiche in Ungheria verrà arrestato e farà ritorno in Italia. Nel 1947 verrà nominato consigliere culturale presso l'Ambasciata italiana a Tokio, dove vi rimarrò fino al 1963. Seguirà un breve soggiorno diplomatico a Ginevra sino al 1964, anno del suo pensionamento.

Widmar e Ramous si incontrarono nel periodo in cui quest'ultimo si accostava al giornalismo, collaborando dal 1923 al 1925 alla rivista "Delta" di Fiume, diretta proprio dallo stesso Widmar, il quale la ritenne un po' la sua creatura visto che «in pieno fascismo era stata un'iniziativa di limpido carattere internazionalista, protesa a contribuire alla reciproca conoscenza tra $\mathrm{i}$

9 Corinna Gerbaz Giuliano, "Intorno agli scambi filosofici nel carteggio Ramous-Widmar," in Osvaldo Ramous. L'impegno culturale e critico, a cura di Gianna Mazzieri Sanković (Fiume: Edizione della Comunità degli Italiani di Fiume, 2008), 76-77. popoli e quindi alla loro autentica fratellanza», ${ }^{\circ \circ}$ e a "La Fiumanella", altra rivista importantissima, che segnò il percorso culturale di quel tempo. «La formazione di Widmar risentì fortemente del clima culturale fiumano degli anni Venti, di chiaro orientamento cosmopolita, proiettato ad operare una sorta di trait d'union tra il mondo slavo e le vicine culture mitteleuropee». ${ }^{\text {II }}$ Le posizioni espresse da Widmar tracciano un percorso critico in cui spiccano le sue convinzioni e idee politiche. In una lettera del 197I l'autore, dichiarando la sua posizione antidannunziana, fa emergere il senso dell'identità linguistica e culturale della Fiume dell'epoca e scrive:

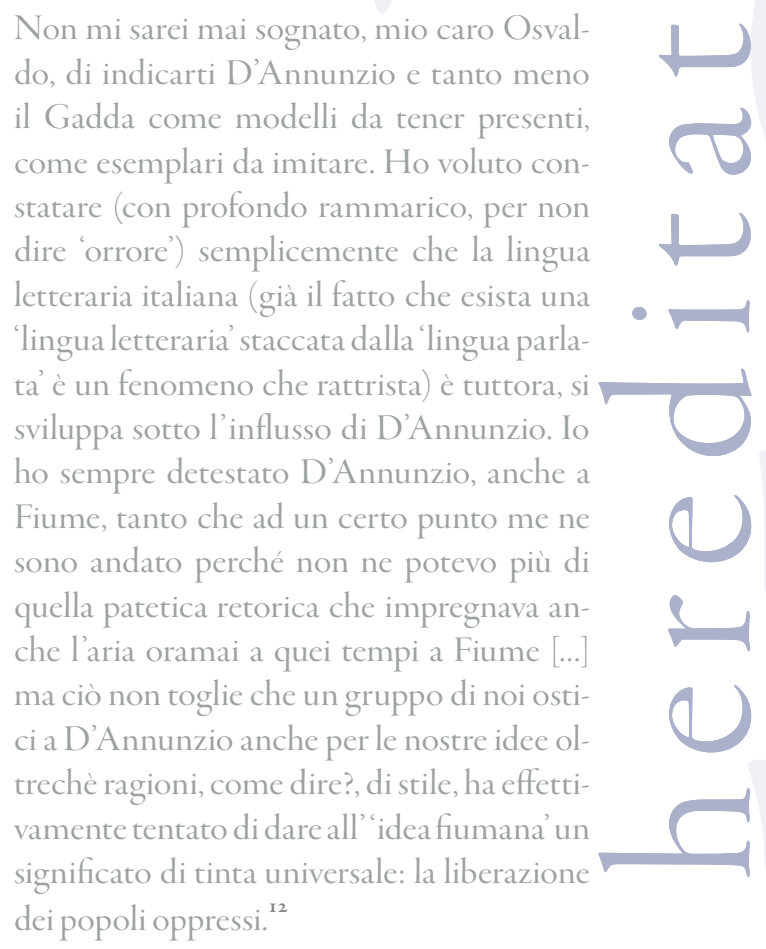

Il lettore viene colpito dalla dimensione intimistica che traspare dallo scambio epistolare tra i due amici: i temi delle lettere risultano variegati e le discussioni che si snodano tra Ramous

io Gianna Mazzieri-Sanković, "Osvaldo Ramous: un fiumano, cittadino del mondo," La Battana, n. speciale 2 (1997): 66.

I I Corinna Gerbaz Giuliano, "Antonio Widmar mediatore culturale e traduttore," Quaderni giuliani di storia, n. 36/I (2015): I25.

I2 Lettera di Antonio Widmar a Osvaldo Ramous, I3 aprile 197 I (archivio privato della famiglia), in Gerbaz Giuliano, "Antonio Widmar mediatore culturale e traduttore," I28. 
e Widmar riguardano questioni filosofiche, politiche e culturali. Al centro delle loro discussioni rimane sempre il discorso letterario che rappresenta per entrambi gli autori il fulcro della loro esistenza. Ciò di cui il lettore si accorge subito sono le dichiarazioni (spesso dirette e forti) e le prese di posizione che ne derivano. Così, in una lettera del 31 agosto 1965 , Ramous delinea all'amico Widmar il suo punto di vista circa la rivista "La Battana" che iniziò a uscire in quel periodo:

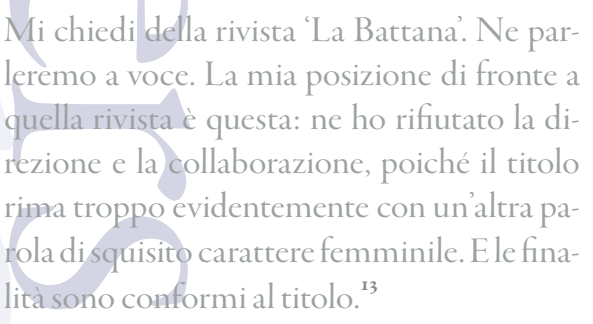

Antonio Widmar è altrettanto diretto nell'esprimere le proprie opinioni, il che si evince da una lettera successiva, datata 23 ottobre 1975 , in cui parla della rivista "Delta" e sottolinea:

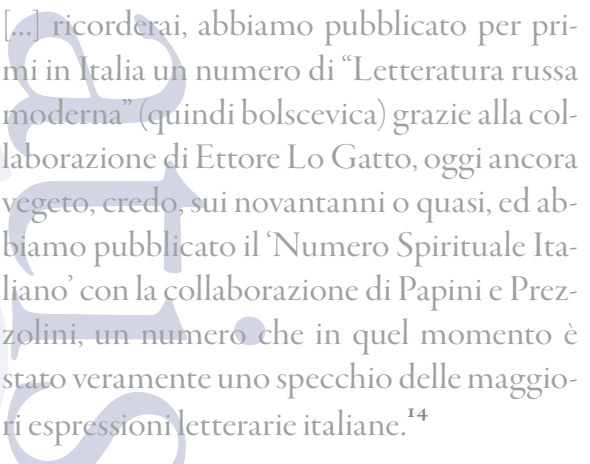

Anche in questo caso fa emergere quello spirito identitario che ha delineato la sua esistenza. Come molti altri fiumani della sua generazione, Widmar conosceva sicuramente quattro lingue: l'italiano, il croato, l'ungherese e il tedesco. Aveva frequentato le scuole ungheresi e, tra le altre sue attività, va sottolineata anche quella di traduttore. Fin da giovane iniziò a collaborare con gli ambienti culturali fiumani e, più tardi, con

I3 Lettera di Osvaldo Ramous ad Antonio Widmar, 3 I agosto 1965 (archivio privato della famiglia).

I4 Lettera di Antonio Widmar a Osvaldo Ramous, 23 ottobre 1975 (archivio privato della famiglia), in Gerbaz Giuliano, "Antonio Widmar mediatore culturale e traduttore," 128. quelli ungheresi e italiani. ${ }^{15}$ Questa attività culturale si affiancò a un certo punto della sua vita alla carriera diplomatica, ma entrambi questi indirizzi, non in contraddizione uno con l'altro, confluirono in ciò che lo rese un intellettuale cosmopolita, aperto a «una cultura che superasse i confini territoriali e linguistici ${ }^{16}{ }^{16}$

\section{Osvaldo Ramous}

Osvaldo Ramous, personalità di spicco dell'area istro-quarnerina, ha lasciato una traccia indelebile nella storia della letteratura fiumana.

\section{Ramous rappresenta la continuità di una let- teratura italiana autoctona dell' istroquarne- rino. La sua produzione letteraria è nata in un periodo in cui Fiume era parte dell'Un- gheria, si è sviluppata in direzione ermetica durante la Fiume italiana ma non ha smesso di esistere nemmeno negli anni successivi, con l'annessione della città alla Jugoslavia. ${ }^{17}$}

Il poligrafo fiumano ci ha lasciato un'eredità preziosa: undici libri di poesia, nove drammi dei quali cinque inediti, due raccolte di racconti, due romanzi, circa quattrocento tra articoli e saggi pubblicati su varie riviste, numerosi radiodrammi. Inoltre, ha firmato quarantasei regie del Dramma Italiano. «Innanzitutto poeta ma pure narratore, drammaturgo, giornalista, critico letterario e teatrale, traduttore, regista e direttore del Dramma Italiano, tradotto in tante lingue, conosciuto nell'America latina, vincitore di numerosi premi e riconoscimenti, Osvaldo Ramous rimane sconosciuto a molti». ${ }^{\text {r\$ }}$

Nell'Archivio di famiglia sono custoditi numerosi carteggi che forniscono una chiave di lettura particolare per ricostruire la sua personalità complessa e non solo letteraria. Nello scambio epistolare con diversi intellettuali appartenenti

is Gerbaz Giuliano, "Antonio Widmar mediatore culturale e traduttore," 125 .

I6 Gerbaz Giuliano, "Antonio Widmar mediatore culturale e traduttore," 129

I7 Corinna Gerbaz Giuliano e Gianna Mazzieri-Sanković, Non parto, non resto... I percorsi narrativi di Osvaldo Ramous e Marisa Madieri (Trieste: Deputazione di Storia Patria per la Venezia Giulia, 2013), 9.

I8 Gerbaz Giuliano e Mazzieri-Sanković, Non parto, non resto... I percorsi narrativi di Osvaldo Ramous e Marisa Madieri, 9. 
alla medesima area che hanno dovuto abbandonare il territorio in seguito alle vicende belliche, emergono il più delle volte pensieri intimi, dubbi e incertezze. Lo testimoniano in particolare lo scambio di lettere con Morovich e con Widmar, che non sono da considerarsi dei semplici carteggi, ma sono indubbiamente un qualcosa di più: sono memorie, racconti intimi, documenti fondamentali dai quali emergono momenti di storia vissuta, visioni personali e impronte culturali.

Ramous impersona una realtà specifica,
quella che segna l'esistenza degli italiani su
queste terre in un periodo tra i più travaglia-
ti, percorso da due guerre mondiali e per di
più in un ambiente di confine che vede al-
terato spesso il volto della propria città. Ep-
pure ama la propria città anche quando sen-
te per le strade una lingua che non conosce
e si ritiene sempre più 'esule su questa terra.
Un atteggiamento che diventa paradigma di
modernità e vede Ramous definirsi cittadi-
no del mondo in una comunione ideale con
altri autori del periodo non solo italiani e ju-
goslavi ma pure portoghesi, brasiliani e sve-
desi. ${ }^{19}$

Osvaldo Ramous viene considerato oggi il maggiore scrittore fiumano di lingua italiana. Nato a Fiume nel 1905 e scomparso nella stessa città nel $198 \mathrm{I}$, crebbe in una famiglia numerosa. A soli due anni rimase orfano di padre, di professione meccanico, e la madre accettò l'aiuto del fratello a sostenere la famiglia. Nonostante le modeste condizioni economiche della stessa, in casa ci fu una ricca biblioteca che permise al giovane Osvaldo di conoscere i classici della letteratura straniera e italiana, tra cui Shakespeare, Molière, Dante, Petrarca, Ariosto e Goldoni. Nonostante un'infanzia difficile, grazie all'aiuto dello zio il giovane Ramous poté frequentare gli studi presso la scuola Comunale, l'Istituto Tecnico Leonardo da Vinci e l'Istituto Magistrale Egisto Rossi, ma anche quelli musicali alla

19 Gerbaz Giuliano e Mazzieri-Sanković, Non parto, non resto... I percorsi narrativi di Osvaldo Ramous e Marisa Madieri, ı.
Scuola comunale di musica, dove seguì gli studi di violino e pianoforte. ${ }^{20}$

Ramos fu un uomo di cultura, capace di immergersi in tutti gli aspetti che riguardavano la cultura italiana dell'ambiente in cui operava, promuovendola al di fuori del suo ambiente e dialogando con altri intellettuali che avevano i suoi stessi interessi, nonostante facessero parte di lingue e culture diverse. Fu poeta, prosatore, drammaturgo, traduttore. Si accostò al giornalismo collaborando con le riviste letterarie fiumane di inizio secolo (come "La Fiumanella" e "Delta", ma estendendo ben presto il suo campo d'azione a numerose altre riviste della penisola), immergendosi in quel fervido e stimolante dibattito culturale che operava nella Fiume di quegli anni e che avrebbe continuato fino alla conclusione della seconda guerra mondiale. Dal '30 al ' 42 fu redattore della "Vedetta d'Italia" e dal 1944 direttore della stessa. Nel dopoguerra, dal 1946 al 196I, fu direttore del Dramma Italiano. Curò 46 regie, tradusse in italiano numerose opere della drammaturgia jugoslava, scrisse nove drammi e una decina di radiodrammi, $\mathrm{Fu}$ autore di dieci raccolte di poesie tra cui $\mathrm{Nel}$ canneto (1938), Vento sullo stagno (1953), Pianto vegetale (1967), La parola nel tempo (1969), Realtà dell'assurdo (1973), Pietà delle cose (1977). Sono suoi pure due romanzi, I gabbiani sul tetto e Il cavallo di cartapesta, numerosi racconti, pubblicati in parte su riviste italiane e in parte confluiti nel volume Lotta con l'ombra e altri racconti (2006) e circa quattrocento articoli e saggi letterari pubblicati su riviste italiane, jugoslave, americane e francesi. ${ }^{2}$

Fiume nel secondo dopoguerra mutò drasticamente nella sua essenza: l'assetto politico e, di conseguenza, quello demografico e sociale risultarono ancora una volta, nel giro di qualche decennio, trasformati. Ramous, in questo nuovo contesto, continuò il suo operato culturale di tipo cosmopolita, di cittadino del mondo, atto a oltrepassare i confini laddove questi furono im-

\footnotetext{
20 Gerbaz Giuliano e Mazzieri-Sanković, Non parto, non resto... I percorsi narrativi di Osvaldo Ramous e Marisa Madieri, 47-48.

2 I Gianna Mazzieri, La Voce di una minoranza (Torino: La Rosa, 1998) 40.
} 
posti. Continuò così a tessere una rete di rapporti culturali che confluirono in collaborazioni e amicizie con numerosi intellettuali dell'epoca. Queste relazioni trovano la loro maggiore espressione nel ricco epistolario ramousiano presente nel lascito dell'autore. Gli intellettuali italiani e jugoslavi con i quali Ramous dialogava venivano coinvolti in discussioni riguardanti le loro ultime pubblicazioni, le possibili traduzioni reciproche, ma anche temi filosofici come la condizione dell'intellettuale e dell'uomo in genere. In questo senso sono significative alcune lettere che Ramous scrisse nella seconda metà degli anni 'so in cui denunciava apertamente le condizioni in cui si trovava a operare un autore il quale, trovandosi tra due nazioni il cui confine era stato stabilito da poco, non riusciva a esprimere fino in fondo il proprio potenziale. Così, in una lettera del I955 allo scrittore Mirko Božić rivela:

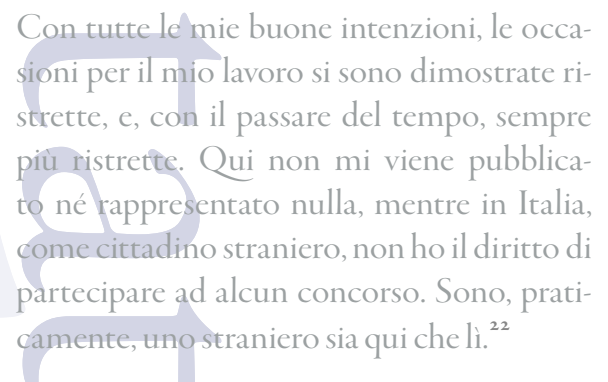

Ramous si sente straniero sia in Jugoslavia che in Italia. Nonostante abbia sempre scritto le sue opere in italiano, la lingua utilizzata non gli apre le porte del mercato editoriale in Italia. Lo stesso problema persiste anche in Jugoslavia, perché Fiume, dal secondo dopoguerra, ha come lingua ufficiale una lingua che non è l'italiano. Tutto ciò avveniva nonostante il fatto che Ramous avesse sempre cercato di mantenere vivo il dialogo tra scrittori italiani e jugoslavi. Prova ne sono le lettere con gli intellettuali jugoslavi e italiani dell'epoca (Drago Ivanišević, Augustin Stipčević, Eraldo Miscia, Ante Cettineo, Enrico Morovich, Antonio Widmar, Ugo Longo, Giacomo Oreglia, Andrè Charmel, Bino Rebellato

22 Ramous Osvaldo, lettera a Mirko Božić, 8 settembre 1955, custodita nell'archivio di famiglia e riportata in Gianna Mazzieri-Sanković e Maja Đurđulov, "Intorno agli scambi epistolari di Osvaldo Ramous," Quadernigiuliani distoria, n. 36/I (2015): I 17. ecc.) attraverso le quali cercava di far dialogare i due mondi culturali.

Una delle iniziative di Ramous che rientrano in questo programma è la pubblicazione nel 1959 del volume Poesia jugoslava contemporanea. Prima traduzione in lingua italiana che, in un periodo in cui la poesia jugoslava era quasi sconosciuta nella penisola, fu una delle prime antologie del genere in Italia. ${ }^{23}$ Qualche anno più tardi, nel 1964, organizzò a Cittadella il primo incontro tra scrittori italiani e jugoslavi.

Nonostante il suo impegno per promuovere il dialogo culturale tra le due sponde dell'Adriatico, Ramous incontrò nel suo percorso non pochi ostacoli, provenienti addirittura da qualche intellettuale della sua città. $\mathrm{Al} 2^{\circ}$ Festival della poesia jugoslava, organizzato a Fiume nel 1958, Ramous non venne invitato per cui denuncia il fatto in una lettera del 5 giugno 1958 indirizzata all'Associazione dei letterati della Croazia e al Consiglio dei letterati della Jugoslavija a Belgrado:

$$
\begin{aligned}
& \text { Al festival della poesia jugoslava, tenutosi a } \\
& \text { Fiume dal } 3 \text { I maggio al } 5 \text { giugno, non sono } \\
& \text { stato invitato né come poeta, né come tra- } \\
& \text { duttore, né come organizzatore, né in al- } \\
& \text { cun altra funzione. [...] Sono venuto a cono- } \\
& \text { scenza (e sono autorizzato a riportarlo) del } \\
& \text { fatto che durante una riunione, svoltasi a Za- } \\
& \text { gabria tra i membri della giuria del festival e } \\
& \text { alcuni rappresentanti dell'ambito educati- } \\
& \text { vo di Fiume, sia stato previsto il mio invito } \\
& \text { al Festival, al quale, però, si è opposto il pre- } \\
& \text { sidente del Consiglio per la cultura del cir- } \\
& \text { condario fiumano (direttore, tra l'altro, del } \\
& \text { Novi list') Milan Slani, dichiarando che tale } \\
& \text { invito sarebbe stato discusso a Fiume a causa } \\
& \text { di questioni specifiche di questa città'. [...] La } \\
& \text { mia esclusione dal festival ha una connota- } \\
& \text { zione molto negativa se si prende in conside- } \\
& \text { razione il fatto che al festival sia stato invita- } \\
& \text { to anche il poeta Luigi Fiorentino, direttore }
\end{aligned}
$$

23 Elvio Guagnini, "Osvaldo Ramous mediatore tra culture. Il critico e il giornalista," in Osvaldo Ramous. L'impegno culturale e critico, a cura di Gianna Mazzieri Sanković (Fiume: Edizione della Comunità degli Italiani di Fiume, 2008), 23. 


\begin{abstract}
della rivista 'Ausonia' (di Siena), alla quale collaboro. Fiorentino, naturalmente, non ha potuto non notare che - mentre lui stesso è un italiano residente in Italia invitato al festival - l'unico autore della minoranza italiana, invece, che abita a Fiume, è stato escluso dal festival. [...] Questo atteggiamento nei miei confronti mi colpisce ancora di più se penso a quanti anni ho sacrificato per dedicare una buona parte del mio impegno letterario alla traduzione e alla diffusione della letteratura jugoslava all'estero. [...] In questi giorni ho terminato un'antologia di poesia jugoslava contemporanea ( 52 autori, 86 poesie), che verrebbe stampata quest'anno da Dino Rebellato, editore di Padova. Per questa, come anche per le traduzioni degli altri autori jugoslavi, stampate all'estero, non ho mai cercato né riceverò mai alcun compenso. ${ }^{24}$
\end{abstract}

Nella lettera emerge chiaramente la delusione dell'intellettuale che si impegna fortemente per il benessere della propria città, cercando di promuovere la collaborazione tra culture diverse e di mantenere a Fiume un pluralismo linguistico, letterario e culturale, ma al quale questo tipo

24 »Na II. jugoslavenski festival poezije, koji se je održao u Rijeci od 3I.V. do 5.VI., ja nisam bio pozvan ni kao pjesnik, ni kao prevodilac, ni kao organizator, ni u bilo kojem drugom svojstvu. (...) Saznao sam (a ovlašten sam da to i saopćim), da je na jednom sastanku, održanom u Zagrebu izmedu književnika festivalskog žirija i nekih predstavnika prosvjete iz Rijeke, bilo predvideno da i ja budem pozvan na Festival, ali da se je tome suprotstavio predsjednik Savjeta za kulturu kotara Rijeka (koji je ujedno i direktor riječkog „Novog lista”) Milan Slani, izjavivši da će se taj moj poziv prodiskutirati u Rijeci radi 'specifičnih prilika ovoga grada'. Moje isključenje iz festivala ima vrlo neugodan značaj ako se uzme u obzir da je na taj festival pozvan i pjesnik Luigi Fiorentino, direktor revije "Ausonia” (iz Siene) u kojoj ja suradujem. Fiorentino, naravno, nije mogao a da ne primjeti da - dok je on, Talijan iz Italije primio poziv- dotle je jedini pjesnik talijanske manjine, koji živi u Rijeci, iskljućen iz tog festivala. (...) Ovaj stav prema meni pogada me tim gorče kad pomislim koliko sam svojih godina žrtvovao posvetivši dobar dio svoga književnoga rada prijevodima i difuziji jugoslavenske literature u inozemstvu (...), a ovih dana upravo sam završio rad na jednoj antologiji suvremene jugoslavenske poezije ( 52 pjesnika, 86 pjesama), koju bi štampao ove godine Bino Rebellato, nakladnik iz Padove. Za taj, kao i za ostale prijevode jugoslavenskih pjesnika, štampane u inozemstvu, niti sam tražio niti ću primiti nikakva honorara «. Ramous Osvaldo, 8 settembre 1955, lettera custodita nell'archivio di famiglia e riportata in Gianna Mazzieri-Sanković e Maja Đurđulov, "Intorno agli scambi epistolari di Osvaldo Ramous," I 16 (traduzione delle autrici) di attività, per svariati motivi, viene spesso ostacolata.

\section{Enrico Morovich}

Nel ricco epistolario ramousiano troviamo testimonianze anche di chi sta dall'altra parte, di chi ha deciso di intraprendere la sofferta via dell'esodo da Fiume. Tra questi c'è Enrico Morovich, scrittore fiumano nato nel 1906 e stabilitosi a Genova nel 1958 dopo un periodo di spostamenti lungo la penisola italica. Come riportato nella nota biografica curata da Marina Petronio, ${ }^{25}$ Morovich a diciott'anni conseguì il diploma di ragioniere. Nonostante maturasse nell'intimo la vocazione dello scrittore, fu impiegato presso la Banca d'Italia prima e i Magazzini Generali di Fiume poi. Nel 1929 iniziò la collaborazione con le riviste "La fiera letteraria" e "Solaria". Nel I950 lasciò Fiume e visse prima a Napoli, poi a Busalla, Lugo, Pisa e nel 1958 prese dimora fissa a Genova, dove lavorò presso il consorzio portuale. Collaborò con riviste e giornali importanti, come "Il Mondo", "La Nazione”, "Il Caffè, "Il Giornale d'Italia” ecc. La sua produzione comprende raccolte di racconti (L'osteria sul torrente, Miracoli quotidiani, I ritratti del bosco, Nostalgia del mare, Ascensori invisibili, Racconti di Fiume e altre cose, Notti con la luna), romanzi (Non era bene morire, Contadini sui monti, Il baratro, Piccoli amanti, finalista al Premio Strega, La caricatura, I giganti marini) e poesie (Cronache vicine elontane).

Nella corrispondenza tra Morovich e Ramous, il primo confessa all'amico alcune delle difficoltà che pure lui trova nell'ambito editoriale italiano, come fa Ramous nella già citata lettera a Mirko Božić. Morovich, tuttavia, in questa situazione non auspica una sorte diversa di quella che gli è toccata ma attribuisce proprio al suo percorso fiumano il merito per la sua propensione alla scrittura:

\footnotetext{
Sono escluso da un' importante antologia di Solaria, ma non credere ch'io abbia prote-

25 Marina Petronio, "Enrico Morovich: cenni biografici" in L'ultimo sapore della vigna, a cura di Enrico Morovich, (Trieste: LINT, 2002), 199-20I.
} 
stato o che mi sia lamentato da qualche par-

te. Sto bene cosi e non mi sento affatto ab-

bandonato ed occulto, penso piuttosto che

se avessi avuto la loro fortuna o il destino di

cominciare a lavorare a Genova invece che a

Fiume, non avrei mai scritto nulla, sarei ma-

gari diventato agente di borsa [... ${ }^{26}$

Per Morovich la nascita e la vita a Fiume rappresentarono le condizioni necessarie per essere divenuto quello che era: un artista, uno scrittore la cui città natale ha saputo innestare in lui lo spirito dell'espressione creativa. Una città che ha subito determinati processi politici e culturali importanti nel corso del Novecento e che, in tutto questo tempo, fu impregnata da quello che Marina Petronio definisce «fervore letterario cosmopolita $\gg .{ }^{27}$ La stessa studiosa nota come Morovich ne sia uno degli esempi caratterizzanti: in casa sua, «oltre alla conoscenza della madrelingua, erano di casa il tedesco e l'ungherese». ${ }^{28}$ Inoltre, Fiume fu, non a caso, la città di numerosi germanisti e studiosi di lingua e cultura ungherese. È proprio da Fiume che, tra il XIX e il XX secolo, partirono le prime traduzioni in lingua italiana di testi letterari ungheresi. Gli intellettuali fiumani, perfettamente bilingui ed esperti della cultura ungherese, avviarono un processo di scambi culturali: le prime traduzioni erano destinate al pubblico fiumano ma, successivamente, si iniziò a tradurre anche per le grandi case editrici italiane. È proprio così che attività del genere, che erano state avviate a finalità didattiche, finirono per espandersi su larga scala creando riviste culturali e letterarie e dando vita a collane di traduzione di opere ungheresi presso i più rinomati editori italiani. Alcuni degli intellettuali fiumani che fecero parte della generazione che avviò questo genere di traduzioni dall'ungherese furono Enrico Burich, Silvino Gigante, ma anche altri, come Antonio Widmar e Paolo

26 Morovich Enrico, lettera a Osvaldo Ramous, 8 agosto 1975, riportata in Gianna Mazzieri-Sanković, "Lettere fiumane. Morovich e Ramous: due scelte," Archeografo Triestino, s. IV v. LXVIII. (2008): 230.

27 Marina Petronio, "Premessa", in L'ultimo sapore della vigna, a cura di Enrico Morovich, (Trieste: LINT, 2002), 6

28 Marina Petronio, "Premessa", 6.
Santarcangeli, che continuarono la loro opera di mediazione culturale anche dopo aver lasciato Fiume. Tra gli autori ungheresi più tradotti troviamo molti scrittori rinomati, autori di veri capolavori, come Ferenc Molnár e Ferenc Herczeg, i quali, grazie al successo che ottennero presso il pubblico italiano, aprirono le porte in Italia alle traduzioni di quegli autori che la critica considera come i più importanti della letteratura ungherese moderna. ${ }^{2}$

Fiume fu indubbiamente un crocevia di culture e lingue, ma lo fu pure la vicina Sussak. Di quest'ultima viene spesso sottaciuto lo spirito altrettanto cosmopolita. In una lettera del 1984 indirizzata a Rinaldo Derossi, Morovich sottolinea la multiculturalità di Sussak:

\section{Era una piccola Babilonia come Fiume. Fu lì che da ragazzino imparai a scrivere tutti i cognomi fossero polacchi o boemi e che ve- devo subito passato il ponte entrando a Sus- sak nomi di bottegai come Angelini, Turina e cosi via. ${ }^{30}$}

In un'altra lettera, Morovich racconta la situazione linguistica della sua famiglia:

In casa quando eravamo bambini le zie sorelle del babbo ci parlavano il tedesco e siccome in casa tutti parlavano il fiumano eravamo abituati al bilinguismo.

Per tacere il piccolo dramma dell' iscrizione nelle scuole ungheresi di Fiume nel I9I3. Infatti una zia che insegnava nelle scuole ungheresi, intuì che avrei imparato anche l'ungherese con facilità [.... In casa c'erano delle riviste in lingua ungherese, ma non ricordo d'aver visto alcun libro illustrato. ${ }^{3 \mathrm{I}}$

Ciò che rimane a Morovich, dopo una vita vissuta a Fiume e un'altra vissuta fuori da Fiume, sono anche i ricordi. Ricordi che riaffiorano a Genova, città per molti versi simile alla sua cit-

29 Peter Sárközy, "Le traduzioni italiane delle opere letterarie ungheresi," Rivista distudi ungheresi, ns., n.3 (2004), 7-10.

30 Morovich Enrico, lettera a Rinaldo Derossi, 15 maggio 1984, in Morovich, L'ultimo sapore della vigna, 54

31 Morovich Enrico, lettera a Rinaldo Derossi, 22 luglio 1987, in Morovich, L'ultimo sapore della vigna, 116. 
tà natale, la quale mantiene le sue radici sempre salde nello scrittore. Questo ha spesso ribadito il suo sentirsi a proprio agio anche fuori da Fiume:

\section{Penso che di tanto in tanto sarebbe bene parlare magari un po' della nostra vita di esu- li in Italia. Nessuno può liberarsi delle pro- prie radici, ma pure, tante volte qui, quanto a Napoli, in Romagna e in Toscana mi sono sentito perfettamente a mio agio e in certo senso anche felice. ${ }^{32}$}

Ma sono proprio le radici che rimangono in Morovich, quelle radici che non si possono estirpare e rimangono nell'individuo ovunque lui vada. Sono radici soprattutto culturali le quali, più che attaccarsi all'individuo, sono origini a cui l'individuo si attacca:

Sono commosso. E rido. Di me, di noi che se anche ci trasferissimo a Parigi, dove senza imbarazzo finiremmo per parlare francese e anche per scriverlo, resteremmo sempre gente delle nostre parti.

I sogni mi dicono che le radici per quanto ci si allontani, restano sempre attaccate. Ossia noi attaccati alle radici. In sogno mi sono trovato anche in America. Ma senza farci gran caso. Una volta annotavo i miei sogni. Ora non più.

I buoni sono indimenticabili, gli altri svaniscano pure. ${ }^{33}$

\section{Conclusione}

Personaggi del calibro di Widmar, Ramous e Morovich sono nati e cresciuti in un contesto che non solo era plurilingue, ma era il punto d'incontro e di passaggio di altrettante culture. È significativo che essi abbiano poi intrapreso dei percorsi personali che, sebbene molto diversi tra di loro, hanno una matrice in comune, e cioè l'impegno di tipo interculturale, che ha

32 Morovich Enrico, lettera a Rinaldo Derossi, senza data, in Morovich, L'ultimo sapore della vigna, I6.

33 Morovich Enrico, lettera a Rinaldo Derossi, 27 marzo 1987, in Morovich, L'ultimo sapore della vigna, 108. mantenuto sempre salde le loro radici identitarie. Nonostante avessero operato in modi diversi e spesso contrastanti uno rispetto all'altro, e di conseguenza avessero avuto sorti di vita differenti, questo contributo ha voluto dimostrare come ci siano dei motivi che si ripetono e ritornano in ciascuna delle storie raccontate.

Il modello culturale che Fiume ha offerto loro e l'attaccamento per questa città hanno influito fortemente sul loro operato, il quale trova espressione nelle loro opere e nella corrispondenza personale che ci è disponibile. Questa espressione è diversa da caso a caso e dipende in parte dalle differenti vicende biografiche. In Widmår è evidente la curiosità per le diverse culture compresenti in lui, in primis quella italiana e quella ungherese, ma anche l'apertura a nuovi mondi e spazi, visibile anche, per esempio, nell'interesse per la cultura giapponese, coltivato durante gli anni di permanenza in Giappone come diplomatico dell'ambasciata italiana.

Anche in Ramous sono presenti questi tratti, nonostante egli avesse avuto una sorte ben dissimile da quella di Widmar e da Morovich, essendo l'unico dei tre a essere rimasto a Fiume per tutta la vita. Anche se Fiume durante la sua vita aveva cambiato diverse volte lingua e nazionalità, egli si assunse il compito di far dialogare i diversi mondi che vi transitavano e si compenetravano.

Scrivendo a proposito delle riviste fiumane degli anni '20, "La Fiumanella" e "Delta”, Ervin Dubrović sottolinea:

Gli intellettuali raccolti attorno a questi pe riodici erano di cultura italiana, ma, passata la sbornia dovuta alla pronunciata ostentazione d'italianità, essi avevano acquisito un orientamento cosmopolita essendo perfettamente consci della posizione culturale di Fiume, trait d'union tra il mondo limitrofo slavo e le vicine culture mitteleuropee, ri conoscendo alla propria missione il ruolo di intermediaria fra dette culture per cui aspiravano a far conoscere agli italiani la cultu- 
ra slava e agli slavi la letteratura e l'arte italiane

Ciò che accomuna, però, tutti questi personaggi è la loro città natale, perché è essa che, in fondo, è il comune denominatore tra tutti loro. Fiume si delinea, così, con le sue molteplici culture e lingue, come punto d'incontro tra biografie, storie e destini diversi, addirittura contrastanti tra di loro, ma pienamente unitari nella volontà di salvaguardare e ricordare la preziosa identità di questa città.

\section{Povzetek}

Članek obravnava pisma reških intelektualcev, kot so bili Osvaldo Ramous, Antonio Widmar in Enrico Morovich, ki še najprej dokazujejo njihov odnos do identitete, ki jo je oblikovalo enkratno okolje, v katerem so odraščali in bili vzgojeni. Specifika Reke na začetku 20. stoletja je bila namreč večkulturnost mesta, ki je imelo dolgo tradicijo večjezičnosti in je v nekaj desetletjih kar petkrat zamenjala politično upravo.

Omenjeni avtorji izražajo svojo večkulturnost na različne načine. Iz njihovih pisem drugim avtorjem, novinarjem in publicistom izhajajo namreč zanimive tematike, kot so lahko položaj pisatelja v novih političnih razmerah in splošni stiki med raznimi kulturami, s katerimi prihajajo vsakodnevno v stik tako v literarnem kot splošno družbenem življenju.

Članek vsebuje tako abstraktna (filozofske in jezikovne) kot praktična (zgodovinske in politične) razmišljanja, ki izhajajo iz pisem prej omenjenih avtorjev, in dokazujejo predvsem identifikacijo identitete s kompleksnim jezikovnim, političnim in kulturnim okoljem. Cilj raziskave je analizirati kompleksne tematike, ki so vzklile iz večkulturne identitete reških intelektualcev, ki so uporabljali italijanščino v času pomembnih političnih, jezikovnih in kulturnih sprememb na Reki, - a tudi v Evropi - in so poskušali definirati bistvo svoje identitete.

Kljucne besede: kulturni krogi na Reki, italijanski jezik, medkulturna identiteta, Reka

\section{Summary}

This paper analyses the letters of intellectuals from $\mathrm{Ri}$ jeka, such as Osvaldo Ramous, Antonio Widmar, En- rico Morovich, which demonstrate their relationship to identity, determined primarily by the unique environment in which they grew up and gained their education. The specificity of Rijeka at the beginning of the 2oth century is the multiculturalism of a city that has a long tradition of multilingualism and in just a few decades changes five times the political system.

These authors express their multiculturalism in different ways. From their mutual letters, and letters to other writers, journalists and publishers, derive interesting topics, such as the position of the writer in the new political environment and the general connections between various cultures with which they relate in their literary activities and in everyday life.

This paper presents some abstract (philosophical and linguistic) and practical (historical and political) considerations which can be read from the letters of the aforementioned intellectuals and which are based on the identification of the identity with a complex linguistic, political and cultural environment. The aim of this study is to analyse the complex issues arising from the multicultural identity of Rijeka's writers who used Italian in the years of important political, linguistic and cultural changes - in Rijeka, but also in Europe - and were trying to define the core of their identity.

Keywords: cultural circles in Rijeka, Italian language, multicultural identity, Rijeka

\section{Bibliografia}

Assmann, Aleida. Ricordare. Forme e mutamenti della memoria culturale. Bologna: Il Mulino, 2002.

Barthes, Roland. "Introduzione all'analisi strutturale dei racconti.” In L'analisi del racconto, 5-46. Milano: Bompiani, 1996.

Darby, Henry Clifford, Seton-Watson, Robert William, Auty, Phyllis, Laffan, Robert George Dalrympl, e Clissold Stephen. Storia della Jugoslavia. Gli slavi del sud dalle origini a oggi. Torino: Einaudi, 1969.

Dubrović, Ervin. "Francesco Drenig. Personaggio d'avanguardia e guida spirituale dei giovani." La Battana, n. speciale 2. (1997): 33-36.

Gerbaz Giuliano, Corinna. "Antonio Widmar mediatore culturale e traduttore." 
Quaderni giuliani di storia, n. 36/1. (2015): I2I-I29.

Gerbaz Giuliano, Corinna. "Intorno agli scambi filosofici nel carteggio RamousWidmar." In Osvaldo Ramous. L'impegno culturale e critico, a cura di Gianna Mazzieri Sanković, 75-87. Fiume: Edizione della Comunità degli Italiani di Fiume, 2008.

Gerbaz Giuliano, Corinna e MazzieriSanković, Gianna. Non parto, non resto... I percorsi narrativi di Osvaldo Ramous e Storia Patria per la Venezia Giulia, 2013.

Guagnini, Elvio. “Osvaldo Ramous mediatore tra culture. Il critico e il giornalista." In Osvaldo Ramous. L'impegno culturale e critico, a cura di Gianna Mazzieri Sanković, 23-34. Fiume: Edizione della Comunità degli Italiani di Fiume, 2008.

Jabès, Edmond. Uno straniero con, sotto il braccio, un libro di piccolo formato. Milano: SE, I99I.

Jedlowski, Paolo. Il senso del passato. Per una sociologia della memoria. Milano: Franco Angeli, I99I.

Mazzieri-Sanković, Gianna. "Lettere fiumane. Morovich e Ramous: due scelte." Archeografo Triestino, s. IV v. LXVIII. (2008): 227-239.

Mazzieri, Gianna. La Voce di una minoranza. Torino: La Rosa, 1998.

Mazzieri-Sanković, Gianna. "Osvaldo Ramous: un fiumano, cittadino del mondo." $\mathrm{La}$ Battana, n. speciale 2. (1997): 66-73.

Mazzieri-Sanković, Gianna, Đurđulov, Maja. "Intorno agli scambi epistolari di Osvaldo Ramous." Quaderni giuliani di storia, n. 36/I. (2015): IOI-I2O.

Milani, Nelida. "Appartenenza e separazione.” Civiltà istriana, ricerche e proposte. Etnia extra serie, n.I (1998): 289-310.

Morovich, Enrico. L'ultimo sapore della vigna. Trieste: LINT, 2002.

Morovich, Enrico. Non era bene morire.

Milano: Rusconi, 1992.

Rovatti, Pier Aldo. "L'io straniero e il silenzio della parola”. In Uno straniero con, sotto il braccio, un libro di piccolo formato, a cura di Jabès Edmond. Milano: SE, I99I.

Sárközy, Peter. "Le traduzioni italiane delle opere letterarie ungheresi." Rivista di studi ungheresi, ns., n.3 (2004): 7-I6. 


\title{
Paolo Sorrentino, la cultura della serie TV e Young Pope
}

\author{
Srećko Jurišić, Paula Jurišić
}

There must be some kind of way outta here

Said the joker to the thief

There's too much confusion

I can't get no relief

Bob Dylan, All along the watchtower

John Wesley Harding, 1967

Lultima opera di Paolo Sorrentino, Il papa giovane (2016, HBO - Sky Atlantic), segna una svolta importante nella poetica filmica del regista e sceneggiatore napoletano. Rispetto alle pellicole precedenti la serialità offre nuove possibilità narrative al regista generando così un genere e un linguaggio nuovi nella cinematografia italiana. L’articolo si prefigge come obiettivo l'analisi dettagliata della serie nonché l'esame dell'evoluzione della poetica di Paolo Sorrentino considerando che il regista sta preparando un film in due volumi.

Parole chiave: Paolo Sorrentino, cinema italiano, serie TV, The Young Pope, poetica

Zadnje delo Paola Sorrentina, Il papa giovane (2016, HBO - Sky Atlantic), predstavlja pomembno prelomnico v filmski poetiki neapeljskega režiserja in scenarista. $V$ primerjavi s prejšnjimi filmi ponuja pripoved $v$ več nadaljevankah nove možnosti naracije režiserju, kar odpira nove perspektive v italijanskem filmskem žanru in jeziku. Članek želi natačno analizirati serijo ter razvoj filmske poetike Paola Sorrentina upoštevajoč pedpostavko, da režiser pripravlja film v dveh nadaljevanjih.

Ključne besede: Paolo Sorrentino, italijanski film, televizijska nadaljevanka, Ilpapa giovane, poetika

a vasta progettualità e la grande mole di lavoro che si celano dietro il progetto 'papale' di Paolo Sorrentino ne lasciano intravedere la complessità che non si esaurirà in una sola stagione. Il cineasta partenopeo, infatti, intende sviluppare il proprio progetto con un follow up che vada al di là delle 9 ore e 6 minuti della prima serie avvalendosi del modello delle pluripremiate serie tv dal successo internazionale quali True Detective e Fargo (la cui prima stagione è l'addattamento dell'omonimo film dei fratelli Coen del '96) che stanno, per molti versi, rivoluzionando il mondo narrativo del piccolo schermo già da qualche anno. La lavorazione sarebbe durata più di due anni come ha affermato a più riprese Sorrentino e il punto di partenza, almeno quello visivo, sarebbe da ricercare in un'immagine curiosa:

\section{Il Papa vestito di bianco sulla neve fa lo sla- lom gigante tra le croci: è la prima scena che ho immaginato pensando a The Young Pope, e non la vedrete nella serie. Bellissima, ma nel processo di scrittura non ha trovato po- sto. Checchè ne dicano i miei detrattori non metto in un film una bella inquadratura a tutti i costi. Questa l'ho sacrificata, però mi piace raccontarla. ${ }^{\mathrm{I}}$}

L'immagine di Sorrentino richiama quella del papa Giovanni Paolo II, ipermediatico e quindi agli antipodi rispetto a Lenny Belardo, fotografato sulla neve anche se qualche dimostrazione d'interesse per l'universo vaticano la

\footnotetext{
Paolo Sorrentino, "The Young Pope. Paolo Sorrentino «Mi intrigava l'idea di un papa non riconducibile agli altri", Ciak magazine, (2 I ottobre 2016), http://www.ciakmagazine.it/the-young-pope-paolo-sorrentino-ami-intrigava-lidea-di-un-papa-non-riconducibile-ad-altria/\#BzpbtYiEjc6ODtlv.99 (21 ottobre 2016).
} 
si può trovare anche nella prefazione al volume fotografico dedicato a La grande bellezza dove Sorrentino raccoglie alcune impressioni delle sue prime visite a Roma («L'osservazione del grande, misterioso universo gravitante attorno al Vaticano era un'altra delle mie passioni $\gg)^{2}$ che poi ribadisce in varie interviste ( $\ll$ Roma è una città dove ci sono le categorie, molto più che altrove, a seconda delle zone puoi esplorare mondi. $\grave{E}$ bellissimo camminare in Vaticano e vedere tutto il mondo ecclesiastico che gravita lì intorno. Un cumulo di persone delle quali spesso a me sfugge il senso ultimo di quello che fanno»). ${ }^{3}$

Nel 2013, nel perodo in cui il regista stava montando La grande bellezza, nei cassetti gli scivolò la storia di un giovane papa americano, bello, conservatore e pieno di contraddizioni anche se lui era preso da un'altra santità, quella di padre Pio, passione nata dalla lettura della biografia del mistico di Pietrelcina firmata da Sergio Luzzatto che gli era piaciuta. A quel punto, Lorenzo Mieli, il produttore prodigio della Wildside, gli propone di farne una serie, ma Sorrentino nicchia perché

in tv di padri Pii ce n'erano stati già due, e un terzo, per quanto diverso, non mi pareva il massimo. Gli ho prospettato invece questa storia sul Vaticano e mi sono messo a scribacchiarla, sicuro che, in un Paese come il nostro, sarebbe stata lettera morta. Invece Mieli mi ha preso sul serio, ha combattuto per realizzarla; è intervenuta massicciamente Sky, poi siamo andati da Hbo, che per la prima volta ha coprodotto una serie europea. È un pionierismo di cui siamo fieri: ha aperto la strada a progetti come la saga della Ferrante e il Limonov di Carrère. I più grandi producer di serie tv al mondo chiedono a noi

2 Paolo Sorrentino, La grande bellezza. Diario del film, Milano, Feltrinelli, 2013, p. 9. Alessandra Coppola, Paolo Sorrentino si confessa: Il mio non è un lavoro per persone intelligenti», in Corriere della Sera, 2 maggio 2011).

3 Alessandra Coppola, Paolo Sorrentino si confessa:«Il mio non è un lavoroperpersone intelligenti», in Corriere della Sera, 2 maggio $201 \mathrm{I}$. italiani se abbiamo qualcosa di buono e dicono: bene, facciamola insieme. ${ }^{4}$

Il lavoro che ha accompagnato il Papa giovane proseguirà, dunque, offrendo nuovi spunti di riflessione con altre stagioni, indipendenti l'una dall'altra mentre l'idea della serialità pare si stia estendendo anche ai film di Sorrentino (è da poco uscito nelle sale Loro, il film su Berlusconi, in due parti.

Le serie americane menzionate appena più su, viste da Sorrentino su suggerimento, nient'affatto peregrino, di Bernardo Bertolucci (anch'egli abile nello sviluppare lunghe narrazioni filmiche ad alto tasso di epicità (vedi Novecento (1976) con le sue 5 ore e 17 minuti di durata) hanno avuto un peso nella scelta televisiva di Sorrentino la cui spiccata propensione per la narratività di celluloide ad ampio respiro l'avevano già avvicinato al mondo delle serie tv in passato (era tra gli autori della Squadra), ma senza che si realizzasse nulla di concreto:

Ne La Giovinezza, nel monologo di Jane Fonda, si parla di televisione. E sembra un po' un modo per mettere le mani avanti: la tv, dice Fonda, non è sminuente, ma anzi forse è proprio il futuro.

$\mathrm{Al}$ di là di quello che dice Jane Fonda in Youth, perché quello è un personaggio e dice quello che deve dire in quella scena, la mia idea è molto semplice: il racconto televisivo, che ti consente di lavorare sulle durate, su cose altrimenti impensabili al cinema, dove le gabbie, i tempi sono molto più rigidi,

4 Paola Zanuttini, "Papale papale: intervista a Paolo Sorrentino su "The Young Pope". La Repubblica, 26 settembre 2016. http://www. repubblica.it/venerdi/interviste/2016/og/26/news/papale_papale_ intervista_a_paolo_sorrentino_su_the_young_pope_-148575057/ (21 ottobre 2016).

5 «on sono uno spettatore bulimico di serie. Bertolucci mi ha suggerito di vedere True Detective, e io ho obbedito. Ė un progetto favoloso, che stravolge il genere. Poi ho visto le due meravigliose serie di Fargo. La buona televisione offre questa folgorante opportunità di prolungare il rapporto con la forza delle immagini cinematografiche e, allo stesso tempo, utilizzare un'ampiezza che è propria del romanzo e che il cinema spesso è costretto a sacrificare». ( $\mathrm{Pa}$ olo Mereghetti, «La grande bellezza» integrale. Sorrentino: «Cosi diventa estenuante come il racconto della vita», in Corriere della Sera, 25 giugno 2016, http://www.corriere.it/spettacoli/16_giugno_26/ grande-bellezza-integrale-racconto-estenuante-vita-sorrentino- $7 \mathrm{fc}$ cre9a-3afb-11e6-ao19-9orbc4c9foro.shtml\#, 21 ottobre 2016). 
e si deve obbedire a durate standard, è un'opportunità meravigliosa. Un'opportunità che io ho inseguito non da poco, devo dire. $\mathrm{Ma}$ per tanto tempo. Ho cercato di girare una serie televisiva con una certa libertà, sia creativa che economica, anche tanti anni fa. Ma non c'erano i presupposti. C'era una specie di dittatura del funzionario televisivo. Che diceva si fa così, devi dire questo, c'è questo pubblico e c’è quest'altro. E questo smorzava tutti i miei entusiasmi. Poi, finalmente, il mercato italiano è cambiato. Finché non c'è stato un cambiamento, esatto. Un'accelerata che è stata impressa dagli americani, che hanno dato vita a delle serie dove si è intelligentemente preso tutto il buono del grande cinema e tutto il buono delle possibilità televisive, e anche tutto il buono del romanzo. Perché la serie televisiva ha un'ampiezza di racconto e una capacità di divagazione che ti puoi permettere nel romanzo.

Quindi anche lei crede che le serie tv siano la "movaletteratura"?

Le serie televisive, per me, sono come quei figli particolarmente belli che vengono fuorida due genitori mediamente belli. Insomma, una serie televisiva può veramente essere il figlio bellissimo della letteratura e del cinema. ${ }^{6}$

Sorrentino, in un'altra intervista, dichiara anche:

Da sensazione e che la dimensione seriale sia congeniale al suo stile, gli conceda piu respiro. In parte è vero. Mi consente di mettere in campo molto materiale e allo stesso tempo mi obbliga a concentrarmi sul piano narrativo, che al cinema non considero determinante, mentre è fondamentale per tenere sulla distanza di dieci puntate. Sono un grafomane, scrivo tantissimo e nello spazio dilatato della serie riesco ad appagare la mia voglia di di

6 Gianmaria Tamaro, Paolo Sorrentino lancia la serie tv 'The Young Pope': "Il mio Papa vuole una Chiesa piu islamica", in Huffington Post, in ottobre 2016, http://www.huffingtonpost.it/2016/10/11/the-young-pope-sorrentino-papa-vuole-chiesa-islamica_n_12437424.html, 21 ottobre 2016)

\section{gressione, di moltiplicazione delle piste e dei personaggi che di puntata in puntata posso- no evolvere da comprimari a protagonisti c viceversa.}

Essendo Sorrentino un regista particolarmente attento alla scrittura, la serialità gli offre delle possibilità inusitate, delle vie non praticabili, insomma con il formato standard dei film. E sono le potenzialità che egli sfrutta sia dal punto di vista della densità della scrittura, molto stratificata, che della sua trasposizione filmica. ${ }^{8}$ A nostro parere, Sorrentino viaggia verso una forma ibrida dal momento che alle regole della spezzettata serialità $\mathrm{tv}$ non si piega in maniera rigida $\mathrm{e}$ che le lunghezze espressive per ottenere determinate atmosfere sono state già uno dei punti forti (e deboli, secondo una parte della critica) dei suoi film (Youth e La grande bellezza, su tutti). Il progetto berlusconiano, appena uscito, come anche la seconda stagione del progetto dedicato ai papi, daranno delle delucidazioni in questo senso e fanno parte della risposta 'europea' alle serie americane che si sono sovrapposte, negli ultimi anni, al cinema concedendosi certi lussi nel racconto che la coazione alla 'frettolosità', imposta dalle major e dal codice della consuetudine, precludeva o che, d'altro canto, lo schema episodico delle serie aveva obliterato del tutto. Sorrentino

s.n., "The Young Pope". Paolo Sorrentino «Mi intrigaval' idea di un papa non riconducibile agli altri», cit.

$8 \quad$ Altri esempi in questo senso: «Vous vous êtes entouré d'autres scénaristes familiers de la télévision. Est-ce pour intégrer la mécanique d'écriture de la série? Pas spécialement. J'ai suivi les règles qu'impose la série télé comme par exemple les cliffhangers (rebondissement, ndlr) qui terminent les épisodes, mais j’ai vraiment profité de la liberté que la longueur me donnait pour essayer de faire ce qu'en tant que cinéaste je ne peux plus faire : c'est-à-dire un grand film d'auteur qui dure plusieurs heures. Quelle autre liberté y avez-vous tronvé ?J'ai eu plus de place pour créer des moments de synthèses. Dans un film, ce sont des séquences assez brèves, des scènes mémorables, intenses - parfois même une simple image - qui vont tout résumer et permettre d'imprimer le souvenir de ce film dans le temps. Les séries télé manquent souvent de ces moments : même lorsqu'elles sont belles, on les oublie. Avec The Young Pope, mon défi était d'essayer de créer ces moments intenses, surprenants, des sommets de l'histoire qu'il faut, en quelque sorte, fixer.» (Isabelle Poitte, Paolo Sorrentino, réalisateur de "The Young Pope": "J'avais besoin de la dualité de Jude Law", in Télérama, 24 ottobre 2016 (http://www.telerama.fr/series-tv/paolosorrentino-j-avais-besoin-de-la-dualite-de-jude-law-pour-incarner-piexiii, 149062.php, 2 1 ottobre 2016). 
parte dai nuovi modelli americani ma per adeguarli alla sua poetica, insomma.

Ora, la conseguenza di queste mutazioni e osmosi tra generi consimili (vi accenna lo stesso Sorrentino in un'intervista a France Cultu$r e^{9}$ è in questo caso l'accentuata stratificazione di significati della serie e la sua densità contenutistica; esse rendono difficoltosa un'analisi dalle proporzioni accettabili in questa sede. Se ne potrebbe tentare, però, una lettura sintetica approcciando, per esempio, Young Pope dall'interessante sigla d'apertura. Quest'ultima compare dalla terza puntata (le prime due puntate erano più lunghe e invece di sacrificare una scena, il regista ha preferito sacrificare la sequenza iniziale) e contiene alcune delle chiavi di lettura possibili rivelandosi come un punto di partenza interessantissimo per un'analisi concentrata del Papa.

2. Questa la sigla: Jude Law, nei panni del pontefice, fresco di conclave, Pio XIII (un nome che lascia pensare ad un pontificato fortemente conservatore), passeggia sorridente in quello che può essere un salone dei Musei Vaticani mentre sullo sfondo vediamo susseguirsi delle opere d'arte che segnano le tappe importanti della storia della Chiesa inclusi alcuni momenti controversi come quelli raffigurati nei quadri di François Dubois (Massacre de la Saint Barthelemy le 24 août 1572) che raffigura il massacro degli ugonotti da parte della fazione cattolica) o nell' icona presente nel Monastero Mégalo Metéoron, in Grecia, che raffigura il Concilio di Nicea, che sancisce l'inizio di cesaropapismo; nella carrellata della sigla il regista non dimentica nemmeno la recente storia d'Italia, contenente non pochi punti oscuri: di Gerard van Honthorst, detto anche "Gherardo delle Notti", pittore influenzato dai maestri italiani e, in particolare, da Caravaggio, Sorrentino inserisce Adorazione dei Pastori che rimase gravemente danneggiata nell'attentato di via dei Georgofili a Firenze, compiuto da Cosa Nostra nella notte tra il 26 e il 27 maggio

9 Si tratta dell'intervista rilasciata a Olivia Gesbert il 3 I ottobre 2016 e ora disponibile al seguente link: https://www.franceculture.fr/emissions/la-grande-table-ıere-partie/young-pope-rencontre-avec-paolo-sorrentino.
1993. ${ }^{\text {10 }}$ La notte tra il 27 e il 28 luglio 1993 avvenne anche la strage di via Palestro a Milano (cinque morti e tredici feriti) e qualche minuto dopo esplosero due autobombe davanti alle chiese di San Giovanni in Laterano e San Giorgio al Velabro a Roma, senza però fare vittime: il giorno successivo due lettere anonime inviate alle redazioni dei quotidiani Il Messaggero e Corriere della Sera minacciarono nuovi attentati: la Chiesa, dunque, viene vista come parte attiva nelle complesse vicende politiche dell'Italia contemporanea come dimostra anche la scena dell'incontro tra Lenny Belardo e il premier, tratto da un modello piuttosto renziano, interpretato da Stefano Accorsi, in cui il neoeletto Sommo pontefice mostra al politico l'effettiva lunghezza della longa manus del Vaticano.

Jude Law è accompagnato, nella stessa sigla, da due cose: la prima è una specie di stella cometa, «la sua stella» (Matteo 2,I-I2.16), che l'accompagna di quadro in quadro per trasformarsi, alla fine della carrellata, in un meteorite e abbattersi sul papa Giovanni Paolo II visto da Maurizio Cattelan, uno degli artisti italiani più controversi in assoluto, nella scultura / istallazione La nona ora; ${ }^{\text {II }}$ il secondo elemento che accompa-

Io L'attentato in questione rientra nelle oscure dinamiche della cosiddetta Trattativa Stato - Mafia come dimostrano le motivazioni dei giudici fiorentini, oltre 500 pagine, della sentenza per il boss Francesco Tagliavia, accusato delle bombe del 1993: «Lo Stato avviò una trattativa con Cosa nostra, una trattativa che indubbiamente ci fu e venne quantomeno inizialmente impostata su un do ut des' per interrompere la strategia stragista di Cosa nostra. Lo scrivono i giudici della Corte d'assise di Firenze che hanno depositato le motivazioni della sentenza di condanna all'ergastolo di Francesco Tagliavia per le stragi del '93 a Firenze, Roma e Milano. E 'l'iniziativa - scrivono - fu assunta da rappresentanti dello Stato e non dagli uomini di mafia» (s.n., Stragi: «La trattativa mafia-Stato ci fu» Forza Italia non fu mandante delle stragi, in Il corriere fiorentino, $17 \mathrm{mar}$ zo 20I2, http://corrierefiorentino.corriere.it/firenze/notizie/cronaca/2012/12-marzo-2012/trattativa-mafia-stato-ci-fu-2003653215332. shtml?refresh_ce-cp, pagina visitata il 2 I ottobre 2016 .

I I La scultura s'intitola la Nona ora (1999, poliestere, resina, roccia vulcanica, tappeto, vetro, polvere metallica, lattice, cera, tessuto, con scarpe in cuoio e pastorale in argento) e raffigura, appunto, il papa Woytila schiacciato al suolo da un meteorite durante il suo incessante pellegrinare. Cattelan inizialmente aveva pensato il papa in piedi per poi segargli le gambe e inserire il meteorite. La Nona ora fa parte della cosiddetta Trilogia del Potere che racchiude, oltre alla la Nona ora, anche Him e Frank e Jamie. Il meteorite si abbatte dall'alto dei cieli sull' infaticabile pontefice riservandogli una fine piuttosto apocalittica considerata la fama mondiale di cui ha goduto durante il suo lunghissimo pontificato. Ciononostante, il livello di fama 
gna Jude Law nei panni di sornione flâneur nei titoli di testa è la canzone di Bob Dylan (qui nella versione di Devlin) All along the watchtower che gioca con quella specie di mistica laica, tanto cara al bardo di Duluth e ad altri cantautori della sua generazione con labili coordinate spazio temporali e riferimenti al libro di Isaia (2I, 5-9) che hanno per decenni confuso i critici nel tentativo di decrittarne i versi. La medesima apertura interpretativa ai limiti dell'arbitrarietà accompagna anche le azioni e le decisioni del pontefice sorrentininiano rendendolo assolutamente imprevedibile e, se si vuole, religiosamente inafferrabile. Alla stregua di una meteora il nuovo papa soppianterà il vecchio, così sovresposto nei media, inaugurando un pontificato all'insegna dell'assenza visto che Pio XIII si negherà ai fedeli.

Dice a proposito della sigla Sorrentino:

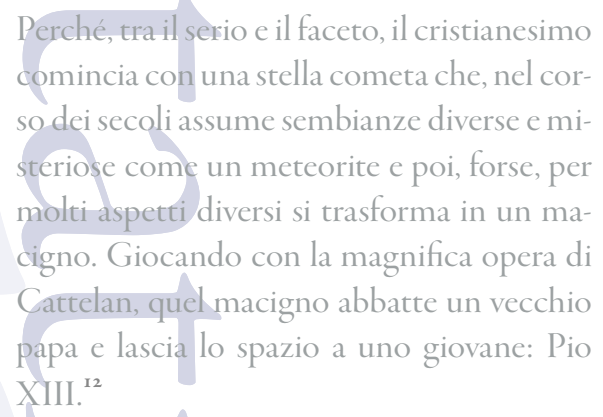

I richiami artistici sin dagli opening credits sono quindi tanti. La Nona ora di Cattelan con il suo sottotesto legato alle manifestazioni del potere (v. la nota 9 del presente lavoro) s' inserisce perfettamente nel disegno sorrentiniano legato

raggiunto, palesatosi attraverso tutti i paraphernalia del caso quali il merchandising ipertrofico e l'onnipresenza massmediatica generando non poche contraddizioni attorno a una figura devota alla Chiesa. L'istallazione controversa di Cattelan a Varsavia ha sollevato interrogativi circa l'ascesa vorticosa, da meteorite, del leader religioso cattolico e la sua fama. Non a caso il papa sorrentiniano eviterà di farsi vedere impedendo anche la produzione di gadget con la sua effigie. Su Cattelan si veda almeno Francesco Bonami, Nancy Spector (a cura di), Maurizio Cattelan, London Phaidon Press, 2003. Per l'interpretazione della Nona ora: Martin Kemp, Message frome the heavens, in Nature, n. 453, 2008, p. I 185.

I2 Lucio Perrotta, La sigla di The Young Pope spiegata da Paolo Sorrentino: "Quel Pio XIII somiglia a me", in Huffington Post, http://www.huffingtonpost.it/2016/11/18/quadri-sigla-young-pope_n_13074200.html, 21 ottobre 2016 alle stesse tematiche che pure sembra prevedere una trilogia:

Sorrentino, ha detto che il suo film migliore è "Il
divo" in cui raccontava il suo Andreotti. Adesso è
il turno del leader di Forza Italia.
«Sto scrivendo il film su Berlusconi, quando
lo farò lo interpreterà Toni Servillo».
Sembra affascinato dal potere, anche The young
Pope racconta cosa vuol dire muoversi nel potere
del Vaticano.
«Il tema del potere è dappertutto, è una del-
le tentazioni più forti del genere umano. Mi
viene da sorridere quando sento dire "Non
siamo governati bene": ci vuole saldezza mo-
rale per comandare. Che inevitabilmente si
erode, il potere prevede spesso l'abuso. È un
tema che mi affascina anche quando parlano
il carabiniere e il netturbino».

Inoltre, la passeggiata in solitario del papa nella sigla invita alla riflessione su un altro tema tanto caro a Sorrentino, quello della solitudine, strettamente legato al tema del potere. In una delle scene, il novello pontefice fa una sorta di elogio di chi rendendosi misterioso, negandosi ed isolandosi dal mondo o dal milieu in cui opera, accresce il proprio potere e la propria sfera d'influenza, esattamente come farà Pio XIII:

\section{Mi consenta, Santo Padre, questo che lei prospetta è un suicidio mediatico bello e buono.}

Come sono ingenue le università americane! Ma dico io, lei è francese, non le conveniva studiare lettere alla Sorbonna? Suicidio mediatico, dice lei? Adesso provi a seguirmi, se ne è capace.

\section{La seguo perfettamente.}

Chi è lo scrittore più importante degli ultimi venti anni? Faccia attenzione, non il più bravo, ma il più importante, quello che ha

13 Silvia, Fumarola, Paolo Sorrentino, dopo il Papa un film su Berlusconi: "Il potere, una delle tentazioni piu forti del genere umano", in Corriere della Sera, 8 aprile 2017 (http://www.repubblica.it/ spettacoli/cinema/2017/04/o8/news/paolo_sorrentino_berlusconi_ the_young_pope-162457314/,21 ottobre 2016). 
destato una curiosità così morbosa da diventare il più importante.

- Non saprei. Diciamo... Philip Roth.

No, è Salinger. Il regista cinematografico più importante?

Spielberg?

No. Kubrick. L'artista contemporaneo?

Jeff Koons o Marina Abramović.

No. Banksy. Il gruppo di musica elettronica?

- Non so nulla di musica elettronica.

E poi dice che Harvard è una buona università! Comunque, i Daft Punk. La più brava cantate italiana?

Mina.

- Brava. E lo sa qual è il filo rosso che unisce tutte queste figure che sono le più importanti nei loro rispettivi campi?

- No, non lo so.

- Non si fanno vedere. E non si fanno fotografare. $^{\mathrm{I} 4}$

L'interrogativo di Sorrentino, dalle tinte inevitabilmente autobiografiche, sembra ruotare attorno alla forza della solitudine ovvero dalla quantità di forza che un uomo solo (in questo caso al comando della Chiesa) può trarre dalla propria esperienza di orfano per farsi strada nella vita. La solitudine di Lenny va al pari passo con il suo potere, è isolato in Vaticano (persino Suor Mary e Dussolier, o anche il mentore Spencer gli voltano le spalle, a turno) e lo è anche sul piano personale a causa della sua condizione di orfano che, in ultima analisi, fa da propellente nel suo percorso di ricerca. In questo senso, la sigla d'apertura della serie si collega al finale in maniera circolare quando la cinepresa esce di scena uscendo di fatto dal mondo, passando attraverso le nuvole raffiguranti una figura crocifissa, una visione di Dio, si presume, dopo che i genitori gli hanno voltato ancora le spalle lasciandolo

14 Paolo Sorrentino, Il peso di Dio. Il Vangelo di Lenny Belardo, Torino, Einaudi, 2017, Pp. $24-25$ (d'ora in avanti PD seguito dal numero di pagina in coda alla citazione). solo nella solitudine definitiva. Anche dal puno di vista spaziale il percorso di Lenny si profila circolare: dalla macabra scena sognata in piazza San Marco, a Venezia, in cui da una pila di neonati morti ne emerge uno vivo si arriva, nell'ultimo episodio alla medesima piazza per l'explicit della serie. Su questo punto Sorrentino dice:

Nel primo episodio c’è una scena splendida in
piazza San Marco: da una piramide di neona-
ti apparentemente morti ne emerge uno vivo. Che
vuoldire?
«Non lo so, non lo so. A volte mi vengono
queste immagini, le trovo potenti, intense,
e decido di metterle, con disinvoltura, per-
ché nascono con un' intuizione istintiva. Poi
affiora un collegamento con la storia, una
plausibilità che, in questo caso, devo anco-
ra scoprire. Un bambino di sette anni abban-
donato ha necessariamente a che vedere con
la morte. E quella è una piramide di morte
perché quando i tuoi genitori ti abbandona-
no - non muoiono, ti abbandonano, ed è an-
cora più doloroso - non c’è niente di più vici-
no alla morte. Il fatto che Belardo, diventato
adulto, esca da questa morte e diventi una
guida dei vivi è una specie di resurrezione».

La resurrezione sognata da Lenny ha una sua valenza nell'economia del personaggio e della sua costante ambiguità, ma ne diremo più in là. Per ora basti ricordare che è un percorso inverso rispetto a quello compiuto da Cristo, che prima muore e poi resuscita. Ora, a non è dato saper se Lenny muoia o meno in seguito al malore perché, in fondo non è importante: ha compiuto la propria missione: nella folla radunatasi in Piazza San Marco ha trovato il proprio Dio credendo di individuare i propri genitori e vedendoli andarsene. Persino quest'ultimo fatto, per quanto dolente, perde in importanza nonostane essi siano stati l'oggetto di una vera e propria quête ${ }^{16} \mathrm{du}-$

is Paola Zanuttini, Papale papale: intervista a Paolo Sorrentino su "The Young Pope", cit.

I6 Per Sorrentino, non credente, Dio s'identifica sovente con qualche cosa che si desidera fortemente. Nel caso di Lenny si tratta dei genitori, un dettaglio, com' è noto che lo accomuna a Sorrentino stesso. In quel senso basti ricordare la scena di Youth (2015) in cui Fred 
rante l'intera serie impedendogli di governare la chiesa in maniera imparziale ed equilibrata perché Belardo guida la Chiesa finendo spesso ad essere guidato in maniera umana, troppo umana, dalle proprie paure e dalle proprie debolezze inducendo addirittura chi gli sta attorno a portare a suo cospetto dei genitori fasulli onde fargli credere che li abbia trovati. Il Giovane Papa va in crisi ad ogni acutizzarsi della sua condizione da figlio abbandonato, ma riesce, come conseguenza, a trovare sé stesso o ad andarci vicino nonostante le crisi d'identità (nelle puntate 7 e 8) che lo confondono, lo distraggono, gli fanno pensare di avere fallito.

Il giovane Pio XIII si accorge, continuando la sua ricerca che in un certo qual modo condivide con lo stesso regista, anch'egli orfano dall'età di diciasette anni, che in questo modo dichiara, adducendo il suo stesso esempio, che in fondo si è sempre ciò che si è come esseri umani mentre tutto il resto viene dopo. La nota frase, apocri$\mathrm{fa}$, di Novalis che Sorrentino mette in bocca ai suoi personaggi in Youth circa il ritorno alla casa paterna («Io sto sempre andando a casa, sempre alla casa di mio padre $\gg)^{17}$ vale anche qui e Lenny Belardo si affanna nella quasi disperata ricerca dei propri genitori che sembra che ogni suo gesto, inclusi i miracoli che gli vengono attribuiti siano gesti con cui o cerca l'approvazione da parte di chi lo ha abbandonato da bambino o cerca di attirare la loro attenzione con azioni fuori dal comune per colmare quell'assenza. Persino il suo negarsi ai fedeli può dare uno spunto in questa direzione:

\section{Il solo fatto che lei ha annunciato il suo primo viaggio pastorale e la prospettiva di una sua prima apparizione pubblica ha avu- to come riflesso un aumento del dodici per}

Ballinger (Michael Caine) e Mick Boyle (Harvey Keitel) contemplano la bellissima Miss Universo interpretata da Madalina Ghenea entrare in acqua e, consapevoli dell' irraggiungibilità della donna la chiamano Dio. Nella serie c'è una scena che conferma quanto appena detto nelle parole di Lenny: «Voi dovete rispondergli: 'Caro Jimmy, pensa a tutto quello che ti piace. Ecco, quello è Dio» (PD, 27)

17 Paolo Sorrentino, La giovinezza, Milano, Rizzoli, p. 129.

\section{cento delle richieste di partecipazione alla sua prossima messa in San Pietro. \\ La curiosità morbosa dell'assenza, Emi- nenza. So bene di cosa si tratta, essendo cre- sciuto come un orfano. (PD, 99)}

In generale, il pontificato di Belardo è un pontificato molto fisico, legato al corpo, nonostante egli paia una persona distaccata dalla fisicità. Il papa si allena (lo vediamo fare Pilates), e anche se all'apparenza rifiuta il buon mangiare quella nefasta diet cherry coke non è che un vezzo gastronomico come lo sono, per certi versi, anche le sigarette che il papa fuma costantemente. Il corpo, dunque, gioca un ruolo molto importante ed è declinato in varie sue espressioni: vecchiaia, obesità, giovinezza, bellezza, laidezza, spesso contrastanti in egual misura in cui lo è l'intero umanissimo pontificato di Lenny. A questo punto possono rientrare in gioco i riferimenti pittorici presenti nella sigla. Ci sono varie ipotesi circa le influenze pittoriche presenti nella serie con il solito Caravaggio che viene sovente associato all'arte di Sorrentino nonostante lo stesso regista si sia premurato a smentire tali influenze in qualche occasione. ${ }^{18}$ Il regista ne evidenzia, però, delle altre che per certi versi legano perfettamente all'opera di Cattelan mostrata in coda alla sigla. La Nona ora colpisce anche grazie all'estrema plasticità con cui è resa la dimensione fisica del papa polacco, talvolta cruda e iperrealistica anche se sempre contraddistinta da un certo pudore; è perfettamente in linea con la rappresentazione sorrentiniana della fisicità umana nella serie che deve molto, dice Sorrentino, a Lucian Freud e Otto Dix nei cui quadri non si fatica a rinvenire la medesima plasticità delle masse corporee con forme e rilievi forti. ${ }^{\text {I9 }}$ Inoltre, il

I8 «La luce caravaggesca dei quadri ricorre nella serie. Oltre ai lati oscuri di Lenny Belardo, c'è qualche altro personaggio che esce fuori dalle tenebre? Io trovo che si cominci ad abusare un po' troppo del termine "caravaggesco". Ogni qualvolta appaiono delle ombre o dei neri si tira in ballo Caravaggio. Ma vi assicuro che da quando lavoro col mio direttore della fotografia non abbiamo mai citato, neanche una volta, Caravaggio.» (Lucio Perrotta, La sigla di The Young Pope spiegata da Paolo Sorrentino, cit.).

19 «Lasciamo per un attimo da parte la sua passione musicale e parliamo di arte, altra fonte d'ispirazione. Le sue inquadrature hanno una bellezza pittorica: ci sono degli artisti che l' hanno particolarmente influenzata? 
concetto di quadro è stato chiamato in causa da Sorrentino stesso come una delle chiave di lettura della serie:

\section{Pensa che la serie piacerá ai cattolici? Si, se la guarderanno con il trasporto che merita un quadro. Quando osservi un dipinto non lo fai per controllare se corrisponda al catechi- smo o per capire se il pittore meriti di esse- re considerato un buon cattolico. Piacerà se staranno al gioco e si accorgeranno che parla alla loro umanità. ${ }^{20}$}

Da non trascurare, tra le influenze artistiche quella fotografica di Luigi Ghirri ${ }^{21}$ con i suoi paesaggi talvolta sospesi, che non sembrano realistici e sconfinano nel metafisico dechirichiano, spesso sono paesaggi privi di figure umane ma mai privi dell'intervento dell'uomo sul paesaggio, il tutto reso attraverso l'uso di colori delicati e non saturi, fondamentali sia nella poetica di Ghirri che in Sorrentino che se ne avvale per trasformare il Vaticano in un non - lieu freddo e assettico o in un'eterotropia foucaultiana. ${ }^{22}$

Abbiamo già fatto riferimento all'ambiguità tout court del papa sorrentiniano che sembra essere l'unica certezza, all'interno del paradosso chiave della serie: è prevedibile che il papa è imprevedibile. Torniamo un attimo alla presunta resurezzione menzionata da Sorrentino nella citazione poco più su. Chiaramente, essa ribalta lo schema biblico visto che rispetto al per-

Caravaggio, Lucian Freud e il tedesco Otto Dix. Soprattutto con quest ultimo credo di avere delle analogie nella composizione delle immagini» (Angelo Sica, Paolo Sorrentino: "Lui è meglio di me“, in Grazia, 19 ottobre 201 I, http://www.grazia.it/stile-di-vita/interviste/ paolo-sorrentino-lui-e-meglio-di-me, pagina consultata il 20 dicembre 2017)

20 Silvia, Fumarola, Paolo Sorrentino, dopo il Papa un film su Berlusconi: "Il potere, una delle tentazioni piu forti del genere umano", cit.

21 Altro nome che ricorre come influenza fotografica è indubbiamenti è Gianni Berengo Gardin ( $«$ I miei fotografi preferiti. Luigi Ghirri e Gianni Berengo Gardin», Paolo Sorrentino, Paolo Sorrentino. Passioni, piaceri, paure: confessione d'autore liberamente ispirata al questionario di Proust, in Vogue, i7 luglio 2017, http://www.vogue. it/news/vogue-arte/2017/07/17/paolo-sorrentino-intervista-vogue-italia-luglio-2017/, pagina consultata 20 novembre 2017. Vogue Italia, luglio 2017, n. 803 , pag. 42

22 Sulla prossimità dei due concetti Cfr. Marc Augé, Non-Lieux. Introduction à une anthropologie de la surmodernité, Paris, Seuil, 1992, p. 14I. Per Foucault cfr: Michel Foucault, Eterotopia, a cura di Salvo Vaccaro, Tiziana Villani, Pino Tripodi, Mimesis, Milano 2010 corso intrapreso da Gesù, quello di Lenny contempla prima la resurrezione e poi, nel finale, la morte. Né l'una né l'altra sono certe: la presunta resurrezione potremmo postularla come vera in quanto da orfano Lenny diviene papa, ma la scena macabra con i bimbi morti è soltanto sognata mentre della morte finale non siamo certi. L'incertezza dei due eventi fondamentali può far pensare, ad esempio, che il sacrificio di Cristo, quello raccontato nella Bibbia, non sia stato poi così grande; esso viene relativizzato, perchè, in fondo, egli è morto soltanto per pochi giorni per poi venir richiamato nei cieli. Nulla di particolarmente eretico o scandaloso: a Sorrentino «piace nelle storie belle [...] proprio il racconto della fatica di stare al mondo» dell'essere umano che, al livello materiale, non viene premiato con un'ascesa nei cieli, ma si fonde piuttosto in un tutt'uno con l'universo, al di là delle deità, come nell'ultima scena della serie. Si spiega così, dunque, l'inversione morte/resurezzione, con la semplice volontà di raccontare le contraddizioni dell'umano, questa volta nel contesto ecclesiasti$\mathrm{co}^{23} \ll$ Il clero è sempre stato rappresentato nella sua infallibilità o malvagità; noi lo raccontiamo per quello che è: fatto da esseri umani $\gg .{ }^{24}$ Dopo avergli concesso persino l'incontro con la meretrice (qui è una escort) pari a quello che ha Gesù, ${ }^{25}$ l'ambiguità di Lenny viene ri-

23 Nell'intervista a Paola Zanuttini il regista ribadisce che la razionalità dell'irrazionale e viceversa fanno parte dell'umano: «Vengo da una famiglia dove tutti i parenti avevano visto fantasmi o munacielli e raccontavano cose incredibili. Sono cose che mi hanno molto impressionato da bambino, influendo sul mio rapporto con la realtà e la paura. Ma oltre le superstizioni la materia è molto più affasçinante. Anche se uno come me fatica ad afferrarne il senso: l'altro giorno parlavo con una donna di una certa età che mi sembrava di un' intelligenza meravigliosa, che poi ha detto: "Ora vado a messa, come tutti i giorni". Mi ha colpito: la sua razionalità, la larghezza di vedute stridevano con la fede, c'è un corto circuito che non riusciamo a capire, come se credere nel trascendente fosse un attentato all'intelligenza. Invece la maggior parte degli studiosi del cattolicesimo sono fra gli intellettuali più attenti, profondi e speculativi, proprio perché sono abituati a porsi domande» (Paola Zanuttini, Papale papale: intervista a Paolo Sorrentino su "The Young Pope", cit.)

24 Silvia, Fumarola, Paolo Sorrentino, dopo il Papa un film su Berlusconi: "Il potere, una delle tentazioni piu forti del genere umano", cit.

25 «Una escort nella hall di un grande albergo vicino al Vaticano dove si sono rifugiati Lenny e Dussolier nella loro fuga notturna in cerca di sigarette, fotografando l'iride di Lenny: 'Che occhi! Questa è la prova dell'esistenza di Dio» $(\mathrm{PD}, 67)$. 
badita da molti altri dettagli oltre che dalle sue stesse parole: «Voiello e Lenny Belardo.- Sa una cosa, Santo Padre? Lei è bello come Gesù, ma non è Gesù. - Forse sono più bello, a dire il vero. Ma non lo dica a nessuno» (PD, 47). Poche pagine prima Suor Mary aveva detto a Lenny che in lui vedeva «il riflesso di Gesù» $(\mathrm{PD}, 3 \mathrm{I})$ mentre poi sentiamo Lenny definire come calunnia la propria santità ( $\mathrm{PD}, \mathrm{IO} 2)$ e leggiamo un dialogo come questo:

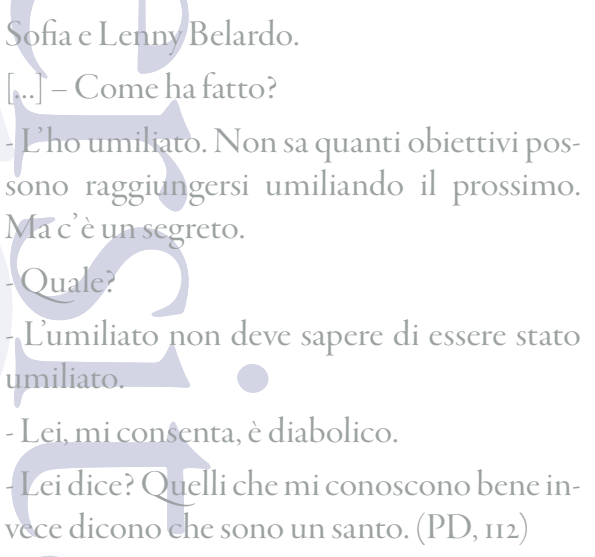

Lenny è qui direttamente associato a chi è stato il prediletto del Signore prima di Cristo stesso e chi si credeva più bello di Cristo stesso, al più luminoso degli angeli ovvero Lucifero e il gioco messo i piedi con il fine di umiliare il Premier italiano ricalca il gioco di Satana, carne di tanta letteratura. In poche parole il trucco dell'umiliare qualcuno senza darlo a vedere ricalca il massimo trucco del Diavolo di esistere convincendovi che non esiste come scrive Baudelaire nel Giocatore generoso; ${ }^{26}$ egli sarà anche bello come vediamo in Shakespeare ${ }^{27}$ o cercherà attraverso una «fede senza sorriso» di ritrovare suo padre tornando da dov'è venuto come scrive Eco nel Nome della rosa ${ }^{28}$ quasi parafrasando la frase di Novalis già citata.

$26 \ll$ Mes chers frères, n'oubliez jamais quand vous entendrez vanter le progrès des lumières, que la plus belle ruse du diable est de vous persuader qu'il n'existe pas» (Charles Baudelaire, Le Joyeur généreux, in Le spleen de Paris, Paris, Gallimard, 2010, p. 97.

$27 \ll$ The devil hath power/ To assume a pleasing shape». William Shakespeare, Amleto, Atto II, scena 2, v. 628.

28 «l diavolo non è il principe della materia, il diavolo è l’arroganza dello spirito, la fede senza sorriso, la verità che non viene mai presa dal dubbio. Il diavolo è cupo perché sa dove va, e andando va sempre
Il lato diabolico di Lenny è decisamente affascinante e letterario, come spesso in Sorrentino, simile a quello del Satana miltoniano, rappresentato come l'oggetto di ammirazione della storia, da imitare e celebrare come un vero eroe che lotta duramente per vincere i suoi stessi dubbi e le sue stesse debolezze per portare a compimento il suo piano di corruzione della specie umana; il più interessante e avvincente dei personaggi del Paradiso perduto, principalmente per la sua complessità e la sua astuzia e che si ribella poprio quando viene ripudiato, convinto com'era che Dio l'avrebbe nominato suo erede; si ribella cioè quando diventa orfano. Egli, come il Diavolo, si nasconde negandosi, questo è il suo trucco per raggiungere i propri scopi. Del resto, a sancire l'ambiguità della figura papale, anche un vero papa, un altro Pio, quello IX, aveva paventato una trattativa Stato della Chiesa - Diavolo qualora le circostanze lo dovessero richiedere nel discorso agli allievi del collegio Mondragone, il I6 maggio 1929: «Quando si trattasse di salvare qualche anima, di impedire maggiori danni di anime, ci sentiremmo il coraggio di trattare col diavolo in persona». Quasi un equivalente religioso di quella tra Stato e mafia di cui abbiamo scritto all'inizio.

Chiaramente, questa linea esegetica non ha lo scopo di ricercare componenti 'sataniche' nel tessuto della serie quanto piuttosto sottolineare l'ampiezza della visione sorrentiniana e la sua complessità che mira proprio all'estrema umanità del meno o del più umano dei papi il cui unico scopo è quello di ritrovare chi lo ha abbandonato settenne.

3. Avviandoci alla conclusione possiamo dire che l'universo vaticano, complesso e pericolosamente sfumato esige un'ampia tela su cui dipingere $^{29}$ e pare quasi che Sorrentino dia vita a un'opera ibrida, sospesa a metà strada tra un film

da dove è venuto» (Umberto Eco, Il nome della rosa, Milano, Bompiani, 198I, p. 364).

29 Nella già citata intervista apparsa su Télérama Sorrentino dice: «Pourquoi une série etpas un film? J'ai eu besoin de raconter le Vatican, le clergé, cet univers qui a beaucoup d'aspects et pour lequel un film aurait été limité. Même la série est limitée: il y a tellement à dire et à explorer» (Isabelle Poitte, Paolo Sorrentino, réalisateur de "The Young Pope": "J'avais besoin de la dualité de Jude Law", cit.). 
di quasi dieci ore e una serie vera e propria. Ciò che viene fuori è una sorta di Recherche di celluloide (con la scorza di mandarino richiamata nell'ultimo episodio a far da madeleine). Del resto, il capolavoro proustiano è sempre presente in Sorrentino, La grande bellezza è repleta di riferimenti ad esso, mentre in Young Pope l'opera viene apertamente citata in una scena della serie. ${ }^{3 \circ}$ Lenny Belardo, il papa non ancora cinquantenne creato da Sorrentino, serve da grimaldello al regista e allo spettatore per potersi introdurre nelle viscere dello Stato della Chiesa, nelle stanze del potere papale andando al di là del solito scandalo, uno dei tanti che scuotono la Chiesa contemporanea dalle fondamenta. In alcuni episodi della serie, svariati temi caldi (la pedofilia scarsamente condannata e la condanna fin troppo severa dell'omosessualità ecc.) vengono toccati o almeno accennati, persino in relazione con lo stesso giovane pontefice (il tentativo di ricatto da parte del segretario di stato Voiello, ma mai questi temi risultano essere centrali. Lo sono in quanto strettamente interconnessi allo spettacolo d'arte varia dell' umanità che gravita attorno al Vaticano. Quella sorrentiniana è una visione fortemente umanistica del sacerdozio e della religione, e quindi antropocentrica. Lo è perchè in fondo il suo obiettivo ultimo è quello di analizzare l'uomo e la sua difficoltà dello stare al mondo nei contesti più disparati, qui nel contesto dello spleen del sacro, per richiamare un'altra volta Baudelaire. Basta passare in rassegna la filmografia del regista per rendersene conto. Vi si scandagliano le tribolazioni, le passioni, i dubbi e le debolezze di uomini e donne di un'Italia a cavaliere del nuovo millenio. Ne La grande bellez$z a$, in cui Sorrentino va a «risciacquare i panni» nel Tevere, assistiamo al peculiare voyage au bout de la nuit (il riferimento a Cèline e dello stesso Sorrentino, è il suo libro preferito) attraverso l'altrettanto peculiare catabasi di Jep Gambardella, il Bardamu viveur de' noantri che persegue un ideale di beltà liminale, in bilico tra il tutto e il

\footnotetext{
30 «Comunque, Santo Padre, capisco la sua riluttanza sull'enciclica. Il suo predecessore mi faceva molto ridere quando diceva che un'enciclica è come la Recherche di Proust. Tutti la citano, ma nessuno la legge...» $(\mathrm{PD}, \mathrm{I} 7)$
}

niente che è tanto il néant sartriano («une nouvelle composante du réel vient de nous apparaître : le non-être») quanto il rien flaubertiano; Youth, magistralmente interpretato da Michael Caine e Harvey Keitel (ottimamente supportati da attori di prim'ordine come Rachel Weisz e Paul Dano o Jane Fonda), indaga l'umanità vegliarda, sull'orlo dell'abisso del trapasso. La scelta in questo caso cade sul pontefice probabilmente perché rappresenta l'uomo, almeno teoricamente, più costretto. Al punto che l'episodio della fuga di Lenny sembra quasi un omaggio a Habemus papam di Moretti dedicato ad un papa che fug$\mathrm{ge}^{3 \mathrm{I}} \mathrm{da}$ limitazioni e regole sociali che sono proprie della sua vocazione. L'indagine sorrentiniana crea così un uomo mosso dalla forte tensione alla metafisica che è invece è molto fisica nel senso che ciò che si crede e si vuole veder realizzato lo si vuol vedere fisicamente reale. Dalle iniziali dichiarazioni di scetticismo circa la propria fe$\mathrm{de},{ }^{32}$ si passa quasi un'accettazione di una visione non univoca della fede che verrà poi vista come qualcosa di personale e irripetibile. «Dio è a Venezia», è la frase di Lenny Belardo che non fa altro che confermarlo in una delle sue omelie analoghe, in vaghezza, alla canzone di Dylan posta in epigrafe di questo lavoro.

\section{Povzetek}

Zadnje delo Paola Sorrentina, Il papa giovane (2016, $\mathrm{HBO}$ - Sky Atlantic) predstavlja pomembno prelomnico v filmski poetiki neapeljskega režiserja in scenarista. V primerjavi z njegovimi zgodnjimi filmi (čeprav so bila nekatera njegova zgodnja dela precej dolga in so vključevala daljš̌ naracije, kot npr. La grande bel-

31 «Habemus Papam raccontava un pontefice in fuga. È un ottimo film, da spettatore sono innamorato di Moretti, ho tirato un sospiro di sollievo perché Nanni si ferma un attimo prima. Il mio Papa invece non vede l'ora di entrare in scena» (Silvia, Fumarola, Paolo Sorrentino, dopo il Papa un film su Berlusconi: "Ilpotere, una delle tentazionipiuforti del genere umano", cit.).

32 «Anche questa è resa 'umana' da Sorrentino: Il suo Pio XIII rivela al confessore di non credere in Dio, ma poi aggiunge: «Scherzavo». Però non scherzava tanto. Il suo è un rapporto con Dio ma capita a una certa età che la persona con cui abbiamo un legame d'amore si affievolisca. Un sacerdote ha la vocazione forte da giovane, poi un grande legame e negli anni crea un nuovo rapporto con Dio. L'amore è amore a tutti i livelli, cambia e si evolve». (Silvia, Fumarola, Paolo Sorrentino, dopo il Papa un film su Berlusconi: "Il potere, una delle tentazioni piu forti del genere umano", cit.). 
lezza (2013) in La giovinezza) dimenzije televizijske serije ponujajo nove možnosti Sorrentinu, ki delno sprejme nekatere nove poetike tako, da usmeri celoten projekt o papežu v televizijsko nadaljevanko desetih ur in pri tem ustvari novo zvrst v italijanski kinematografiji. Članek podrobno analizira Sorrentinovo zadnje delo, obenem pa ga umešča v razvoj njegove kinematografske poetike upoštevajoč predpostavko, da Sorrentino načetuje film $\mathrm{v}$ dveh nadaljevanjih.

Ključne besede: Paolo Sorrentino, italijanski film, televizijska nadaljevanka, Il papa giovane, poetika

\section{Summary}

The very last work by Paolo Sorrentino, The Young Pope (2016, HBO - Sky Atlantic) marks an important turn in the cinematic poetics of the neapolitan director and screenwriter. Compared to his earlier films (even though some of his earlier work was lenghty and encompassed extended narrative volumes, as in The Great Beauty (2013) or Youth) the dimension of the TV show opens to new possibilities to Sorrentino who accepts serial poetics only partially by orienting the entire 'papal' projects towards a tv movie of ten hours creating almost a new genre and a new language in the italian cinema. This article aims at the detailed analysis of Sorrentinos last work as well as at the accurate study of the evolution of his cinematic poetics considering that Sorrentino is currently working on a two-volume movie.

Keywords: Paolo Sorrentino, italian cinema, TV shows, The Young Pope, poetics

\section{Bibliografia}

Augé, Marc. Non-Lieux. Introduction à une anthropologie de la surmodernité. Paris: Seuil, 1992.

Baudelaire, Charles. "Le Joyeur généreux“. In Le spleen de Paris, 95-1 I0. Paris: Gallimard, 2010.

Coppola, Alessandra. "Paolo Sorrentino si confessa: $\ll$ Il mio non è un lavoro per persone intelligenti»”. Corriere della Sera, 2 maggio $201 \mathrm{I}$.

Eco, Umberto. Il nome della rosa. Milano: Bompiani, 1981.

Fumarola, Silvia. "Paolo Sorrentino, dopo il Papa un film su Berlusconi: "Il potere, una delle tentazioni più forti del genere umano". Corriere della Sera, 8 aprile 2017 http://www.repubblica.it/spettacoli/ cinema/2017/04/08/news/paolo_ sorrentino_berlusconi_the_young_popeI62457314\%.

Kemp, Martin. "Message frome the heavens". Nature, n. 453 (2008): II 85.

Mereghetti, Paolo. “«La grande bellezza» integrale. Sorrentino: «Così diventa estenuante come il racconto della vita»". Corriere della Sera, 25 giugno 2016. http:// www.corriere.it/spettacoli/r6_giugno_26/ grande-bellezza-integrale-raccontoestenuante-vita-sorrentino-7fccrega-3afbIre6-aor9-9orbc4c9foro.shtml\#.

Perrotta, Lucio, "La sigla di The Young Pope spiegata da Paolo Sorrentino: "Quel Pio XIII somiglia a me". Huffington Post 18 novembre 2116. http://www. huffingtonpost.it/2016/11/18/quadri-siglayoung-pope_n_13074200.html.

Poitte, Isabelle. "Paolo Sorrentino, réalisateur de "The Young Pope": "J'avais besoin de la dualité de Jude Law”. Télérama, 24 ottobre 2016. http://www.telerama.fr/series-tv/ paolo-sorrentino-j-avais-besoin-de-ladualite-de-jude-law-pour-incarner-piexiii,I 49062.php.

Sica, Angelo. "Paolo Sorrentino: „Lui è meglio di me”. Grazia, 19 ottobre 201r. http:// www.grazia.it/stile-di-vita/interviste/ paolo-sorrentino-lui-e-meglio-di-me.

Sorrentino, Paolo. La grande bellezza. Diario del film. Milano: Feltrinelli, 2013.

Sorrentino, Paolo, “The Young Pope. Paolo Sorrentino «Mi intrigava l'idea di un papa non riconducibile agli altri”. Ciak magazine, 21 ottobre 2016. http:// www.ciakmagazine.it/the-youngpope-paolo-sorrentino-ami-intrigavalidea-di-un-papa-non-riconducibile-adaltria/\#BzpbtYiEjc6ODtIv.99.

Sorrentino, Paolo. La giovinezza. Milano: Rizzoli, 2016. 
Sorrentino, Paolo. Il peso di Dio. Il Vangelo di

Lenny Belardo. Torino: Einaudi, 2017.

Sorrentino, Paolo. "Paolo Sorrentino. Passioni, piaceri, paure: confessione d'autore liberamente ispirata al questionario di Proust". Vogue, 17 luglio 2017, http://www. vogue.it/news/vogue-arte/2017/07/17/ paolo-sorrentino-intervista-vogue-italialuglio-2017.

Tamaro, Gianmaria. "Paolo Sorrentino lancia la serie tv 'The Young Pope': "Il mio Papa vuole una Chiesa più islamica". Huffington Post, II ottobre 2016. http:// www.huffingtonpost.it/2016/10/II/theyoung-pope-sorrentino-papa-vuole-chiesaislamica_n_I2 437424.html.

Zanuttini, Paola. "Papale papale: intervista a Paolo Sorrentino su "The Young Pope”. La Repubblica, 26 settembre 2016. http://www.repubblica.it/venerdi/ interviste/2016/09/26/news/papale_ papale_intervista_a_paolo_sorrentino_ su_the_young_pope_-I $48575057 /$. 


\title{
Letteratura dialettale come caratteristica della «letteratura minoritaria»
}

\author{
Jadranka Cergol
}

Lo scopo dell'articolo è di provare che l'espressione artistica dialettale è una caratteristica tipica della letteratura minoritaria. Le ricerche hanno infatti finora dimostrato che gli autori che decidono di esprimersi originalmente nella forma dialettale, provengono principalmente dalle zone limitrofe di una cultura, nelle quali la lingua entra in contatto con altre realtà linguistiche e culturali.

Parole chiave: letteratura minoritaria, letteratura dialettale, Sloveni in Italia, Italiani in Slovenia e in Croazia, rapporto con la lingua

Namen prispevka je dokazati, da je lahko narečna književnost ena izmed tipičnih značilnosti manjšinske literature. Dosedanje raziskave so namreč pokazale, da izhajajo avtorji, ki se odločajo za izvirno pisanje v narečju, večinoma iz obmejnih območij neke kulture, na katerih prihaja materni jezik v stik z drugimi jezikovnimi in kulturnimi skupnostmi.

Ključne besede: manjšinska književnost, narečna književnost, Slovenci v Italiji, Italijani v Sloveniji in na Hrvaškem, odnos do jezika

T 1 dialetto è probabilmente l'espressione artistica più intima, con la quale gli autori vogliono penetrare nella sfera più profonda del rapporto verso se stessi e il mondo che li circonda. La letteratura dialettale, soprattutto quella slovena, è stata per lunghi anni ignorata dalla critica letteraria per vari motivi: la sua comprensione richiede uno sforzo particolare nel capire il codice linguistico usato, oltre a ciò è necessaria un'approfondita conoscenza culturale, etnica, antropologica e geografica degli autori. Ma probabilmente la ragione più profonda per la quale la poesia dialettale è rimasta trascurata dalla critica letteraria è legata sia allo status sociale più basso degli autori che ad una loro provenienza geografica più periferica rispetto ai centri culturali, come viene ribadito dalla ricercatrice slovena Novak Popov. ${ }^{\mathrm{I}}$ Il fenome-

Irena Novak Popov, "Razmišljanje o sodobni narečni poeziji," in Slovenska narečja med sistemom in rabo, ur. Vera Smole (Ljubljana: Znanstvena založba Filozofske, 2009), 435 . no ha avuto un riscontro diverso nella letteratura italiana, per la quale il dialetto è parte integrante ed ineliminabile. ${ }^{2}$ Anche in Italia però la poesia dialettale ha vissuto un momento di crisi in concomitanza con i grandi cambiamenti sociali del dopoguerra che hanno portato ad una maggiore alfabetizzazione della popolazione e al lento ma inesorabile abbandono del dialetto rispetto alla lingua standard. Negli ultimi decenni del Novecento però la letteratura dialettale e soprattutto la poesia dialettale vive un periodo di rinascita anche in Italia. ${ }^{3}$ Così come in Italia questa tipologia di espressione artistica sta prendendo in $\mathrm{Eu}-$ ropa un particolare valore, non solo letterario, ma anche antropologico ed etnico: la forma dia-

2 Gianfranco Contini, La letteratura italiana (Firenze-Milano: Sanoni-Accademia, 1974), 45 .

3 Luigi M. Cesaretti Salvi. "Le letteratura dialettale." Enciclopedia Treccani (2006), http://www.treccani.it/enciclopedia/letteratura-dialettale_\%28Enciclopedia-Italiana\%29/(28-4-2017) 
lettale sta diventando la nuova forma di espressione di quelle radici culturali, senza le quali le varie culture non riuscirebbero a trarre linfa vitale per la loro esistenza futura. La letteratura dialettale, e in particolare la sua espressione poetica, si sta quindi presentando come un ramo che cresce rigoglioso parallelamente alla letteratura scritta nella lingua standard. Di questo si rendono conto soprattutto i poeti e le poetesse dialettali che controtendenza e contro la convenzione decidono di usare la loro parlata locale anche per narrare le loro storie o esprimere se stessi in versi. Questo fatto è particolarmente riscontrabile proprio in modo alquanto evidente nelle letterature minoritarie, sia all'interno del sistema letterario degli Italiani in Slovenia e in Croazia, come è stato già dimostrato sia nell'antologia di Nelida Milani e Roberto Dobran ${ }^{4}$ che in quella della prof. Zudič Antonič, 5 ma anche quasi contemporaneamente anche nel sistema letterario degli Sloveni in Italia, come viene invece dimostrato dai ricercatori Miran Kosuta, David Bandelj e la sottoscritta. Infine, nel 2007 è uscita una consistente monografia scientifica della ricercatrice slovena Marija Stanonik ${ }^{6}$ che rappresenta un'analisi completa e approfondita di tutta la letteratura dialettale slovena.

Come viene definita da Miran Hladnik, la letteratura dialettale è una "forma di letteratura scritta in un dialetto di una qualsiasi lingua letteraria. Secondo i criteri più ristrettivi, rientrano in essa soltanto quelle opere che sono nate dopo la standardizzazione della lingua, secondo invece i limiti più ampi, possono rientrare anche le opere delle letteratura orale ovvero le opere folkloristiche dai tempi prima della standardizzazione della lingua." La critica letteraria di entrambe le lingue di norma non prende in considerazione le opere popolari e folkloristiche che

$4 \quad$ Nelida Milani and Roberto Dobran, Le parole rimaste (Pula: Pietas Iulia; Rijeka: Edit, 2010), 5 I e seg.

5 Nives Zudič Antonič, Storia e antologia della letteratura italiana di Capodistria, Isola e Pirano (Capodistria: Unione italiana, 2014).

6 Marija Stanonik, Slovenska narećna književnost (Maribor: Slavistično društvo Maribor, 2007)

7 Miran Hladnik, "Regionalism in Slovene Rural Prose," Slovene Studies 13, no.2 (1991): 143-53. sono nate sì in dialetto, ma perché non c'era la possibilità di usare nessun altro codice linguistico. Mi sembra quindi opportuno distinguere tra coloro che coscientemente decidono di usare il dialetto al posto della lingua standard e coloro che invece usavano il dialetto perché non conoscevano altra forma espressiva. Soltanto nel momento in cui si arriva nella società ad un avanzato processo di scolarizzazione della popolazione che usa il linguaggio standard e si ha quindi la possibilità di scegliere coscientemente se usare la lingua standard o la parlata locale, allora è possibile parlare anche di una letteratura dialettale riflessa, cioè tale, nella quale gli autori scelgono il dialetto con un determinato scopo molto preciso, e cioè quello di dare precedenza al dialetto. Ed è per questa ragione che nell'articolo non verranno presi in considerazione autori dei secoli passati come neanche non verrà presa in considerazione la letteratura folkloristica che ha altri tipi di caratteristiche e deve essere analizzata con altri parametri letterari.

\section{Letteratura minoritaria}

Sulla letteratura minoritaria di entrambe le comunità linguistiche sono state già svolte delle ricerche che sono sfociate per la parte italiana nei due volumi della Milani e di Dobran e adesso recentemente anche nella monografia della prof. Nives Zudič Antonič; per la parte slovena invece vanno citate le antologie di David Bandelj per la poesia e le monografie scientifiche di Miran Košuta e di Marija Pirjevec. ${ }^{8}$ Inoltre nel 2006 sono uscite due antologie bilingui: Dru gačni verzi: pesniki dveh manjšin / Versi diversi: poeti di due minoranze curate da Miran Košuta per la parte slovena e da Elis Deghenghi Olujić per quella italiana che raccolgono e mettono a confronto i poeti delle due minoranze. Anche la sottoscritta aveva già pubblicato un articolo sulle caratteristiche principali della letteratura mi-

8 Miran Košuta, E-maili: eseji o mejni literaturi (Maribor: Litera, 2008); David Bandelj, Rod Lepe Vide: antologija sodobne poezije Slovencev v Italiji (Ljubljana: Študentske založba, 2009); David Bandelj "Literature of Slovenians in Italy: A subsystem of Slovenian supernational system?" Interlitteraria 5, no.2 (2010): 432-44I; Marija Pirjevec, Questa Trieste (Trieste: Mladika, 2016) 
noritaria: ${ }^{9}$ è stato dimostrato che la letteratura minoritaria è caratterizzata da una dimensione ontologica, da un'innata interculturalità, dalla stigmatizzazione nazionale, da un innato attaccamento alla regione e al territorio d'appartenenza, dal valore linguistico e dalla memoria storica. Il presente articolo ha lo scopo di analizzare soltanto la dimensione linguistica e in specifico l'espressione dialettale.

\section{La dimensione linguistica}

Tra tutte le dimensioni sopra elencate rappresenta la lingua dell'autore quel valore che è strettamente connesso alla stigmatizzazione nazionale, come portatore principale della dimensione ontologica. Studiando il rapporto degli autori minoritari nei confronti della loro lingua madre si può riscontrare una particolare relazione che comprende anche un senso di difficoltà a padroneggiare la propria lingua madre che bisogna impararla, svilupparla e mantenerla viva in un contesto sociale nel quale questa stessa lingua non viene usata.

\section{La maestra con la macchina rossa e gli occhi neri dice che scrivo male in italiano. Fa che diventi bravo e che agli esami, quando la ma- estra farà il dettato, scriva in modo corretto tutte quelle parole che hanno le doppie. Fa che la signora Slapnik, dalla quale mi manda la mamma, mi insegni, come si parla lo slove- nobene e in modo corretto. ${ }^{\text {Io }}$}

Si tratta di quella mancanza di disinvoltura o scioltezza, della quale scrive Miran Kosuta, che può portare addirittura ad un eccessiva accuratezza della lingua, perché la parola slovena significa anche la lotta per la propria identità minacciata e per la propria libertà linguistica. ${ }^{\mathrm{II}}$ Per entrambe le minoranze linguistiche è caratteristico che sul piano linguistico evitino le forme

9 Jadranka Cergol, "Some Typological Features of,Minority' Literatures: the Case of the Slovenian and Italian Minorities." L'analisi linguistica eletteraria 24, no. I (2016): 61-76.

Io Marko Sosič, Tito, amor mijo (Trieste: Comunicarte, 2012), 13.

I Košuta, E-maili: eseji o mejni literaturi; Marija Pirjevec, $»$ Periodizacija slovenske književnosti na Tržaškem (od 16. do 20. stoletja) «, Annales, Series historia et sociologia 21, no.2 (2011): 360. estreme di sperimentalismo linguistico, il ludismo, il dadaismo ecc., ma si è alla continua "ricerca della letterarietà, in un certo senso un lavoro teorico e poetico sulla scrittura; quindi in fondo, a volte tra le righe e a volte apertamente, è all'opera una forte attenzione alla componente estetica".

Il rapporto nei confronti della lingua madre e/o del dialetto locale è espresso molto chiaramente anche dal seguente passo, tratto dal romanzo Martin Muma di Ligio Zanin, pure lui poeta dialettale.

Era un appassionato della felicissima teoria, specialmente per Martino, dei linguaggi regionali italiani. Secondo la quale, in breve, la lingua italiana pura sarebbe un desiderio, un sogno, a cui si avvicinerebbero pochi: eminenti linguisti, alcuni giornalisti dell'EIAR e diversi italianisti. Mentre la maggioranza, stragrande, anche delle persone dotte, parlerebbe e scriverebbe una lingua, colorita e profumata variamente, in conformità del particolare humus linguistico, i dialetti, delle regioni d'Italia, sempre nel rispetto delle regole fondamentali dell'italiano. Il professor Callegarini, perciò raccomandò a mamma Checchina, sin dal primo colloquio, di parlare al figlio come meglio sapeva, cioè in rovignese. Dialetto nobile che traeva le sue origini direttamente dal parlato latino, ricco di simboli, di immagini, di modi di dire, fioriti, attraverso quasi due millenni, nel quotidiano di quella gente italiana. Il figlio, poi, studiando, sarebbe stato in grado di porgere quegli antichi doni al dialetto della propria nazione, e, attraverso questa, a tutte le altre. [...]

E Martino, prossimo a finire le magistrali, a maledir la cattiva sorte che gli aveva dato in tutti quegli anni quella bonadagninte, quella buon a nulla, che lo aveva sempre bloccato con il suo spappagallare il fiorentino. Ora con Callegarini, che sapeva favalà, cioè parlare, essendo un uomo e non un vaso di pitI2 Milani, Dobran: Le parole rimaste II, 338 . 
tura, si esprimeva senza paura, a non finire.

Non aveva più paura, chè, se i pescatori di Aci Trezza parlavano per la penna di Verga, consigliatogli dal professore, un italiano dal profumo siciliano, anche lui poteva dir qualcosa che avesse l'aroma del ginepro istriano. L'Istria non aveva nulla da vergognarsi al cospetto della Sicilia. ${ }^{13}$

\section{Letteratura minoritaria dialettale}

Da una veloce analisi delle varie letterature europee emerge che non tutte le nazioni hanno una propria letteratura dialettale che molto spesso nasce a causa della "mancanza di una politica centralizzante dello stato nazionale, di una mancanza di un unico centro culturale, del frazionamento amministrativo ovvero di una tradizione culturale regionale". ${ }^{14}$ La letteratura dialettale è così molto sviluppata in Croazia, in Italia, in Slovenia, in Austria, in Germania e in America, mentre non la conoscono gli Inglesi, i Francesi e i Serbi. ${ }^{15}$ Dalla monografia scientifica della prof. Marija Stanonik Slovenska narečna književnost ${ }^{16}$ emerge che la letteratura dialettale è nata prima di tutto sui confini del territorio etnico sloveno, in ambienti, nei quali vivevano e vivono ancora le minoranza slovene: la Carinzia austriaca, la regione in Ungheria lungo il confine con la Slovenia, e la zona confinaria tra Tarvisio e Muggia in Italia. Soltanto negli ultimi decenni il fenomeno si è allargato nelle restanti parti della Slovenia. Un fenomeno simile è riscontrabile anche nella letteratura della comunità italiana in Slovenia e in Croazia: la produzione letteraria in dialetto è estremamente ricca, la maggior parte degli autori minoritari pubblica opere originali, descrivendo fatti, persone, luoghi, territori, sensazioni che hanno loro stessi vissuto. Il mondo raccontato dai poeti istro-dalmati italiani ci mostra soprattutto un dualismo tra la città e la campagna,

I3 Ligio Zanini, Martin Muma (Fiume: Edit, 1999): I40-I.

I4 Hladnik, "Regionalism in Slovene Rural Prose", I48.

is Hladnik, "Regionalism in Slovene Rural Prose", i 47; Irena Novak Popov, "Razmišljanje o sodobni narečni poeziji," in Slovenska narećja med sistemom in rabo, ur. Vera Smole (Ljubljana: Znanstvena založba Filozofske fakultete, 2009), 435-453

I6 Stanonik, Slovenska narećna književnost, 23-35. si estende alla descrizione del patrimonio culturale dei pescatori e dei contadini, ma è sempre intessuto di una sensazione individuale di se stessi e della comunità, sia della ristretta comunità nazionale italiana, sia della più ampia comunità sociale, tutto ciò espresso nei due dialetti principali, cioè nel dialetto istro-veneto e istro-romanzo.

A riprova del fatto che la letteratura dialettale originale nasce sui confini di un territorio etnico ne è il dato che emerge dall'analisi nella monografia sulla letteratura dialettale slovena, cioè la constatazione che la prima poetessa a imboccare la via dell'espressione dialettale slovena sia stata Marija Mijot, autrice slovena di Trieste che ha pubblicato la sua prima raccolta di poesie in dialetto nel 1962 Souze jn smeh. ${ }^{17}$ Di lei, il suo allora compaesano Vladimir Bartol, scrisse: "Il dialetto non serve all'autrice per descrivere fatti interessanti, lei la lingua dialettale la vive proprio. Anzi, direi che la lingua di Marija Mijot addirittura canta! Il dialetto la ubbidisce e anche se non è particolarmente ricco di significato, lẹi riesce con esso ad esprimere i propri sentimenti più profondi, come vive in esso la propria terra $\mathrm{e}$ la sua gente.... Come un amore sfortunato, semplice, ingenuo, ma comunque genuino". ${ }^{18}$ Sicuramente la poesia della Mijot, intrisa sì di elementi locali, ma legata strettamente alla società culturalmente vivace di Trieste non è fiorita in mezzo ad deserto, se pensiamo al fatto che la Mijot leggeva molto volentieri poeti dialettali come Biagio Marin e sicuramente conosceva i saggi di Pier Paolo Pasolini sul friulano.

Alla stessa maniera anche i critici italiani descrivono la letteratura dialettale italiana in Istria, quando parlano di autori che decidono di usare il dialetto perché questo permette loro una certa verginità, genuinità, rigogliosità rispetto alla lingua standard che loro invece sentono rigida, incolore, vuota, sterile. "Sa [il poeta dialettale], perché non ha mai avuto dubbi, che il dialetto è una lingua vera ed esprime un mondo completo come qualsiasi lingua nazionale, dagli

I7 Marija Mijot, Souze jn smeh (Trst: Založništvo tržaškega tiska, 1962).

i 8 Vladimir Bartol, "Predgovor," in Souze jn smeh, ur. Marija Mijot (Trst: Založništvo tržaškega tiska, 1962), 7 . 
oggetti ai sentimenti: sa che col dialetto può ridere e piangere, narrare aneddoti e parlare di Dio e dell'anima." ${ }^{\text {"9 }}$ Questa affermazione ricorda anche il pensiero della ricercatrice slovena Novak Popov:

Moltidifensori [delle identità regionali] fanno notare anche il rigetto verso l'integralismo nazionale e globale, verso l'uniformazione, verso l'impoverita monoculturalità $\mathrm{e}$ autoritarismo, a causa dei quali vengono in silenzio sacrificati e dimenticati i risultati ottenuti dai gruppi emarginati [...] La poesia dialettale si mostra quindi come un'espressione di libertà, di coraggio, di una forza interiore. ${ }^{20}$

Le tematiche affrontate dai poeti dialettali

Le tematiche affrontate dai poeti dialettali sono di solito di natura molto soggettiva, scrivono prevalentemente di sé, del proprio vissuto quotidiano, dei propri luoghi, del mare e degli ulivi, della vita e dell'amore, dei luoghi che visitano e sui quali riflettono. Come viene però constato dai ricercatori Milani e Dobran, c'è un'altra motivazione, forse addirittura più importante, cioè il livello psicologico della scelta del dialetto che viene definito da Brevini "lingua dell'autobiografia vs lingua dell'anonimato”. ${ }^{21}$ Per gli appartenenti ad una comunità nazionale minoritaria la scelta del dialetto è anche un fattore psicologico di una rivalsa nei confronti della storia che ha visto già molteplici cambiamenti politici: scegliere il dialetto vuol dire quindi ribadire il senso di una diversa appartenenza, di dimostrare delle radici linguistiche e culturali che usano un codice diverso. ${ }^{22}$ Ad esempio il poeta rovignese Giusto Curto descrive così il proprio luogo nella poesia Elmeio logo:

19

Claudio Marabini, "Poesia contemporanea in lingua e dialetto: quale rapporto?" in La maschera del dialetto, ur. Andrea Foschi, Elio Pezzi (Ravenna: Longo, 1988), 64.

20 Novak Popov, "Razmišljanje o sodobni narečni poeziji”, 440.

2 I Franco Brevini, Le parole perdute: Dialetti e poesia del nostro secolo (Torino: Einaudi, 1990): 55

22 Milani, Dobran, Leparole rimaste, 521.
I ma ganbio i drapi e cradime nu mal dol

sa anche i paro oûn pupo da pisiol,

i son sul mieîo e ma sento un gigante

e qua i nu iè pagoûra manco del cavalgante. ${ }^{23}$

Molte delle poesia dialettali ricordano i paesaggi bucolici e idilliaci della vita in campagna ed esprimono spesso il forte attaccamento alla terra sia dell'autore che dell'intera comunità alla quale appartiene. Se la poesia fosse stata scritta nella lingua standard, probabilmente non avremmo potuto captare la genuinità delle sue parole.

Anche la poetessa di Pola Ester Sardoz Barlessi descrive così il profumo dell'Istria:

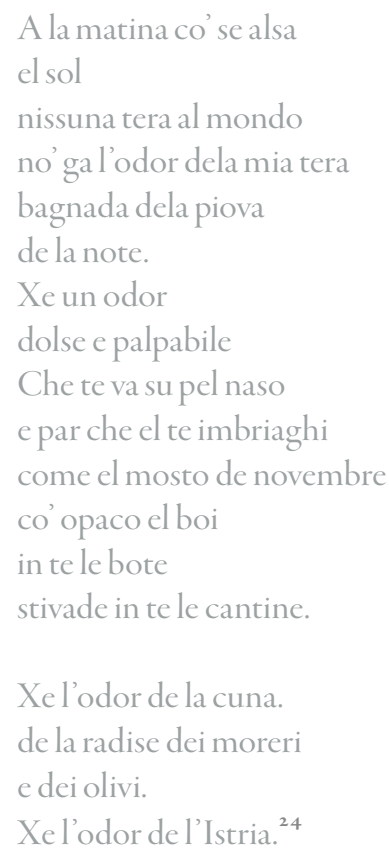

L'attaccamento alla propria terra è un tema prevalente anche nella poesia dialettale slovena in Italia, come lo dimostra la già citata poetessa Marija Mijot di San Giovanni, oggi rione di Trieste, ma cinquant'anni fa ancora villaggio alle porte della città, che descrive così i luoghi della sua infanzia, ai quali sono legati molti ricordi:

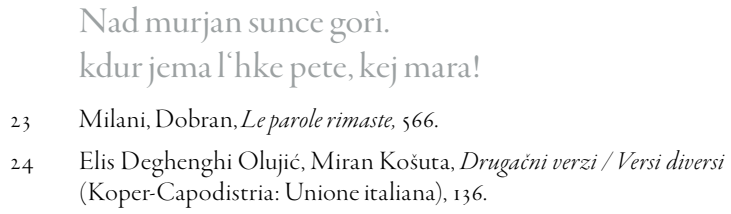


T'n se na s'mnje na Šance vrti,

v's Luonjar, Mandrja, Četnara! $!^{25}$

Ma la descrizione dei luoghi non è l'unico motivo presente nei poeti dialettali. Se decenni fa valeva ancora il sintagma che la poesia dialettale fosse solo una forma di espressione soggettiva, personale, forse una poesia dedicata ai bambini e alla vita campestre, le tematiche degli ultimi anni si sono allargate. Ad esempio il poeta sloveno di Trieste Atilij Kralj scrive prevalentemente poesie umoristiche; in altri poeti è possibile trovare anche il tema del patriottismo, dell'attaccamento alla propria terra natia, alle proprie radici, alla propria storia, ma anche dei sentimenti umani, come l'amore o la sofferenza per la perdita di una persona cara. Se pensiamo a questo fattore sociologico, diventa chiaro che "scrivere nella lingua viva, ovvero nel dialetto, è segno di ribellione di ogni comunità più piccola (anche di una popolazione) nei confronti di una unificazione funzionalista, del mondo globalizzato, dove tutto ciò che è individuale, unico, personale, a misura d'uomo, non vale molto e dovrebbe addirittura scomparire. Molti hanno a questi piccoli gruppi (anche al popolo sloveno) predetto una sorte avversa, ma queste previsioni non si sono avverate, perché in natura ci sono delle forze che remano contro le forze distruttrici, forze che mantengono in vita, vicino alle grandi creature anche creature piccole". ${ }^{26}$ A dimostrazione della tesi di Hočevar citiamo una poesia di Silvana Paletti, poetessa della Resia, dal titolo Ta rozajanski glas, che dimostra l'attaccamento dell'autrice alla parlata locale.

Tu-w ti rožinëj dulïni,
puložanä pod Canïnom,
tej da vilažnji din,
se mi jasnijo lipe biside,
od noga glasa.
Iti, jë glas od me zamje. nnk

25 Marija Mijot, Souze jn smeh (Trieste: Založništvo tržaškega tiska, 1962), 18 .

26 Jože Hočevar, "Pride vse en vse pasá," in Pride vse en vse pasá (Pesmi o Istri in njenih ljudeh), ur. Nelda Štok-Vojska (Marezige: samozaložba, 1999): 148.

\section{Od mlade od särca \\ wzira, pod suncon. \\ Särčne biside mu stjijo. \\ Sam, zna, jübit od rožicöw \\ nu na jasnimö, nëbëske racjune. \\ Iti jë glas, od mëh judi. \\ Iti jë glas, Rozajanski, \\ ki zadavit, ni smin, \\ zabit, ni mörën. \\ Mo mati, za šenk, na mi dala, \\ da ja se znej po svëtö, \\ da ja si maköj Rozajän.}

Iti jë glas, Rozajanski,

ki od vište od sunca,

skryt, ni mörën ...

Zakoj, iti, jë glas

od me duline ..

od me zamje...

od mëh samih judi. ${ }^{27}$

군

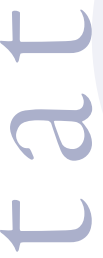

Ciò che abbiamo già notato per Curto, vale anche per la Paletti che si lascia trasportare dalla parlata resiana per descrivere la sua bella valle verde sotto il Kanin, ma che contemporaneamente indirizza il suo pensiero anche verso un altro tema, cioè verso l'uso della lingua, di quella lingua che sua madre le ha donato nella culla e che lei continuerà ad usare, perché è la voce della sua valle, della sua terra e della sua gente.

Sulla lingua e il codice usato riflettono anche altri poeti, tra i quali spicca Libero Benussi che ha descritto la sua parlata nella lirica Ca faviela! (Che favella!): perdere la propria lingua significa per Benussi perdere la propria anima.

\footnotetext{
Nu curo fa altro

ca tirala $\int u$ cul prufoumo del mangrei

e insanbralo cun quil de li greighe

e cun quil dela gruojula.

Nu curo daghe oun culur,

la uo fa quil del marinoun

e quil del $\int$ bulo saltula del sabusein

insanbra cul canto del merlo in amur.

Nu curo darghe armuneia,
}

27 
la uo đa quila de la tiera calda,

quila del busco grungula

e quila del mar ca carisa i denti de can;

\section{sulruso deifeighi. 28}

In entrambi i casi abbiamo potuto notare che le poesie vanno oltre la mera predisposizione individuale, ma si tratta di voci che sono destinate alla comunità più ampia, soprattutto alla comunità linguistica che legge queste poesie e si identifica in esse. Perciò è possibile in alcune di queste poesie ritrovare anche il tema del ricordo storico di una comunità. Un esempio ne è Tino Gavardo, poeta italiano di Capodistria che attacca il potere austro-ungarico, verso il quale non dimostra nessuna predisposizione positiva, a causa della sensazione della perdita dello stato italiano, del rammarico per la caduta della repubblica di Venezia e a causa dell'amarezza per il cambiamento politico della città.

Etuto xe sito; soltanto un momento

se senti una yose che par un lamento,

na vose de pianto che par quasi umana;

xe un boto che manda la vecia campana.

a vecia campana che, a fianco le tori,

ciamava a seduta $\mathrm{i}$ antichi signori,

la vecia campana che dormi lassù,

che sempre ricorda per chi l'à batù... (...)

Ma adesso sti veci che più no comanda,

in morte i patissi l'ofesa più granda;

l'ofesa più granda: cambiarghe la sèna,

menarli in berlina fra i turchi de Viena.

Ma, atenti là in alto che, se anca de gesso,

el cuor de San Marco xe sempre l'istesso;

atenti lá in alto che forsi de novo

no'l vegni rabioso de fora del covo.

Chè alora, se'l urla sto vecio Leon,

al Prater va in tera le quinte e'l tendon...

28

Milani, Dobran, Le parole rimaste I, 612.
O turchi e Viena, porteghe rispeto,

se no, garantisso, fini int-un sguasseto. ${ }^{29}$

\section{Conclusione}

Attraverso gli esempi presentati ho voluto dimostrare che gli appartenenti di due comunità linguistiche minoritarie decidono di usare il dialetto con scopi letterari. La scelta del vernacolo locale non è una scelta frivola, dietro alle confessioni personali possiamo intravedere anche messaggi diretti a tutta la comunità minoritaria e a tutta la società in genere, dato che tangono anche problemi politici, dilemmi linguistici, patrimonio culturale e ricordo storico. Mi è sembrato soprattutto interessante analizzare e dimostrare come queste tematiche che ho appena menzionato sono presenti in due sistemi letterati diversi, che usano due codici linguistici distinti (dialetto sloveno e dialetto istro-veneto), ma che evidentemente vivono la stessa situazione sociale e problemi sia soggettivi che comunitari molto simili. Si tratta quindi di una forma letteraria, quella della letteratura dialettale, che vale la pena ricercare soprattutto per il fatto che sta diventando sempre più consistente e ricca. Anche grazie all'impegno, alla tenacia e al desiderio di coloro che vogliono mantenerla.

\section{Povzetek}

Cilj članka je dokazati, da je narečna literatura ena tipičnih izraznih sredstev manjšinske literature. Pretekle raziskave so dokazale, da različni narečni literarni sistemi so še najprej vzklili na obrobju etničnega naselitvenega prostora, $v$ sosednjih deželah in predvsem $v$ tistih okoljih, v katerih jezik prihaja v stik z drugimi jeziki in kulturami. $\mathrm{Na}$ istih geografskih območjih je odnos do narečja veliko bolj izrazit in pomemben. $Z$ analizo dveh manjšinskih skupnosti, slovenske v Italiji in italijanske v Sloveniji in na Hrvaškem, avtorica poskuša dokazati, da je narečna literatura zelo tipičen fenomen manjšinske literature, poleg tega pa je pri tem razbrati poseben odnos do maternega jezika nasploh. Avtorji, ki se odločijo za pisanje v narečju, svojo izbiro izpostavljajo tako, da se tudi delno oddaljujejo od ostalih piscev, ker zelo po-

29 Zudič Antonič, Storia e antologia della letteratura italiana di Capodistria, Isola e Pirano, 393. 
udarjajo svoje korenine v kraju, kjer so bili rojeni in kjer so živeli.

Ključne besede: manjšinska književnost, narečna književnost, Slovenci v Italiji, Italijani v Sloveniji in na Hrvaškem, odnos do jezika

\section{Summary}

The purpose of this paper is to demonstrate that the dialectal literature is one of the typical expression of the minority literature. Previous studies have shown that various dialect literatures arise first on the outskirts of an ethnic settlement area, in neighbouring countries and even in those areas where the language comes into contact with other languages and cultures. In the same areas also the relationship with the mother tongue and with the dialect itself is much more distinguished and significant. Analysing the cases of two minority communities, the Slovenian in Italy and the Italian minority in Slovenia and Croatia, the author tries to prove that the dialect literature is a very typical phenomenon in minority literature, in which it can be noticed a special relationship to language in general. The authors that decide to write in dialect, do it with special purposes trying to distinguish themselves from the others and to emphasise their linguistic and cultural roots in the land, where they were born and where they live.

Keywords: minority literature, dialect literature, Slovenians in Italy, Italians in Slovenia and Croatia, relationship to the language

\section{Bibliografia}

Bandelj, David. Rod Lepe Vide: antologija sodobne poezije Slovencev v Italiji. Ljubljana: Študentske založba, 2009.

Bandelj, David, "Literature of Slovenians in Italy: A subsystem of Slovenian supernational system? " Interlitteraria 5 , no. 2 (2010): 432-44I.

Bartol, Vladimir. "Predgovor." In Souze jn smeh, ur. Marija Mijot, 7-9. Trst: Založništvo tržaškega tiska, 1968.

Berruto, Gaetano. Introduzione all'italiano contemporaneo, La variazione e gli usi. Roma-Bari: Laterza, 2003.
Brevini, Franco. Le parole perdute. Dialettie poesia del nostro secolo. Torino: Einaudi, 1990.

Cergol, Jadranka. "Some Typological Features of ,Minority' Literatures: the Case of the Slovenian and Italian Minorities." L'analisi linguistica e letteraria 24, no. I (2016): 6I76.

Cesaretti Salvi, Luigi Maria, "La letteratura dialettale.” Enciclopedia Treccani (2006), http://www.treccani.it/enciclopedia/ letteratura-dialettale_\%28EnciclopediaItaliana\%29/ (28-4-2017)

Contini, Gianfranco. La letteratura italiana. Firenze-Milano: Sanoni-Accademia, 1974. Curto, Sergio. Meingule insanbrade = Briciole sparse. Trieste : Unione degli italiani dell'Istria e di Fiume: Università popolare, 1983.

Deghenghi Olujić, Elis, Miran Košuta. Drugačni verzi / Versi diversi. KoperCapodistria: Unione italiana, 2006. 1

( ( $\checkmark$

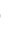
$\sqrt{2-10}$ Hladnik, Miran. "Regionalism in Slovene Rural Prose." Slovene Studies I3, no. 2 (I99I): I 43-I53.

Hočevar, Jože. "Pride vse en vse pasá." In: Pride vse en vse pasá (Pesmi o Istri in njenih ljudeb), ur. Nelda Štok-Vojska, I 43-I 48. Marezige: samozaložba, 1999.

Košuta, Miran. E-maili: eseji o mejni literaturi. Maribor: Litera, 2008.

Marabini, Claudio. "Poesia contemporanea in lingua e dialetto: quale rapporto?” In $\mathrm{La}$ maschera del dialetto, ed. Andrea Foschi, Elio Pezzi, 64-72. Ravenna: Longo, 1988.

Milani, Nelida, e Roberto Dobran, Le parole rimaste. Pula: Pietas Iulia; Rijeka: Edit, 2010.

Mijot, Marija. Souze jn smeh. Trst: Založništvo tržaškega tiska, 1962.

Novak Popov, Irena. "Razmišljanje o sodobni narečni poeziji.” In Slovenska narečja med sistemom in rabo, ur. Vera Smole, 435-453. Ljubljana: Znanstvena založba Filozofske fakultete, 2009. 
Pirjevec, Marija. "Periodizacija slovenske književnosti na Tržaškem (od I6. do 20. stoletja)." Annales, Series historia et sociologia 21, no. 2 (2011): 353-362.

Pirjevec, Marija, Questa Trieste. Trieste:

Mladika, 2016.

Sosič, Marko. Tito, amor mijo. Trieste:

Comunicarte, 2012.

Stanonik, Marija. Slovenska narečna

književnost. Maribor: Slavistično društvo Maribor, 2007.

Zanini, Ligio. Martin Muma. Fiume: Edit, 1999.

Zudič Antonič, Nives. Storia e antologia della letteratura italiana di Capodistria, Isola e Pirano. Capodistria: Unione italiana, 2014.

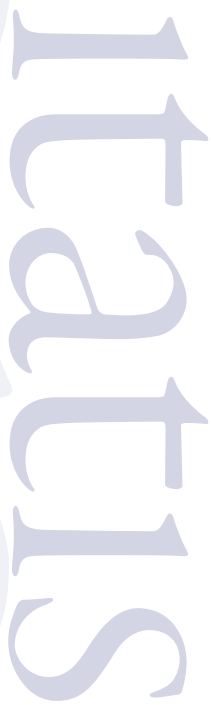




\section{NAVODILA ZA AVTORJE}

Revija objavlja primarno v slovenskem jeziku, toda tudi v večjih svetovnih jezikih (angleščina, nemščina, francoščina, italijanščina, ruščina). V objavo se sprejmejo tudi članki v cirilici. V primeru tujejezičnega članka morata biti izvleček in povzetek poleg angleščine obvezno v slovenskem jeziku. Za oboje poskrbi avtor. Članek (praviloma v obsegu 7000, vendar največ 10.000 besed) naj ima na začetku: I) naslov ter ime in priimek avtorja/-ice; 2) izvleček v slovenskem in abstract angleškem jeziku, do 250 besed; 3 ) ključne besede v slovenščini in angleščini (do 5); 4) kratko predstavitev avtorja/-ice (do 10o besed v slovenščini in angleščini), navedena naj bo tudi organizacija zaposlitve. Članek naj po razpravnem besedilu vsebuje še: I) povzetek v slovenščini in angleščini ter 2) seznam virov in literature.

Prispevki naj bodo napisani $\mathrm{v}$ knjižni slovenščini (ali $\mathrm{v}$ knjižni različici katerega tujih jezikov, v kolikor gre za tujejezično delo) ob upoštevanju veljavnega pravopisa, v nasprotnem primeru si uredništvo pridržuje pravico, da članka ne recenzira oziroma ga zavrne. Če je prispevek že bil objavljen v kaki drugi reviji ali če čaka na objavo, je treba to izrecno navesti.

Prispevek naj ima dvojni medvrstični razmik, tip črk naj bo Times New Roman, velikost 12 pik (v opombah 10). Besedilo naj bo levo poravnano, strani pa zaporedno oštevilčene. Odstavki naj bodo ločeni s prazno vistico.

Uporabiti je mogoče do tri hierarhične nivoje podnaslovov, ki naj bodo ośtevilčeni (uporabljajte izključno navaden $s l o g$, v prelomu bodo ravni ločene tipografsko): I. - I.I - I.I.I

Za poudarke uporabite izključno ležeći tisk(v primeru jezikoslovnih besedil, kjer so primeri praviloma v ležečem tisku, lahko za poudarke izjemoma uporabite polkrepki tisk). Ležeče pišite tudi besede v tujih jezikih. Raba drugih tipografskih rezov (podčrtano, velike male črke, krepko kurzivno ...) ni dovoljena. Ne uporabljajte dvojnih presledkov, prav tako ne uporabljajte preslednice za poravnavo besedila. Edina oblika odstavka, ki je dovoljena, je odstavek z levo poravnavo brez rabe tabulatorjev prve ali katerekoli druge vrstice $v$ ostavku (ne uporabljajte sredinske, obojestranske ali desne poravnave odstavkov). Oglate oklepaje uporabljajte izključno za fonetične zapise oz. zapise izgovarjave. Tri pike so stične le, če označujejo prekinjeno bese... Pri nedokončani misli so tri pike nestične in nedeljive ... Prosimo, da izključite funkcijo deljenja besed.

Sprotne opombe naj bodo samooštevilčene (številke so levostično za besedo ali ločilom - če besedi, na katero se opomba nanaša, sledi ločilo) in uvrščene na tekočo stran besedila.

Citati v besedilu naj bodo označeni z dvojnimi (» «), citati znotraj citatov pa z enojnimi (") narekovaji. Izpuste iz citatov in prilagoditve označite s tropičjem znotraj poševnic /... /. Daljše citate (več kot 5 vrstic) izločite v samostojne odstavke, ki jih od ostalega besedila ločite z izpustom vrstice in umikom v desno. Vir citata označite v okroglem oklepaju na koncu citata. Če je avtor/-ica naveden/-a v sobesedilu, priimek lahko izpustite.
V besedilu označite najprimernejša mesta za likorno opremo (tabele, slike, skice, grafikone itd.) po zgledu: [Tabela i približno tukaj]. Posamezne enote opreme priložite vsako v posebni datoteki (v .eps, .ai, tif ali.jpg formatu, minimalna resolucija $300 \mathrm{dpi}$, tabele prilagajte $\mathrm{v}$ posebni datotetki v formatu .doc, grafe pa v formatu.xls, kjer naj ob grafu stoji tabela, ki je podlaga za graf). Naslov tabele je nad tabelo, naslov grafa/slike pa pod grafom/sliko.

Prostor, ki ga oprema v prispevku zasede, se šteje v obseg besedila, bodisi kot 250 besed (pol strani) ali 500 besed (cela stran).

Ob oddaji preda avtor uredništvu članek v formatu .doc in hkrati tudi.pdf.

Za citiranje literature in za pripravo seznama uporabljene literature se uporablja izkljucno stil Chicago, in sicer v obliki, kot je aktualna, tj. v svoji 16. izdaji (http://www.chicagomanualofstyle.org/home.html, 16. izdaja na razpolago na zahtevo tudi pri uredniku izdaje)

I: Enoavtorska monografija

a) Polna oblika reference pod črto: Michael Pollan, The Omnivore's Dilemma: A Natural History of Four Meals (New York: Penguin, 2006), 99-100.

b) Kratka oblika reference pod črto: Pollan, Omnivore’s Dilemma, 3 .

c) Navedba v virih in literaturi: Pollan, Michael. The Omnivore's

Dilemma: A Natural History of Four Meals. New York: Penguin, 2006. II: Većavtorska monografija

a) Polna oblika reference pod črto: Geoffrey C. Ward and Ken Burns, The War: An Intimate History, 1941-1945 (New York: Knopf, 2007), 52 .

b) Navedba v virih in literaturi: Ward, Geoffrey C., and Ken Burns. The War: An Intimate History, 1941-1945. New York: Knopf, 2007.

III: Knjiga z urednikom

a) Polna oblika reference pod črto: Joel Greenberg, ed., Of Prairie, Woods, and Water: Two Centuries of Chicago Nature Writing (Chicago: University of Chicago Press, 2008), 42.

b) Kratka oblika reference pod črto: Greenberg, Prairie, Woods, and Water, 326-27.

c) Navedba v virih in literature: Greenberg, Joel, ed. Of Prairie, Woods, and Water: Two Centuries of Chicago Nature Writing. Chicago: University of Chicago Press, 2008.

IV: Poglavje v knjigi

a) Polna oblika reference pod črto: Glenn Gould, "Streisand as Schwarzkopf," in The Glenn Gould Reader, ur. Tim Page (New York: Vintage, 1984),310.

b) Kratka oblika reference pod črto: Gould, "Streisand as Schwarzkopf," 309 .

c) Navedba v virih in literaturi: Gould, Glenn. "Streisand as Schwarzkopf." In The Glenn Gould Reader, ur. Tim Page, 308-11. New York: Vintage, 1984 .

Gould, "Streisand as Schwarzkopf," 309 
V: Clanek v reviji

a) Polna oblika reference pod črto: Walter Blair, "Americanized Comic Braggarts," Critical Inquiry 4, no. 2 (1977):331-32.

b) Kratka oblika reference pod črto: Blair, "Americanized Comic Braggarts," 335 .

c) Navedba v virih in literaturi: Blair, Walter. "Americanized Comic Braggarts." Critical Inquiry 4, no. 2 (1977): 331-49.

VI: Clanek v reviji (digitalna objava; DOI)

a) Polna oblika reference pod črto: William J. Novak, "The Myth of the 'Weak' American State," American Historical Review Ir3 (June 2008): 758, doi:10.1086/ahr.113.3.752.

b) Kratka oblika reference pod črto: Novak, "Myth," 770 .

c) Navedba v virih in literaturi: Novak, William J. "The Myth of the 'Weak' American State." American Historical Review 113 (June 2008): 752--72. doi:10.1086/ahr.113.3.752., "Streisand as Schwarzkopf," 309.

VII: Članek v reviji (digitalna objava, URL)

a) Polna oblika reference pod črto: Wilfried Karmaus and John F. Riebow, "Storage of Serum in Plastic and Glass Containers May Alter the Serum Concentration of Polychlorinated Biphenyls," Environmental Health Perspectives II2 (May 2004): 645, http://www. jstor.org/stable/3435987 (datum dostopa do spletne strani).

b) Navedba v virih in literaturi: Karmaus, Wilfried, and John F. Riebow. "Storage of Serum in Plastic and Glass Containers May Alter the Serum Concentration of Polychlorinated Biphenyls." Environmental Health Perspectives II2 (May 2004): 643--47. http:// www.jstor.org/stable/3435987.

O morebitnih drugih posebnostih se posvetujte z uredništvom

Naslov uredništva: dr. Gregor Pobežin, Fakulteta za humanistične študije Univerze na Primorskem, Titov trg 5,

SI-6000 Koper, gregor.pobezin@fhs.upr.si 

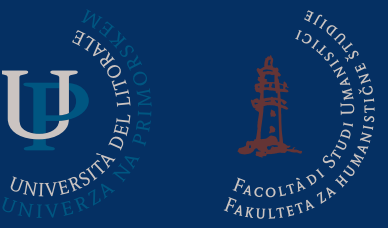

Založba Univerze na Primorskem www.hippocampus.si ISSN 2350-5443

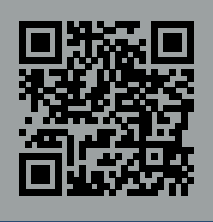

